\title{
Expression und Wirkungsmechanismen von Gonadotropin-Releasing Hormon Typ II (GnRH-II) und seines Rezeptors in humanen Ovarial- und Endometriumkarzinomen
}

\author{
Dissertation \\ Zur Erlangung des Doktorgrades \\ der Mathematisch-Naturwissenschaftlichen Fakultäten \\ der Georg-August-Universität zu Göttingen
}

vorgelegt von

Nicola Eicke

aus Bremen

Göttingen 2006 
D 7

Referent: Herr Prof. Dr. R. Hardeland

Korreferent: Herr Prof. Dr. F. Schürmann

Tag der mündlichen Prüfung: 



\section{INHALTSVERZEICHNIS}

ABKÜRZUNGSVERZEICHNIS 8

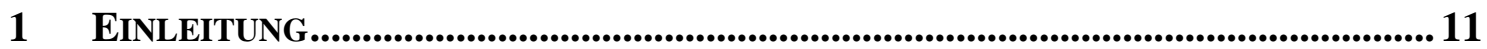

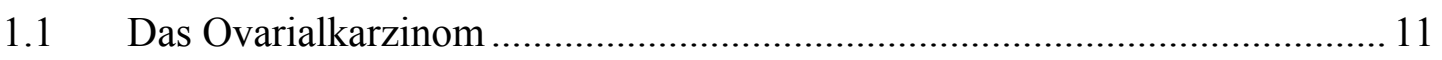

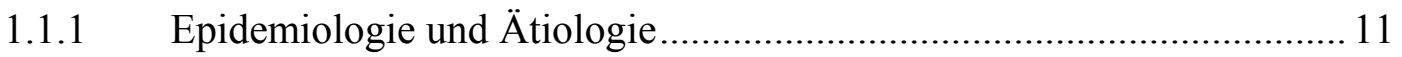

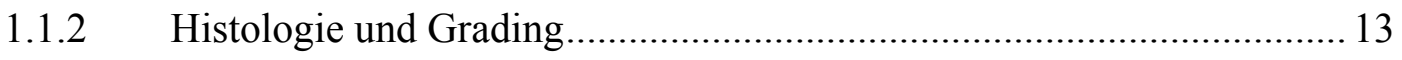

1.1.3 Therapieformen des Ovarialkarzinoms................................................ 15

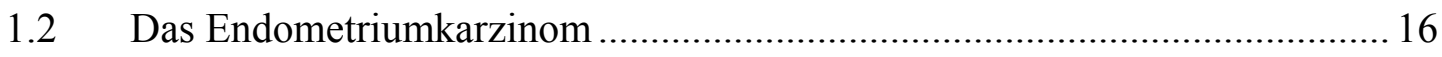

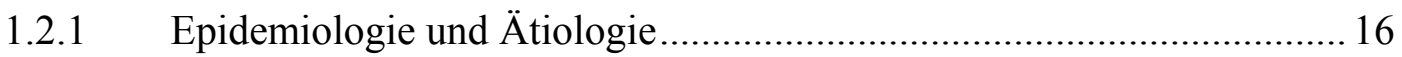

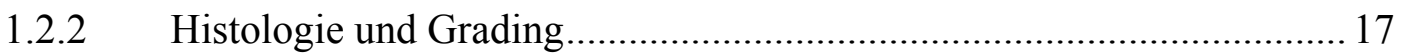

1.2.3 Therapieformen des Endometriumkarzinoms........................................ 19

$1.3 \quad$ Hormontherapie mit GnRH-Agonisten...................................................... 20

$1.4 \quad$ Der epidermale Wachstumsfaktorrezeptor ................................................... 21

1.4.1 Die mitogen-aktivierten Proteinkinasen ............................................ 23

1.4.2 Das ,Immediate Early Response ${ }^{e}$ Gen $c$-fos ......................................... 23

1.4.3 Der EGF-Rezeptor in der Onkologie ................................................. 24

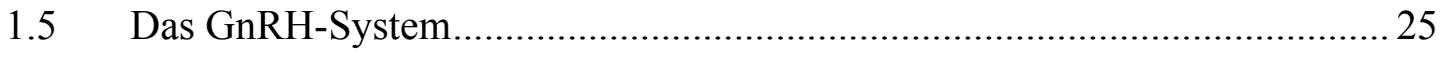

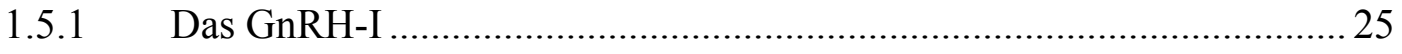

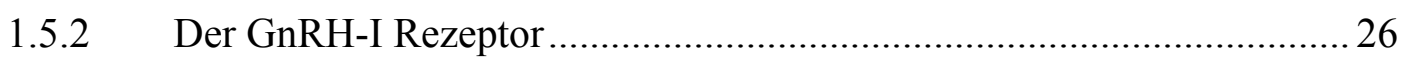

1.5.3 Signaltransduktionsweg des GnRH-I Rezeptors in der Hypophyse ....... 27

1.5.4 Das GnRH-System in gynäkologischen Tumoren ............................... 28

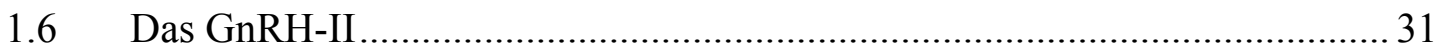

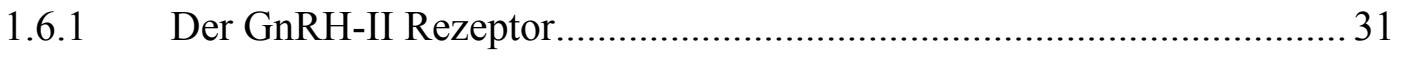

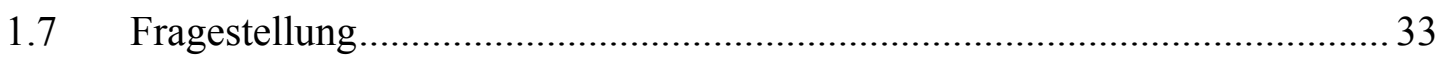

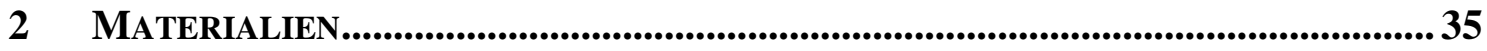

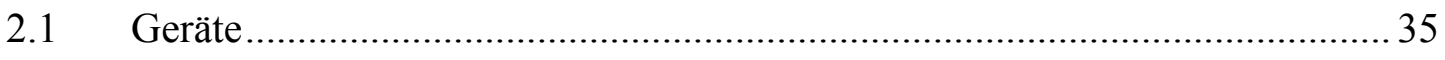

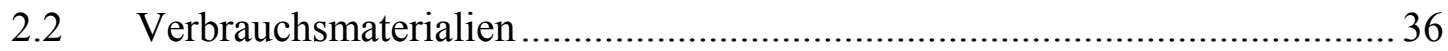




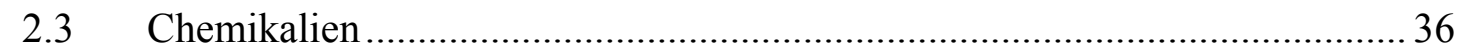

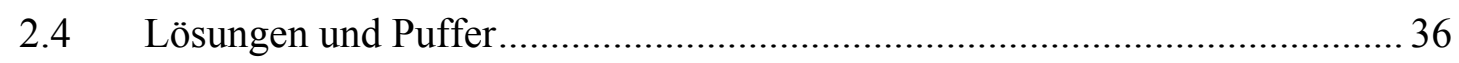

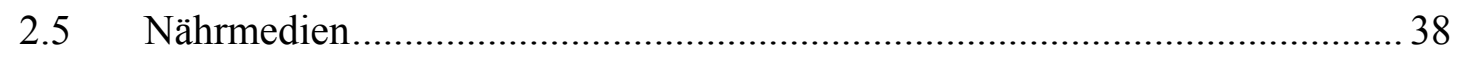

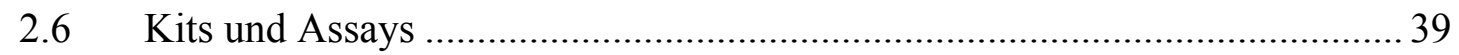

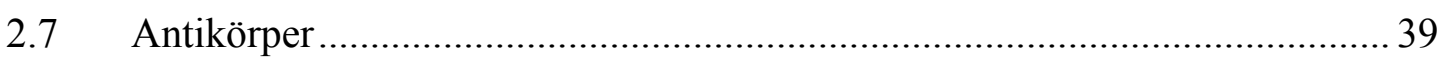

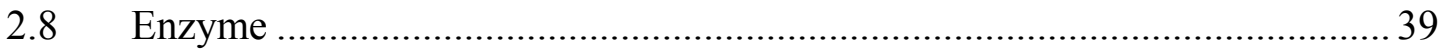

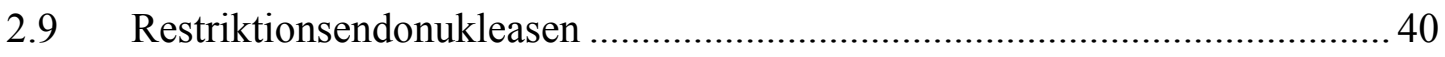

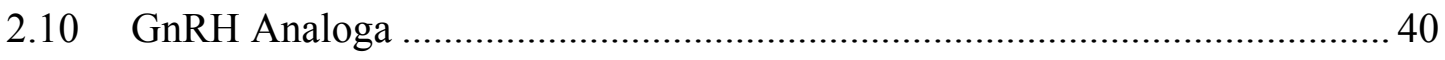

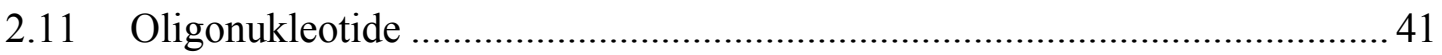

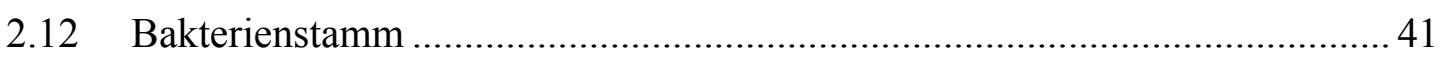

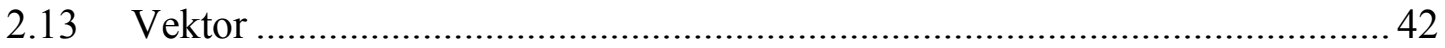

2.14 Gewebe und Gewebeschnitte.................................................................... 42

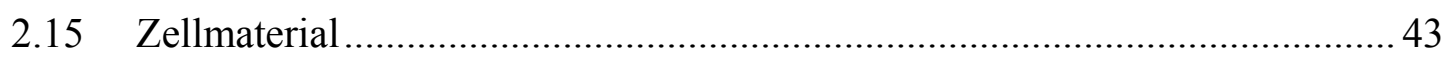

3 METHODEN............................................................................................................ 44

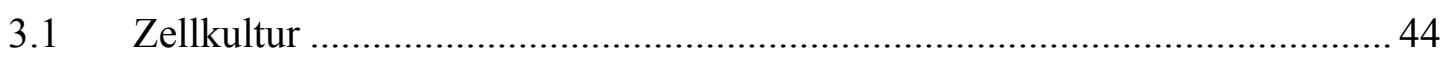

3.1.1 Passagieren adhärenter Zellen ........................................................... 44

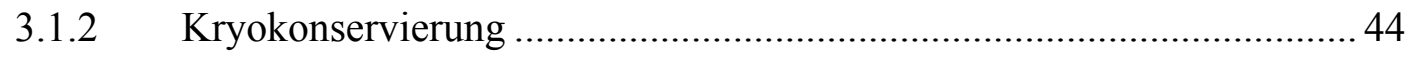

3.1.3 Herstellung von Zellmembranen aus Zellkulturen ................................. 45

3.2 Molekularbiologische Methoden …………………………………………..... 45

3.2.1 Isolierung der mRNA.................................................................... 45

3.2.2 Quantifizierung von Nukleinsäuren.......................................................... 46

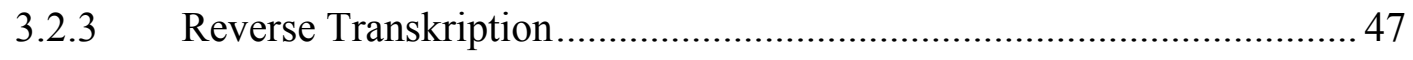

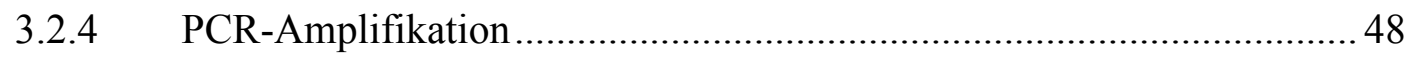

3.2.5 Agarose Gelelektrophorese ………………………………………..... 50

3.3 Herstellung des GnRH-I Rezeptor-Plasmids ............................................... 51

3.3.1 Bakterien-Medien und Kulturplatten ..................................................... 51

3.3.2 Transformation kompetenter Zellen ...................................................... 52

3.3.3 Amplifikation des pIRES-Vektors....................................................... 52 


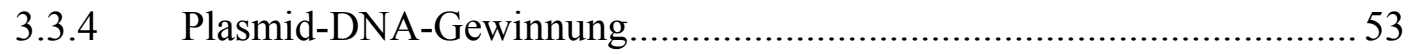

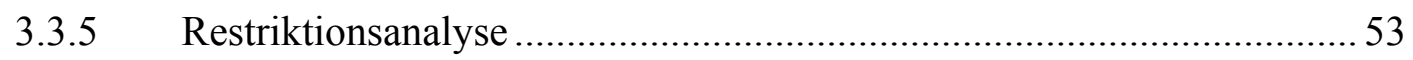

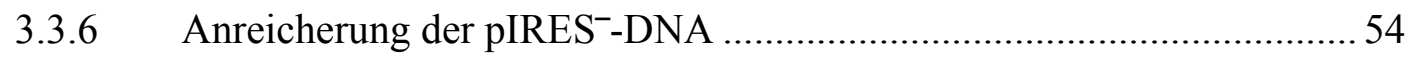

3.3.7 Herstellung des GnRH-I Rezeptor-mRNA-Inserts ............................... 54

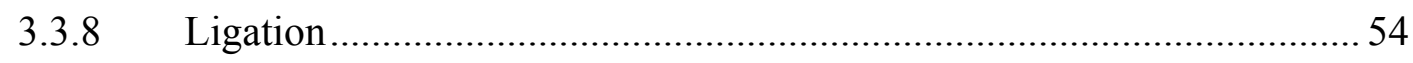

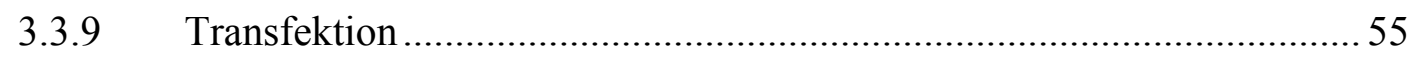

3.3.10 Ernten der Zellen nach der Transfektion .............................................. 56

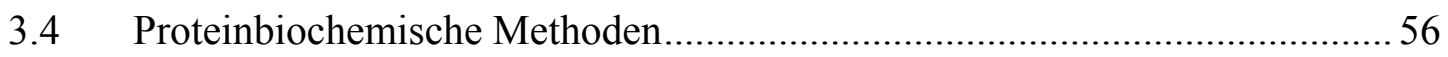

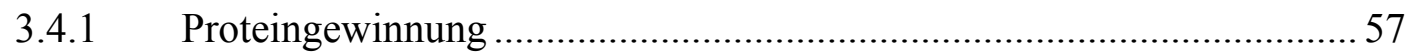

3.4.2 Bestimmung der Proteinkonzentration ............................................. 57

3.4.3 SDS-Polyacrylamid-Gelelektrophorese ............................................5

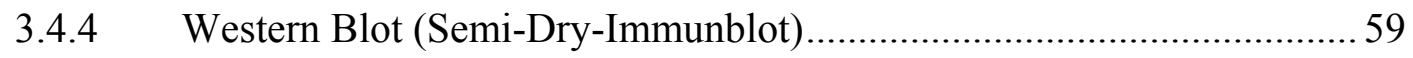

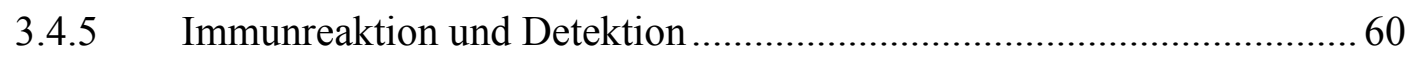

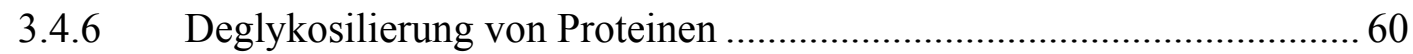

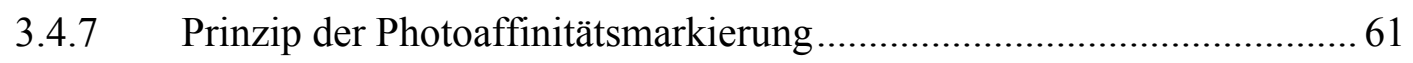

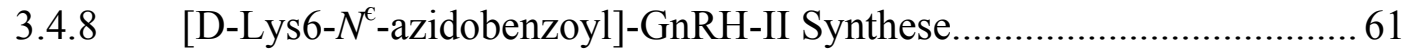

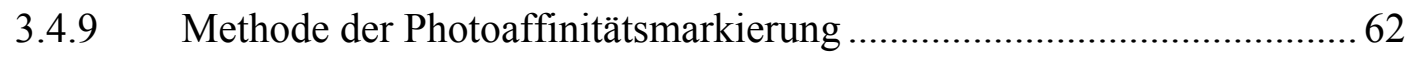

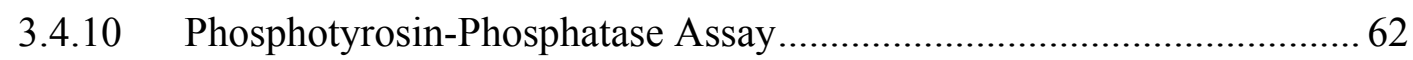

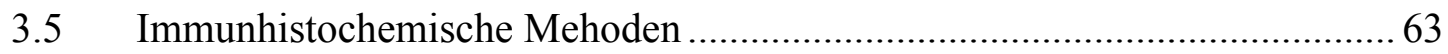

3.5.1 Gewinnung des anti-human GnRH-II Rezeptor Antiserum ...................63

3.5.2 Einbettung der Gewebe in Paraffin........................................................... 64

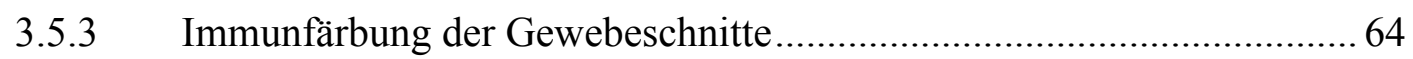

3.6 Statistische Auswertung der Gen- und Protein-Expression ............................ 66

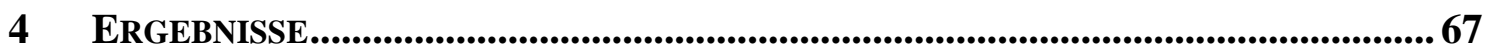

4.1 Wirkungsmechanismen des GnRH-II Rezeptor Systems .............................. 67

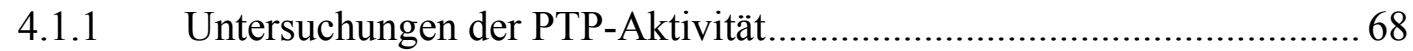

4.1.2 Nachweis der GnRH-II Rezeptor-mRNA Expression nach GnRH-I

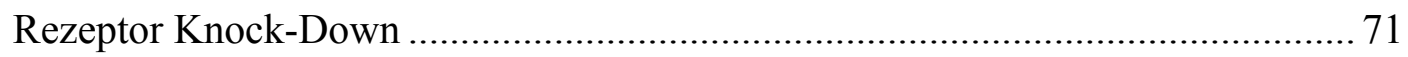


4.1.3 Effekte des GnRH-II Agonisten [D-Lys ${ }^{6}$ ]GnRH-II auf die EGFinduzierte MAPK (ERK1/2) Aktivität.

4.1.4 Effekte des GnRH-II Agonist [D-Lys $\left.{ }^{6}\right] \mathrm{GnRH}-\mathrm{II}$ auf die EGF-induzierte c-fos Expression 74

4.2 Nachweis des GnRH-II Rezeptor Proteins ................................................. 78

4.2.1 GnRH-II Rezeptor Antiserum Spezifität an Gewebeschnitten des Callithrix jacchus-Ovars 78

4.2.2 Immunhistochemischer Nachweis der GnRH-II Rezeptor Expression in humanen reproduktiven Geweben 79

4.2.3 Western Blot Analyse des GnRH-II Rezeptor-ähnlichen Proteins an Zellmembranfraktionen 80

4.2.4 Deglykosilierung des putativen GnRH-II Rezeptor Proteins 81

4.2.5 Photoaffinitätsmarkierung als Nachweis eines GnRH-II Rezeptor ähnlichen Proteins 82

5 DisKusSiON . 85

5.1 Der GnRH-II Agonist [D-Lys $\left.{ }^{6}\right] \mathrm{GnRH}-\mathrm{II}$ inhibiert die mitogene Signaltransduktion des EGF-Rezeptors ..... .85

5.2 Die antiproliferative Wirkung des GnRH-II Agonisten 87

5.3 GnRH-II wird nicht über das GnRH-I Rezeptorsystem reguliert 88

5.4 Nachweis eines GnRH-II Rezeptor-ähnlichen Proteins. .89

5.5 Identifikation des GnRH-II Rezeptors 91

$5.6 \quad$ Fazit 94

6 LITERATUR .95

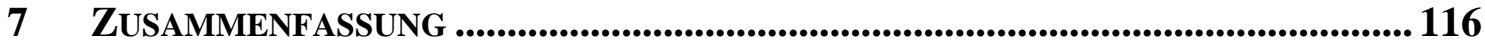

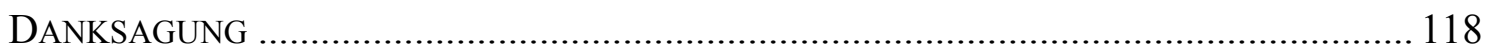

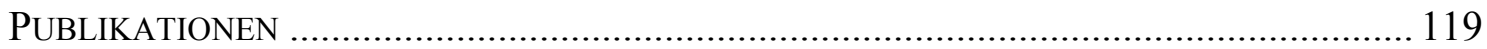

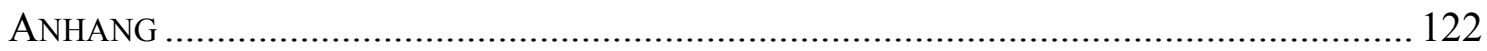

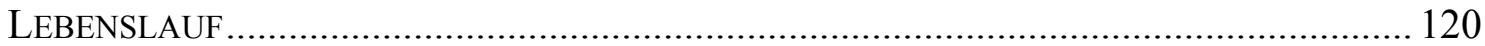




\section{ABKÜRZUNGSVERZEICHNIS}

AK

AP

AP-1

APS

BRCA1/2

DAB

DAG

DEPC- $\mathrm{H}_{2} \mathrm{O}$

DMSO

dNTPs

DTT

EDTA

EGF

ER

ERK

FCS

FIGO

FSH

GAP-DH

GnRH

GPCR

HER
Antikörper

Alkalische Phophatase

activator protein 1

Ammoniumperoxodisufat

breast cancer genes

Diaminobenzidin

Diazylglycerol

Diethylpyrocarbonat

Dimethylsulfat

Didesoxynukleotidtriphosphate

Dithiotreithol

Ethylendiamtetraacetat

epidermal growth factor

Endoplasmatisches Retikulum

extracellulare-regulated kinase

fetal calf serum (fetales Kälberserum)

Fédération Internationale de Gynécologie et d'Obstéstrique

Follikelstimulierendes Hormon

Glycerinaldehyd-3-Phosphat-Dehydrogenase

Gonadotropin-Releasing Hormon

G-protein coupled receptor

human epidermal growth factor receptor 
HRP

IAA

IEF

IGF-1

$\mathrm{IP}_{3}$

IRES

JNK

LB

LH

MAPK

MEM

MEK

Mol

$\mathrm{NF} \kappa \mathrm{B}$

PCR

PI3K

$\mathrm{PIP}_{2}$

PKC

PLC

$\mathrm{P} / \mathrm{S}$

PTP

Rpm

RT

SDS

STAT
Horseraddish peroxidase (Meerrettich-Peroxidase)

Jodacetamid

Isoelektrische Fokussierung

insulin-like growth factor

Inositol 1,4,5-Triphosphat

internal ribosome entry site

c-Jun N-terminale kinase

Luria-Bertani

Luteinisierendes Hormon

mitogen-activated protein kinase

Minimal Essential Medium

mitogen-activated protein kinase kinase

6,3 x 1023 Teilchen

Nekrosisfactor $\kappa \mathrm{B}$

polymerase chain reaction

Phposphatidylinositol 3-Kinase

Phposphatidylinositol 4,5-Bisphosphat

Proteinkinase C

Phospholipase C

Penicillin/Streptomycin

Phosphotyronin-Phosphatase

rounds per minutes

Raumtemperatur

Sodiumdodecylsulfat

signal transducers and activators of transcription 
TAE

Taq

TBP

TEMED

TGF $\alpha$

7TM

Tris
Tris/EDTA-Puffer

Thermus aquaticus

Tributylphosphin

N,N,N'N`- Tetramethylethylendiamin

transforming growth factor alpha

Sieben-Transmembranrezeptor

Tris(hyxdroxymethyl)aminoethan 


\section{EINLEITUNG}

\subsection{Das Ovarialkarzinom}

\subsubsection{Epidemiologie und Ätiologie}

In vielen westlichen Ländern ist das Ovarialkarzinom nach dem Cervix- und Endometriumkarzinom die dritthäufigste Tumorart des Genitaltrakts. Jede 70ste Frau wird in ihrem Leben an einem Ovarialkarzinom erkranken (AWMF-Leitlinienregister 2002). Von allen gynäkologischen Malignomen hat es die schlechteste Prognose. Wird das Ovarialkarzinom entdeckt, so handelt es sich in $70 \%$ aller Fälle um ein fortgeschrittenes bereits metastasiertes Tumorstadium, bei dem die 5-JahresÜberlebensrate zwischen 20 und 40\% liegt (Schmidt-Matthiesen und Bastert 1995) (Tab.1.1). Somit stellt das Ovarialkarzinom die häufigste Todesursache unter den gynäkologischen Malignomen dar. Für diese hohe Mortalitätsrate ist ein ungünstiger Verlauf dieser Karzinogenese verantwortlich. Die Gründe sind die Abwesenheit von Symptomen im Frühstadium, das Fehlen von diagnostizierbaren Läsionen des Ovarepithels und der Mangel an spezifischen und sensitiven Screeningverfahren. Die Wahrscheinlichkeit, dass die Ovarialtumoren maligne sind, steigt im Alter. Die höchste Inzidenz liegt bei 80 Jahren, am häufigsten wird die Diagnose zwischen dem 60 . und 70. Lebensjahr gestellt (Tortolero-Luna und Mitchell 1995, AWMF-Leitlinienregister, 2002).

Tab.1.1: Stadiumabhängige Inzidenz und 5-Jahres-Überlebensrate bei Ovarialkarzinom-Patientinnen (nach der FIGO-Klassifikation 1986)

\begin{tabular}{lll}
\hline Stadium & Inzidenz & 5-Jahres-Überlebensrate \\
\hline I & $26 \%$ & $60-90 \%$ \\
II & $15 \%$ & $40-70 \%$ \\
III & $43 \%$ & $4-15 \%$ \\
IV & $16 \%$ & $0-5 \%$ \\
\hline
\end{tabular}


Der Krankheitsverlauf des Ovarialkarzinoms und seine Prognose sind im Wesentlichen von der Tumorausbreitung zum Zeitpunkt der Diagnosestellung bzw. der Primärtherapie abhängig. Global werden die Inzidenz und die 5-Jahres-Überlebensraten wie in Tab. 1.1 angegeben (nach FIGO; Fédération Internationale de Gynécologie et d Obstéstrique).

Faktoren für die Prognose sind der Grad der Differenzierung und der histologische Subtyp des Tumors (Ozols et al. 1980, De Souza und Friedlander 1992), die Tumorausbreitung, der Ploidiegrad (Schueler et al. 1993), das Residualvolumen nach operativem Eingriff sowie das Alter und der Allgemeinzustand der Patientinnen. Letztere Faktoren limitieren die Möglichkeiten der Chemotherapie (Rodenburg et al. 1987, De Souza und Friedlander 1992, Schueler et al. 1993).

Die Ätiologie des Ovarialkarzinoms ist noch weitgehend unklar. Faktoren, die zur Entwicklung eines Ovarialkarzinoms führen können, werden kontrovers diskutiert. Patientinnen mit einem Ovarialkarzinom haben häufig keine oder eine geringe Anzahl an Schwangerschaften in der Vorgeschichte. Eine frühe Menarche (unter elf Jahren), eine späte Menopause (über 55 Jahre) oder eine späte erste Schwangerschaft (über 35 Jahre) sind weitere Risikofaktoren (Tortolero-Luna und Mitchell 1995, La Vecchia 2001). Diese Beobachtungen legen die Vermutung nahe, dass häufige Ovulationen verbunden mit Rupturen des Zölomepithels mit anschließenden Regenerationsvorgängen, eine maligne Transformation wahrscheinlicher machen. Ebenso werden die erhöhten Östrogenspiegel in der Follikelflüssigkeit während der Ovulation als mitogener Stimulus angesehen, der $\mathrm{zu}$ einer Entartung der Zellen beitragen kann (Godwin et al. 1993).

Als protektive Faktoren gelten mehr als eine ausgetragene Schwangerschaft, Stillen und die Einnahme von oralen Kontrazeptiva. Die Einnahmen von Kontrazeptiva über einen Zeitraum von mehr als 5 Jahren soll zu einer Risikoreduktion von bis zu 50\% führen (La Vecchia und Franceschi 1999, Walker et al. 2002) und das Risiko für Frauen mit drei oder mehr Geburten verringert sich gegenüber kinderlosen Frauen ebenfalls um ca. 50\% (Rao und Slotman 1991).

Etwa 5\% aller Ovarialkarzinome sind hereditären Ursprungs (Holschneider und Berek 2000, La Vecchia 2001), davon liegen in 80\% BRCA1- und in 15\% BRCA2- Mutationen vor. Wenn in der Familie einer Patientin ein Mamma- und ein Ovarialkarzinom 
aufgetreten sind, beträgt die Wahrscheinlichkeit einer Mutation von BRCA1/BRCA2 ca. 30-50\% (Piver et al. 1991).

\subsubsection{Histologie und Grading}

Die gewebliche Zusammensetzung des Ovars ist komplex. Es besteht aus Zölomepithel, gonadalem Stroma, mesenchymalen Zellen und Keimzellen. Etwa 70\% aller Ovarialtumoren entwickeln sich aus dem Oberflächenepithel. Weitere Ovarialneoplasien entstehen aus den Keimzellen (15-25\%) und aus dem Ovarialstroma (6\%). Ovarialtumoren zeigen einen unterschiedlichen histologischen Aufbau und ein vielfältiges biologisches Verhalten. Eine derzeitige Klassifizierung erfolg nach den Richtlinien der World Health Organization (WHO, Serov und Scully 1973) und teilt die Ovarialtumoren nach ihrer vermuteten Histogenese ein. Die epithelialen Tumoren werden histologisch in benigne Tumoren, Karzinome mit niedrigem Malignitätsgrad und Karzinome unterschieden. Ausserdem teilt man sie entsprechend ihrer histologischen Differenzierungsformen in papillär-seröse (40-45\%), muzinöse $(10 \%)$, endometroide (10-20\%), hellzellige (5-10\%) und unklassifizierbare Karzinome ein. Das histologische Grading bei den epithelialen Tumoren richtet sich nach dem Differenzierungsgrad. Es werden vier Grade unterschieden, G1 (gut differenziert), G2 (mäßig differenziert), G3 (schlecht differenziert) und G4 (undifferenziert). Die folgende Tabelle (Tab. 1.2) zeigt die Stadieneinteilung von Ovarialkarzinomen nach der FIGOKlassifikation 1986. 
Tab. 1.2: Stadieneinteilung von Ovarialkarzinomen (nach der FIGO-Klassifikation 1986)

Stadium I Das Tumorwachstum ist auf die Ovarien beschränkt

Ia Ein Ovar befallen ohne Kapseldurchbruch, kein Aszites

Ib Beide Ovarien befallen ohne Kapseldurchbruch, kein Aszites

Ic (Ia und/oder Ib) mit Kapseldurchbruch und/oder Aszites mit Tumorzellnachweis

Stadium II Das Tumorwachstum geht über die Ovarien hinaus, ist aber auf das kleine Becken begrenzt

IIa Beteiligung von Uterus und/oder Tube(n)

IIb Weitere Lokalisation im kleinen Becken

IIc (IIa und/oder IIb) mit Aszites und Tumorzellnachweis

Stadium III

Tumornachweis außerhalb des kleinen Beckens auf die Peritonealhöhle beschränkt und/oder alle Stadien I und II mit Lymphknotenbefall (inkl. Leberkapselmetastasen, Omentumbefall, Befall der Dünndarm-/Dickdarm-serosa)

IIIa Tumor makroskopisch auf das kleine Becken beschränkt, mikroskopisch Peritonealkarzinose außerhalb des kleinen Beckens, kein Lymphknotenbefall

IIIb Wie IIIa, Peritonealkarzinose $<2 \mathrm{~cm}$

IIIc Wie IIIa, Peritonealkarzinose $>2 \mathrm{~cm}$, Lymphknotenbefall

Stadium IV Befall eines oder beider Ovarien mit Fernmetastasen 


\subsubsection{Therapieformen des Ovarialkarzinoms}

Die Behandlung von Ovarialkarzinomen beruht im Wesentlichen auf einer möglichst radikalen chirurgischen Tumorreduktion mit anschließender Chemo- und/oder Strahlentherapie (Ozols et al. 1992). Die Bedeutung von endokrinen Therapien haben in den vergangenen Jahren stark zugenommen und sind $\mathrm{zu}$ einer etablierten stützenden Maßnahme in der Behandlung von Ovarialkarzinomen geworden.

\subsubsection{Endokrine Therapie}

Von besonderem Interesse für die Forschung und Gegenstand vieler klinischer Studien ist derzeit die endokrine Therapie des Ovarialkarzinoms. Die üblichen Therapiestrategien, wie die radikale Tumorresektion mit anschließender Chemotherapie erzielen nur bescheidene Langzeitergebnisse und die Häufigkeit von primären Progressionen und Rezidiven ist unverhältnismäßig hoch. Der sensible HypothalamusHypophysen-Gonaden-Regelkreis mit seinen Rückkopplungsmechanismen macht die Erforschung von Eingriffen in das System, besonders bei malignem Zellwachstum interessant. Eingehende Untersuchungen ergaben, dass Ovarialkarzinome Rezeptoren für Steroid-, Proteo- und Peptidhormone aufweisen. So finden sich bei etwa $62 \%$ der Ovarialkarzinome Östrogenrezeptoren, bei 49\% Progesteronrezeptoren und bei $69 \%$ Androgenrezeptoren (Rao und Slotman 1991). Eine Kombination aus Östrogen- und Progesteronrezeptoren ließ sich bei ca. 36\% der Tumoren nachweisen, während nur $25 \%$ rezeptornegativ sind. Trotz dieser ermutigenden Daten wurden durch die Gabe von Antiöstrogenen und Gestagenen Remissionserfolge von nur 10-15\% erreicht (Hatch et al. 1991, Emons et al. 1993). Der Vorteil einer hochdosierten Gestagengabe, unabhängig von ihrer Wirkung auf den Tumor, besteht jedoch auch in einer Verbesserung des Allgemeinzustandes der Patientin. Aufgrund der starken Nebenwirkungen ist der Einsatz von Gestagenen allerdings begrenzt (Schmidt-Rhode 1991).

In mehreren Untersuchungen konnte die Existenz von Gonadotropin-Releasing Hormon (GnRH) Rezeptoren, sowie eine spezifische GnRH-Bindung im Tumorgewebe nachgewiesen werden. Ebenfalls wurde gezeigt, dass die Poliferation in vitro und in vivo durch diese Gonadotropine stimuliert werden kann (Emons et al. 1992a, 1992b, 
Emons und Schally 1994). In der Folge beschrieben mehrere Autoren, dass die Supression der endogenen LH- und FSH- Spiegel durch GnRH-Analoga bei 10-15\% der Patientinnen mit fortgeschrittenem, rezidivierten Ovarialkarzinom zur Remission oder zur ,Stable-Disease führen kann (Bruckner und Motwani 1989, Jäger et al. 1989, Lindt et al. 1992, Emons et al. 1992a).

In rund $80 \%$ der Ovarialtumoren konnten spezifische Bidungsstellen für GnRH nachgewiesen werden (Emons et al. 1989, Pahwa et al. 1989). Untersuchungen zum Einsatz von GnRH-Agonisten und -Antagonisten beschäftigen sich mit dem Wirkungsmechanismus der Wachstumsinhibition mit geringen Nebenwirkungen (Emons und Schally 1994).

\subsection{Das Endometriumkarzinom}

\subsubsection{Epidemiologie und Ätiologie}

Das Endometrium- oder Korpuskarzinom ist in vielen westlichen Ländern die häufigste maligne Erkrankung des Genitaltrakts der Frau. Die Inzidenz beträgt 25 pro 100000 Frauen jährlich mit einem Altersgipfel zwischen 65 und 70 Jahren (AWMFLeitlinienregister 2002). Etwa 15\% der Patientinnen sind in der Prämenopause, 3,5\% sind jünger als 40 Jahre (Schmidt-Matthiesen und Bastert 1995).

Gegenüber dem Ovarialkarzinom ist die Prognose für EndometriumkarzinomPatientinnen relativ günstig, da etwa 70\% der Erkrankungen bereits im FIGO-Stadium I (Tab. 1.3) erkannt werden und damit eine 5-Jahres-Überlebensrate von 74\% verbunden ist (Petterson 1988). Zum Zeitpunkt der Diagnosestellung ist in 70\% der Fälle das Karzinom auf das Corpus uteri beschränkt. Erfolgt die Diagnose zu einem späteren Stadium und/oder ist bereits eine extrauterine Aussaat des Tumormaterials erfolgt, steigt die Letalität rapide an. Die 5-Jahres-Überlebensraten liegen bei einem Endometriumkarzinom im Stadium II bei $58 \%$, im Stadium III bei $43 \%$ und im Stadium IV nur noch bei 8\% (Petterson 1988).

Das Endometriumkarzimom ist vorzugsweise eine Erkrankung älterer Frauen. Ätiologisch müssen aber auch exogene und endogene Faktoren genannt werden. 
Exogene Faktoren sind nicht-zyklische, alleinige Östrogen-Ersatztherapien, TamoxifenLangzeittherapien im Zusammenhang mit einem Mammakarzinom oder vorhergehende Bestrahlungstherapien (Weiderpass et al. 1999, Bernstein et al. 1999). Als dominierender Faktor wird die langandauernde Östrogeneinwirkung auf das Endometrium gesehen. Zusammen mit dem fehlenden Progesteroneinfluß auf die Gebärmutterschleimwand, kann es zum Auftreten unterschiedlicher Formen einer Endometriumhyperplasie führen, die wiederum in ein Endometriumkarzinom einmünden kann. Als endogene Faktoren gelten Adipositas, auch im Zusammenhang mit Diabetes mellitus (Weiderpass et al. 2000), frühe Menarche, späte Menopause oder Nulliparität (Bristow 1999). Mit der Einnahme von Östrogenen wurde ein bis zu zwölffach erhöhtes Risiko für die Entstehung eines Endometriumkarzinoms ermittelt, wobei das Risiko proportional zu der Dauer und Dosis der Östrogenzufuhr ist (Jelovsek et al. 1989). Im Gegensatz dazu stehen allerdings Studien, die keinen direkten Kausalzusammenhang zwischen Östrogeneinnahme und dem Auftreten eines Endometriumkarzinoms feststellen konnten (Silverberg 1984). Man unterscheidet aus diesem Grund zwischen zwei pathogenetisch unterschiedlichen Karzinomtypen. Dem hormonabhängigen (Typ 1) und hormonunabhängigen (Typ 2) Endometriumkarzinom. Das hormonabhängige Endometriumkarzinom enthält viele Östrogen- und Progesteronrezeptoren und ist hoch differenziert. Das hormonunabhängige Karzinom (ca. 20\%) hat wenig oder keine Hormonrezeptoren. Aufgrund seiner Entdifferenzierung ist die Prognose schlecht. Es tritt gehäuft bei Frauen ohne entsprechende Risikofaktoren auf (Bokhman 1983, Akhmedkhanov 2001).

\subsubsection{Histologie und Grading}

Während der Geschlechtsreife unterliegt das Endometrium einem regelmäßigen Aufund Abbau. Aufgrund ovarieller Dysfunktionen kommt es in den letzten Jahren vor der Menopause zu einer übermäßigen Endometriumproliferation. 
Tab. 1.3: Stadieneinteilung des Endometriumkarzinoms (nach der FIGOKlassifikation 1988)

Stadium $0 \quad$ Präinvasives Karzinom (Carcinoma in situ)

Stadium I

Karzinom ist auf das Corpus uteri beschränkt

Ia Der Tumor ist auf das Endometrium beschränkt

Ib Invasion des Tumors bis zu 50\% der Myometriumdicke

Ic Invasion des Tumors über 50\% der Myometriumdicke

Stadium II $\quad$ Befall der Zervix uteri

IIa Tumor ist auf endozervikale Drüsen beschränkt

IIb Invasion des Tumors in das Stroma der Zervix

Stadium III Ausdehnung des Karzinoms über den Uterus hinaus, aber auf das kleine Becken begrenzt

IIIa Uterusserosa, Adnexe, pos. Peritonealzytologie

IIIb Vaginalbefall, auch metastatisch

IIIc Lymphknotenbefall

\section{Stadium IV}

IVa Karzinomeinbruch in Blase oder Rektum und/oder Ausdehnung des Karzinoms über das kleine Becken hinaus

IVb Fernmetastasen, intraperitoneale Metastasen, positive LeistenLymphknoten 
Unter den Endometriumkarzinomen ist das endometroide Adenokarzinom mit einem Anteil von $80 \%$ die häufigste Variante. Mischformen, die neben glandulären auch plattenepitheliale Anteile aufweisen, treten in 5-15\% der Fälle auf. Die Endometriumkarzinome werden nach ihrem Differenzierungsgrad in gut differenzierte (G1), mittelgradig differenzierte (G2) und gering differenzierte Formen (G3) eingestuft. Je höher der Differenzierungsgrad, desto schlechter ist die Prognose. Mit abnehmender Differenzierung sinkt der Östrogen- und Progesteronrezeptorgehalt, die DNA-Diploidie geht zunehmend in Aneuploidie über und die Aggressivität des Tumors steigt an (Baltzer und Maaßen 1989).

Seit 1988 gilt in der FIGO-Klassifikation die chirurgische, d.h. postoperative Klassifizierung (Creasman 2001) (Tab. 1.3).

\subsubsection{Therapieformen des Endometriumkarzinoms}

Für eine Primärtherapie des Endometriumkarzinoms stehen unterschiedliche Ansätze zur Auswahl, wobei sich die Therapie nach der Ausdehnung, dem Zustand der Patientin und weiteren Prognosefaktoren richtet. Primär steht die operative Behandlung im Vordergrund (Fuchtner et al 1993), kombiniert mit einer prä- oder postoperativen Strahlentherapie. Diese Kombination verspricht eine 10-20\%ige Verbesserung des Heilungsergebnisses (Hacker 1991, Schulz 1991). Aber auch bei dieser Tumorentität rückt die endokrine Therapie immer mehr in den Vordergrund.

\subsubsection{Endokrine Therapie}

Der Einfluss auf das Wachstum von hormonsensitiven Endometriumkarzinomen durch Östrogen und Progesteron ist weitgehend bekannt (Schulz und Emons 1995). Da gut differenzierte Endometriumkarzinome Progesteronrezeptoren enthalten, kann man in 30\% der Fälle mit einem Ansprechen einer Gestagentherapie rechnen. Bei rezeptorreichen Tumoren liegt das Ansprechen bei 60\%. Der Allgemeinzustand der Patientinnen kann dadurch deutlich verbessert und eine Tumorremission vorübergehend oder anhaltend in 10-30\% der Fälle erreicht werden (Schulz et al. 1991, Park et al. 1992, Schulz und Emons 1995). Der Nachweis von Östrogenrezeptoren gegenüber 
rezeptornegativen Patientinnen verbessert die Prognose nicht (Kleine 1991). Es besteht ein direkter Zusammenhang zwischen dem Steroidrezeptorgehalt und dem Differenzierungsgrad des Karzinoms. Man kann sagen, dass der Steroidrezeptorgehalt und damit das Ansprechen auf eine Gestagentherapie mit fortschreitender Entdifferenzierung abnimmt (Schulz und Emons 1995, Kleine 1991). Wenn der Gestageneffekt keinen Erfolg mehr zeigt, dann kann durch die Gabe von Antiöstrogenen, z.B. von Tamoxifen, durchaus der Zustand der Patientin verbessert werden.

Zur Hormontherapie des fortgeschrittenen, metastasierenden, inoperablen oder rezidivierenden Endometriumkarzinoms können neben Gestagenen und Antiöstrogenen auch Aromatasehemmer und GnRH-Analoga zur Anwendung kommen (Emons et al. 1993a, Kullander 1992, Thigpen 1999). In ca. $80 \%$ aller untersuchten Endometriumkarzinome konnten GnRH-Bindungsstellen detektiert werden (Emons et al. 1989, Pahawa et al. 1989, Pahawa et al. 1991), was diesen Therapieansatz unterstützt.

\subsection{Hormontherapie mit GnRH-Agonisten}

In ca. $80 \%$ aller Ovarial- und Endometriumkarzinomen konnten GnRH Rezeptoren sowie GnRH-Bindungsstellen nachgewiesen werden (Emons et al. 1989, Pahawa et al. 1989, Pahawa et al. 1991), womit der therapeutische Nutzen dieses Hormons sehr bedeutend geworden ist. Nachdem die Struktur des GnRH-Moleküls aufgeklärt (Abb. 1.5) und seine Synthese möglich war (Schally 1971), konnte es modifiziert werden. Die auf diesem Wege synthetisierten Peptide, ähneln ihrer Struktur nach dem nativen GnRH. Allerdings besitzen die GnRH-Agonisten eine bessere Bioverfügbarkeit, sowie eine verlängerte Wirkdauer und eine erhöhte Rezeptoraffinität. Bei kontinuierlicher Applikation führen sie $\mathrm{zu}$ einer reversiblen Entkopplung der Hypothalamus-Hypophysen-Ovar Achse, in dem sie einen Abfall der GnRH-Rezeptoren und eine Desensibilisierung der gonadotropen Adenohypophysenzellen hervorrufen. Aufgrund der verringerten Gonadotropinbildung und -sekretion kommt es $\mathrm{zu}$ einer Supression der ovariellen Steroidsynthese. Nach ihrer Applikation bewirken sie 
zunächst eine gesteigerte Gonadotropinfreisetzung aus dem Hypophysenvorderlappen (,flare-up Effekt ${ }^{e}$ ). Gleichzeitig kommt es zur transienten Vermehrung der membranständigen Rezeptoren der gonadotropen Zellen (,up-Regulation ${ }^{e}$ ).

Nach der Desensibilisierung sind die gonadotropen Zellen gegenüber dem nativen wie auch den GnRH-Agonisten gegenüber refraktär. Es wird durch das Absinken der FSHund LH-Spiegel im Serum die ovarielle Steroidsynthese vermindert. Der medizinische Nutzen der GnRH-Agonisten in der Therapie von sexualhormonabhängigen Erkrankungen ist ausserordentlich. So wird die Unterdrückung der Steroidhormonsynthese im Bereich der Onkologie zur ablativen Therapie, unter anderem von Ovarialund Endometriumkarzinomen gnutzt (Fekete et al. 1989, Emons et al. 1989, Pahwa et al. 1991, Limonta et al. 1992).

\subsection{Der epidermale Wachstumsfaktorrezeptor}

Die epidermale Wachstumsfaktorrezeptor-Familie (EGFR, epidermal gwoth factor receptor) von Rezeptor-Tyrosin-Kinasen werden in unterschiedlichen Konzentrationen und Kombinationen in einer Vielzahl von Geweben epithelialen, mesenchymalen und neuronalen Ursprungs exprimiert, wobei sie eine fundamentale Rolle in der Entwicklung, Proliferation und Differenzierung spielen. Sie sind von großer Bedeutung für die Regulation der mitogenen Signaltransduktionswege in gesunden Zellen, die schließlich zur Zellproliferation führen können (Zwick et al. 1999, Cohen 2002). Störungen dieser Signalkaskade können daher leicht zur Hyperaktivierung und damit zum malignen Wachstum der Zelle führen. In Säugern konnten bisher vier Mitglieder der EGF-Rezeptorfamilie identifiziert werden: der EGF-Rezeptor (auch ErbB1 oder HER1), sowie die Rezeptoren ErbB2/Neu/Her2, ERbB3/HER3 und ErbB4/HER4. Sie werden von einer Vielzahl von Liganden aktiviert, wie dem ,Epidermal Growth Factor ${ }^{e}$ (EGF) oder dem ,Transforming Growth Factor alpha ${ }^{e}$ (TGF $\alpha$ ), die eine EGF-ähnliche Domäne haben (Kira et al. 1997). Die Mitglieder der EGF-Rezeptor-Familie besitzen alle zwei cysteinreiche Regionen in der extrazellulären Domäne, eine Transmembrandomäne und eine Tyrosin-Kinasedomäne im zytoplasmatischen Teil. 


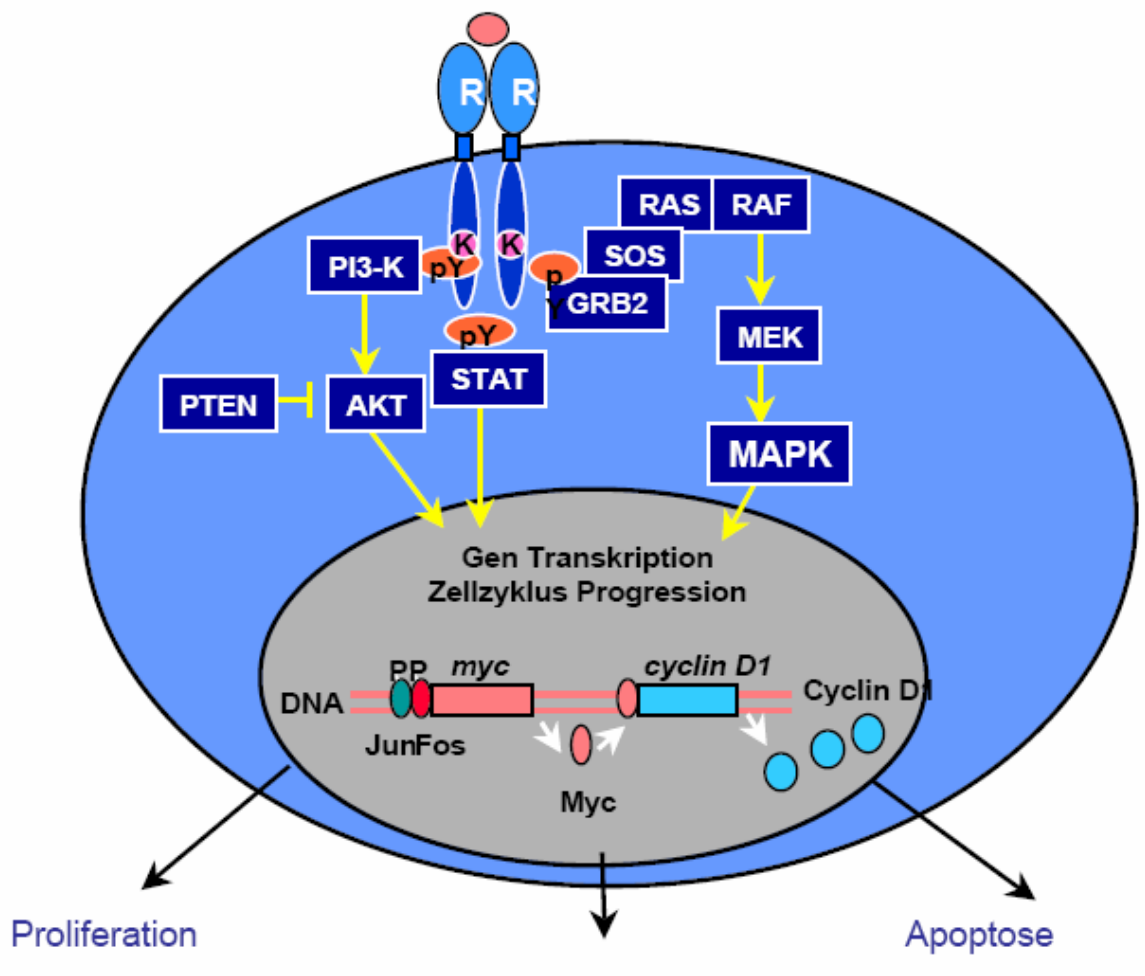

Wachstum

Abb. 1.1: Durch die Rezeptor-Tyrosin-Kinasen aktivierte Signalwege. Durch die Autophosphorylierung verschiedener Tyrosinreste des Rezeptors können SH2Domänen enthaltene Effektormoleküle an den Rezeptor binden und dadurch aktiviert werden. Diese aktivieren ihrerseits verschiedene Signalwege: den MAP-Kinase-Weg, den STAT-Signalweg oder den anti-apoptotischen PI3-Kinase-Weg. Dies führt zur Aktivierung von Transkriptionsfaktoren, die die Expression von Proteinen z.B. c-Fos aktiviere, somit den Zellzyklus vorantreiben und damit zu einer proliferativen Reaktion der Zelle führen. Andererseits wird durch die Aktivierung von Akt ein

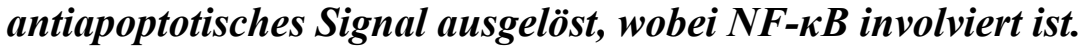

Diese spezifischen Tyrosinreste im C-terminalen Teil, kreieren nach der ligandeninduzierten Rezeptordimerisierung und Autophosphorylierung, Bindungsstellen für SrcHomologie (SH2)- oder Phosphotyrosinbindungsdomänen enthaltene Signalmoleküle. Dabei kann es sich entweder um Adapterproteine, wie z.B. Shc, Grb2, Gab1 oder Crk handeln, welche Signalplattformen aufbauen, an die weitere Effektormoleküle binden oder es sind Enzyme, wie z.B. Phospholipase C (PLC $\gamma$ ), c-Src Phosphatidylinositol 3kinase (PI3-K) oder Phosphatasen wie SHP1 und SHP2. 
Jedes Mitglied der EGF-Rezepetor Familie weist ein typisches C-terminales Phosphorylierungsmuster auf, welches verschiedene Signalproteine rekrutiert und aktiviert, so dass ein hoch diverses Signalnetzwerk entsteht (Wells 1999, Kim et al. 2001). Der MAP-Kinase-Weg ist der am Besten untersuchte Signalweg. Nach der Rekrutierung von Shc und Grb2 zum phosphorylierten Rezeptor, wird das G-Protein Ras, über den Grb2-gebundenen Austauschfaktor Sos, aktiviert. Dieses G-Protein aktiviert die Serin/Threonin-Kinase Raf, welche über die mitogen-aktivierte Kinase Kinase (MEK1, mitogen-activated protein kinase kinase) schließlich die extrazellulärregulierte Kinase (ERK1/2, extracellular-regulated kinase) induziert, die Transkriptionsfaktoren wie Elk-1 und c-fos phosphorylieren (Rubinstein et al. 2005). Die Aktivierung dieses Signalweges führt vor allem zu proliferativen Antworten auf eine EGF-Stimulation. Desweiteren werden durch die EGF-Stimulation die STAT (signal transducers and activators of transcription) -Signalwege oder der antiapoptotische Phposphatidylinositol 3-Kinase (PI3K) -Weg aktiviert (Abb. 1.1).

\subsubsection{Die mitogen-aktivierten Proteinkinasen}

Die mitogen-aktivierten Proteinkinases (MAPK, mitogen-activated protein kinase) gehören zu den wichtigsten, durch extrazelluläre Signale aktivierten Signalkaskaden (Chan-Hui, 1998). Eine Supgruppe der MAP-Kinase bilden die ERKs. Es handelt sich hierbei um zytoplasmatische Proteinkinasen, die ihren Namen aufgrund ihrer Regulierbarkeit duch extrazelluläre, häufig mitogen wirkende Liganden tragen. Die p44/p42 MAPK (ERK1/2) wird vor allem durch Wachstumsfaktoren wie EGF und TGF $\alpha$ aktiviert, aber auch durch Zytokine oder Liganden G-Protein-gekoppelter Rezeptoren (Johnson et al. 2002). Über die Aktivierung der ERK1/2 werden Zellzyklusprogression und eine Hemmung der Apoptose vermittelt (Cross et al. 2000, Rubinfeld 2005).

\subsubsection{Das ,Immediate Early Response' Gen c-fos}

Das ,Immediate Early Response ${ }^{e}$ Gen $c$-fos ist ein im Zellkern lokalisiertes Protoonkogen. Es gehört zu den sehr früh exprimierten Genen, die bei vielen Signalkaskaden die erste Antwort der Zellen auf exta- oder intrazelluläre Reize 
darstellen. Deren Produkte veranlassen als Transkriptionsfaktoren die Aktivierung der späten Genantwort veranlassen. Die ,Immediate Early Response Gene werden durch eine Vielzahl von externen Wachstums- und Differenzierungssignalen aktiviert (Greenberg 1984, Curran 1988). Protoonkogene werden sehr schnell nach dem Stimulus exprimiert und die mRNA hat eine Halbwertzeit von nur ca. 30 min (You et al. 1992).

Das Produkt des c-fos Protoonkogens ist ein instabiles nukleäres Phosphoprotein, c-Fos (Sambucetti et al. 1986). Mit dem Produkt anderer Protoonkogene aus der Jun-Familie bildet es je eine Untereinheit des Transkriptionsfaktors AP1 und reguliert somit die Transkription von vielen an Zellwachstums- und Differenzierungsprozessen beteiligten Genen (Rauscher et al. 1988, Chiu et al. 1988). Im Gegensatz zu seinem Dimerisationspartner Jun, ist Fos nicht in der Lage Homodimere zu bilden und kann somit nicht als alleiniger Faktor an die Ziel-DNA binden (Kouzarides et al. 1988).

\subsubsection{Der EGF-Rezeptor in der Onkologie}

Unter normalen Bedingungen unterliegt der EGF-Rezeptor einer strikten Kontrolle. Die Deregulation dieses kontrollierten Systems durch Überexpression, Genamplifikation oder Mutationen begünstigt die maligne Transformation gesunder Zellen. So kann eine durch Genamplifikation verursachte Überexpression des EGF-Rezeptors den Zellzyklus oder die Zelldifferenzierung empfindlich stören und zum Entstehen eines Tumors beitragen. Im Fall eines bestehenden Tumors bedeutet die Überexpression des Rezeptors eine besonders ungünstige Prognose. Die Stimulation des EGF-Rezeptors führt in diesem Falle zu einem verstärkten Tumorwachstum, der Stimulation von Metastasierung, Angiogenese und Gefäßinvasion, sowie Apoptoseinhibition (Salomon et al. 1995, Wells 1999, Woodburn 1999). Tumoren verschiedenen Ursprungs (unter anderem auch Ovarial-, Endometrium- und Mammakarzinome) weisen oft eine Überexpression des EGF-Rezeptors auf und sind deswegen meist resistent gegenüber Chemotherapien (Harari 2004). Die Funktionalität des EGF-Rezeptors ist auf unterschiedliche Weise beeinflussbar, so dass z.B. durch die Inhibition der Wachstumsfaktorsignalkaskade eine Reduktion der Zellroliferation erreicht werden kann (Harari 2004). 


\subsection{Das GnRH-System}

\subsubsection{Das GnRH-I}

Das Gonadotropin-Releasing Hormon Typ I (mammalian GnRH, GnRH-I, syn. LHRH) ist ein Decapeptid (Abb. 1.4), dessen Aminosäuresequenz erstmals 1971 (Shally et al. 1971) charakterisiert wurde. Es wird von den Neuronen des Hypothalamus (medialer Nucleus präopticus, Nucleus arcuatus) in pulsatiler Form im Abstand von Minuten bis wenigen Stunden in das hypophysäre Portalvenensystem sezerniert (Knobil 1990). Diese Freisetzung erfolgt als Reaktion auf neurale oder neuroendokrine Signale des Gehirns, sowie Steroid- und Peptidhormonsignale verschiedener endokriner Organe. Über das Portalvenensystem gelangt das GnRH zum Hypophysenvorderlappen, wo es an membranständige Rezeptoren gonadotroper Zellen bindet (GnRH-I Rezeptor).

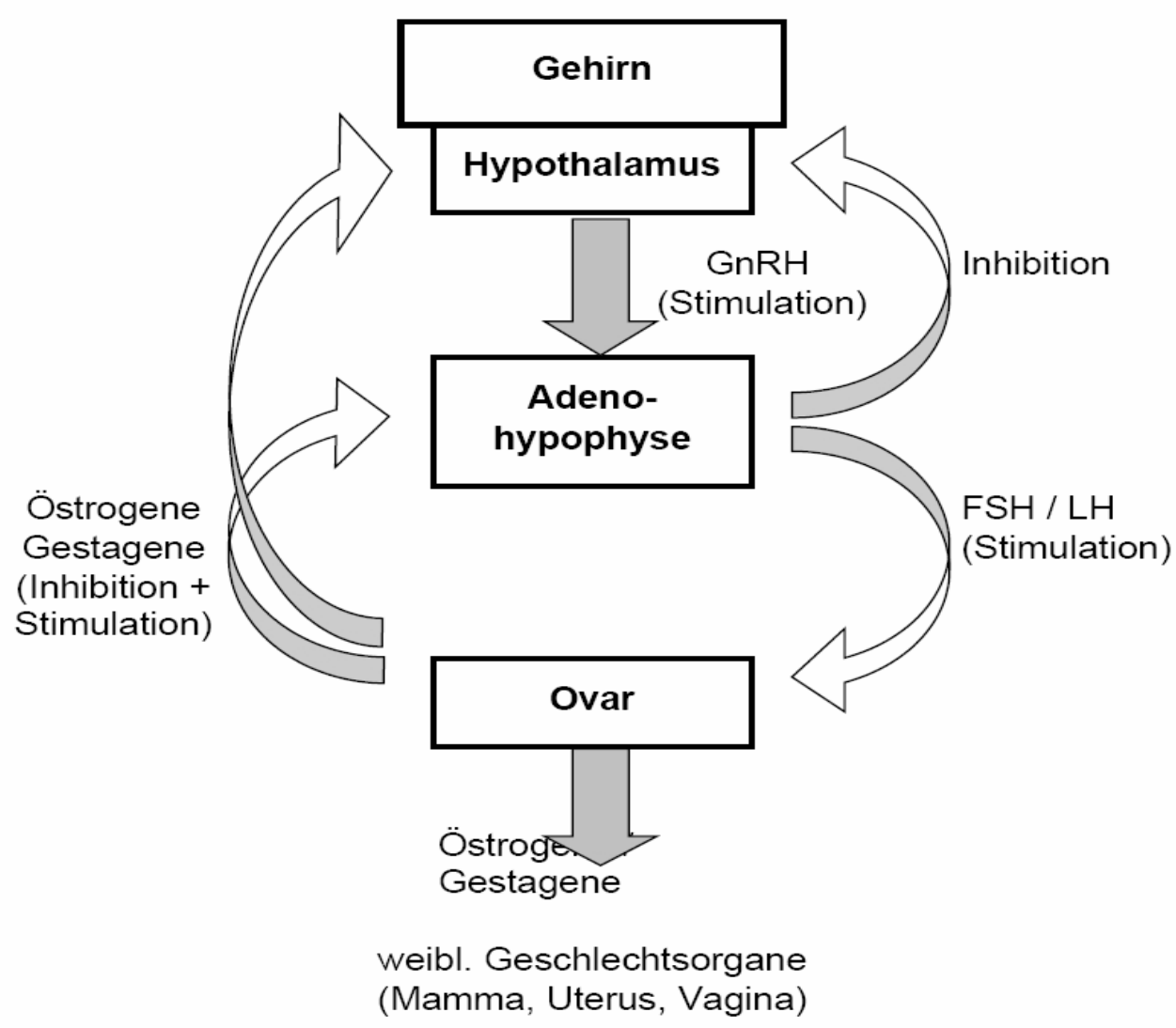

Abb. 1.2: Schematische Darstellung der Hypothalamus-Hypophysen-Ovar Achse. GnRH und FSH/LH stimulieren Hypophyse bzw. Ovar, so dass es in den Ovarien zur Östrogenproduktion kommt. Über einen Rückkopplungsmechanismus wird die Hormonsekretion reguliert. 
Durch die Bindung an seine Rezeptoren reguliert das GnRH über eine Reaktionskaskade (Naor 1990, Stojilkovic et al. 1994) die Synthese und Freisetzung des Luteinisierenden Hormons (LH) und des Follikel-Stimulierenden Hormons (FSH) in den gonadotropen Zellen. Durch die induzierte Freigabe dieser Hormone in den Blutkreislauf wird in den Ovarien die Follikelreifung hervorgerufen, es kommt zur Ovulation und zur Bildung des Corpus luteum. Ausserdem wird die Steroidsynthese angeregt, wobei das LH die Androgensynthese und das FSH die Östrogenproduktion stimuliert. Zwischen dem Ovar und der hypothalamisch-hypophysären Achse bestehen verschiedene Rückkopplungsmechanismen (Abb.1.2). Somit wird die Stimulation bzw. Hemmung der Hormonsekretion über die Blutspiegel der einzelnen Hormone initiiert.

\subsubsection{Der GnRH-I Rezeptor}

Der humane GnRH-I Rezeptor wurde erstmals 1992 (Kakar et al. 1992) kloniert und sequenziert. Das Gen ist auf Chromosom vier lokalisiert und besteht aus drei Exons und zwei Introns. Das Glykoprotein ist 329 Aminosäuren (AS) lang. Es handelt sich um einen G-Protein gekoppelten Rezeptor (GPCR, G-protein-coupled receptor), dessen Signale durch GTP-bindende Proteine ins Zellinnere weitergeleitet werden. Die G-Proteine binden an die Aminosäuresequenzen der zweiten und dritten intrazellulären Schleife. GPCRs gehören zur Familie der Sieben-Transmembranrezeptoren (7TM), deren charakteristisches Merkmal sieben transmembranäre Helices sind (TM1-7) (Abb. 1.3). Diese Helices sind untereinander durch Peptidschleifen verbunden. Der glykosilierte Aminoterminus befindet sich an der TM1 und liegt extrazellulär. Der cytoplasmatische Carboxyterminus ist in der Plasmamembran verankert und liegt an TM7.

Rezeptoren mit einer extrazellulären Liganden-Bindungsdomäne wie der GnRH-I Rezeptor sind durch lange N-terminale Aminosäuresequenzen gekennzeichnet (bis zu 2800 AS). Der intrazelluläre C-terminale Anteil hingegen ist in der Regel sehr kurz und scheint für die Rezeptorfunktion nur von untergeordneter Bedeutung zu sein. Dem GnRH-I Rezeptor fehlt dieser Teil komplett (Stojilkovic et al. 1994, Sealfon et al. 1997). 


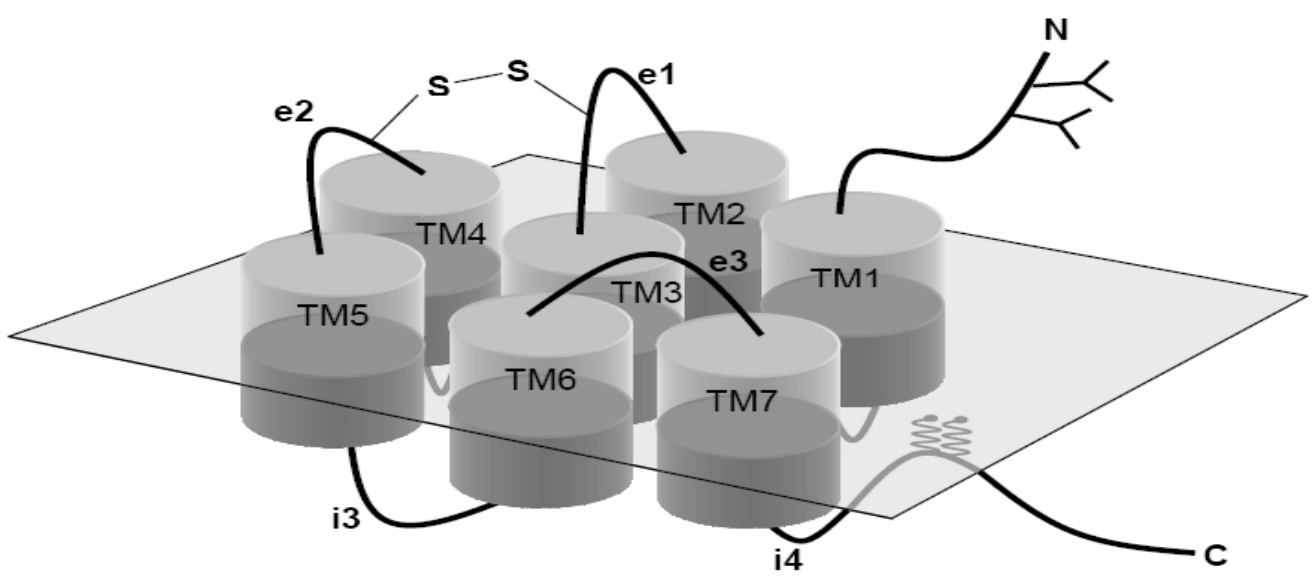

Abb. 1.3: Schematische Darstellung der Anordnung der sieben Transmembrandomänen G-Protein gekoppelter Rezeptoren. TM1-7: transmembranäre Helices, e1-3: extrazellulär verlaufende Peptidschleifen, i1-3: intrazellulär verlaufende Peptidschleifen.

Im Anschluss an die Bindung des GnRH-I Moleküls an seinen Rezeptor, wird der gesamte Ligand-Rezeptor-Komplex durch eine rezeptorvermittelte Endozytose in die Zelle aufgenommen. Diese Internalisierung ist jedoch nicht essentielle Vorraussetzung für die Sekretion der Gonadotropine, ebenso erfolgt die Desensibilisierung der Zelle für GnRH unabhängig von der Internalisierung des Rezeptor-Komplexes (Hopkins und Gregory 1977, Noar et al. 1981).

\subsubsection{Signaltransduktionsweg des GnRH-I Rezeptors in der Hypophyse}

Die Bindung von GnRH-I an seinen Rezeptor resultiert in einer Konformationsänderung der Rezeptoranteile. Dies ermöglicht eine Interaktion mir den assoziierten G-Proteinen, wobei es zu einem Austausch eines Guaninnukleotids innerhalb der $\alpha$-Untereinheit des jeweiligen G-Proteins kommt. Andere Effektorsysteme werden aktiviert, um die Bildung von ,second messenger ${ }^{\circledR}$ zu ermöglichen (Conn 1994, Stojilkovic et al. 1994).

In der Hypophyse koppelt der GnRH-I Rezeptor an das G-Protein $\alpha \mathrm{q}$ und aktiviert kalziumabhängig ein Netztwerk von Signalmechanismen mit Phospholipase C (PLC) als Schlüsselfaktor (Naor et al. 2000). Nach der primären Aktivierung der PLC 
hydrolysiert diese das membrangebundene Inositol Phospholipid Phosphatidylinositol 4,5-Bisphosphat (PIP2). Als Produkte der Hydrolyse entstehen die 'second messenger Diazylglycerol (DAG) und Inositol 1,4,5-Triphosphat (IP3). Das IP3 diffundiert an die Oberfläche des Endoplasmatischen Retikulums (ER) und bindet dort an IP3-spezifische Rezeptoren. Hierdurch wird die Freisetzung von intrazellulär gespeicherten $\mathrm{Ca}^{2+}$-Ionen hervorgerufen (Keizer et al. 1995, Berridge 1993), welche hauptsächlich an der frühen Zellantwort beteiligt sind. Das membranassoziierte DAG aktiviert auf den GnRH-I Stimulus hin, ebenfalls kalziumabhängig, die Proteinkinase C (PKC). Die PKC leitet ihrerseits verschiedene Phosphorylierungsschritte zytoplasmatischer und nukleärer Proteine ein und aktiviert eine Reihe von Transkriptionsfaktoren. Hierdurch wird die Induktion oder Repression spezifischer mRNA induziert. Die Regulierung der Zellantwort durch die Steuerung der Genexpression auf Transkriptionsebene ist somit erreicht. Durch eine Veränderung der Rezeptordichte an der Plasmamembran der gonadotropen Zellen wird die Synthese, sowie die Ausschüttung der Gonadotropine gesteuert (Conn et al. 1994).

\subsubsection{Das GnRH-System in gynäkologischen Tumoren}

In den letzten Jahren konnten überzeugende Beweise dafür erbracht werden, dass das GnRH-I neben seinen physiologischen Bindungsstellen in der Adenohypophye ausserdem eine Reihe von extrahypophysären, menschlichen Organen direkt beeinflusst (Hsueh et al. 1981). So konnte gezeitgt werden, dass ein autokrines/parakrines GnRH-I System in der Plazenta (Merz et al. 1991, Bramley et al. 1992, Lin et al. 199), in Granulosazellen (Peng et al. 1994, Minaretzis et al. 1995), im Myometrium (Chegini et al. 1996) und in lymphatischen Zellen (Standaert et al. 1922, Chen et al. 1999) existiert. Eine Expression des GnRH-I und seines Rezeptors konnte ebenfalls in einer Vielzahl von malignen Tumoren nachgewiesen werden.

In $80 \%$ der untersuchten Endometrium- und Ovarialkarzinome, sowie in über 50\% aller Mammakarzinome konnte das GnRH-I Rezeptorsystem in den vergangenen Jahren detektiert werden (Irmer et al. 1994, Irmer et al. 1995, Emons et al. 1997, Emons et al. 2000, Völker et al. 2002). Zusätzlich fand man heraus, dass GnRH-I-positive Endometrium- und Ovarialkarzinomzellinien durch die Behandlung von GnRH-I 
Agonisten als auch durch Antagonisten in ihrer Proliferation zeit-und dosisabhängig gehemmt werden können. Bereits bei einer Konzentration von $1 \mathrm{nM}$ des GnRH-I Agonisten Triptorelin konnte eine signifikante Reduktion der Zellzahl der Tumorzellinien beobachtet werden (Emons et al. 1993b, Emons et al. 1993c). Vergleichbare antiproliferative Effekte wurden mit dem GnRH-I Antagonisten Cetrorelix erzielt. Dass die Proliferation von Ovarial- und Endometriumkarzinomen durch GnRH-I Analoga direkt beeinflusst wird, wird dadurch gestützt, dass in Biopsien dieser beiden Tumorentitäten zu einem hohen Prozentsatz (75-80\%) spezifische Bindungsstellen für GnRH-I und dessen Analoga gefunden werden konnten. Ausserdem wurde der hypophysäre GnRH-I Rezeptor in 80\% dieser Biopsien detektiert (Emons et al. 1989, Imai et al. 1994, Irmer et al. 1995, Srkalovic et al. 1998).

Kakar et al. zeigten, dass die DNA-Sequenz des Hypophysen-GnRH-I Rezeptors mit der der Tumoren der reproduktiven Geweben übereinstimmt (Kakar et al. 1994). Wegen dieser Sequenzübereinstimmung wurde spekuliert, dass der Signaltransduktionsweg in den Tumoren mit dem der hypophysären gonadotopen Zellen übereinstimmt. Emons et al. konnten allerdings nachweisen, dass der klassische hypophysäre GnRH-I Rezeptor Signaltransduktionsweg nicht in die Weiterleitung der antiproliferativen Effekte von GnRH-I Analoga involviert ist (Emons et al. 1996). Vielmehr interagieren die GnRH-I Analoga mit dem mitogenen Signaltranduktionsweg von Wachstumsfaktorrezeptoren und den entsprechenden Onkogenprodukten, die mit einer Tyrosin-Kinase-Aktivität assoziiert sind (Emons et al. 1997). Zusätzlich wird die Expression der Rezeptoren (EGF-R, IGF-1-R) selbst reduziert (Yano et al. 1994, Shirahige et al. 1994, Moretti et al. 1996).

In gynäkologischen Tumorzellen sind die Mechanismen um Phosoholipase C (PLC) und Proteinkinase $\mathrm{C}$ (PKC) zwar pharmakologisch induzierbar, werden aber nicht durch GnRH-I und seine Analoga aktiviert. In diesen malignen Zellen aktiviert GnRH-I über das G-Protein ai eine Phosphotyrosin-Phosphatase (PTP), dadurch wird die TyrosinAutophosphorylierung von Wachstumsfaktorrezeptoren und damit die mitogene Signaltransduktion gehemmt (Emons et al. 1997, Gründker et al. 2000a, Gründker et al. 2001a) (Abb. 1.4). In Endometrium- und Ovarialkarzinomzellinien wird die ,Epidermal Growth Factor ${ }^{e}$ (EGF) -induzierte Aktivierung der mitogen-aktivierten Proteinkinase (MAPK), ein Enzym dass sich weit unten in der Wachstumsfaktorsignalkaskade 
befindet, mit Hilfe des GnRH-I Agonisten Triptorelin eindeutig herunterreguliert (Hunter 1995). Ebenso konnte nachgewiesen werden, dass die Expression des ,Immediate Early Response ${ }^{e}$ Gens $c$-fos durch die Behandlung der Tumorzellen mit dem selben Agonisten, zu einem noch späteren Zeitpunkt in der Kaskade reduziert werden kann (Grünker et al. 2000a). GnRH-I aktiviert ausserdem Nukleus Faktor kappa $\mathrm{B}(\mathrm{NF \kappa B})$ und schützt die Tumorzellen vor Zytostatika-induzierter Apoptose (Gründker et al. 2000b). Gleichzeitig wird der Aktivator-Protein-1 (AP-1) Signalweg aktiviert (Gründker et al. 2001b, Günthert et al. 2002) und der Zellzyklus elongiert (Abb. 1.4).

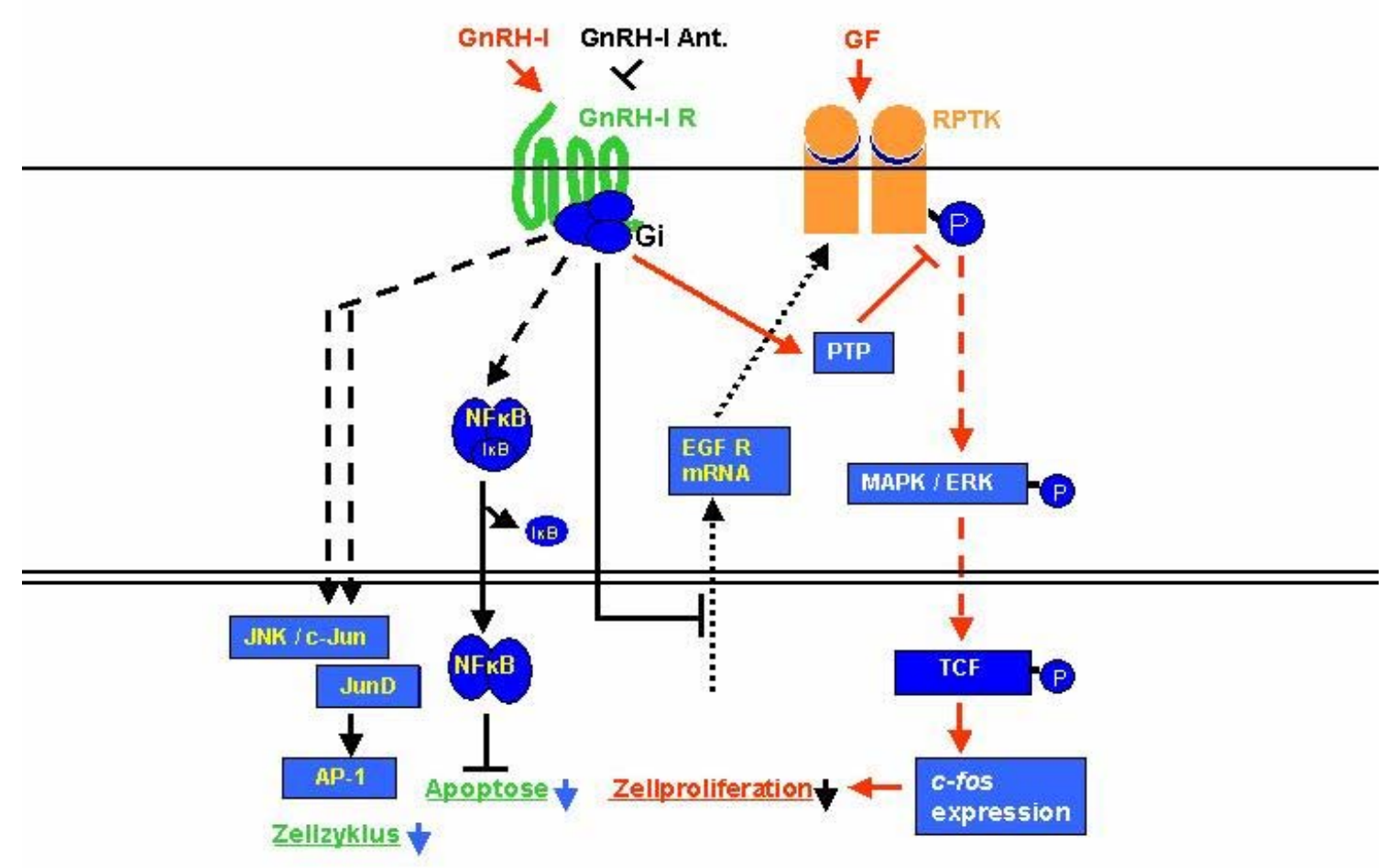

Abb. 1.4: Graphische Darstellung der GnRH-I Rezeptor Signaltransduktionskaskade in gynäkologischen Tumorzellen. GnRH aktiviert eine PTP und inhibiert die mitogene Signaltransduktion von Wachstumsfaktorrezeptoren. Eine Reduktion der Zellproliferation ist die Folge (rot gekennzeichnet).

GnRH-I (R): Gonadotropin-Releasing Hormone (Rezeptor), GF: growth factor, RPTK: Rezeptor(phospho)-Tyrosin-Kinase (EGF-Rezeptor), NFkB: Nukleus Faktor kappa B, JNK: Janus Kinase, c-Jun: c-Jun N-terminal kinase, AP-1: AktivatorProtein-1, PTP:Phosphotyrosin-Phosphatase, MAPK: mitogen-activated protein kinase, ERK: extracellulare-regulated kinase, c-fos: immediate early response gene, EGF R: epidermal growth factor receptor, TCF: transcription factor, P: Phophat (nach Gründker et al. 2002) 


\subsection{Das GnRH-II}

Zusätzlich zum hypothalamischen GnRH wurden auch andere GnRH-Formen gefunden. Insgesamt sind vier GnRH-Formen in Vertebraten bekannt, die sich durch die Aminosäuresequenz, der Lokalisation und dem embryonalen Ursprung unterscheiden (Millar 2002, Dubois et al. 2002). Nur zwei Formen davon kommen im Primaten vor, das GnRH-I und das GnRH-II (chicken GnRH-II). Das GnRH-II ist ebenfalls ein Decapeptid und zu 70\% mit GnRH-I homolog (Abb. 1.5) (White et al. 1998, Chen et al. 1998, Urbanski et al. 1999, Chen et al. 2001). Wegen der hohen Homologie ist anzunehmen, dass es durch Genduplikation vom GnRH-I entstanden ist. Da die Struktur des GnRH-II vom Fisch bis zum Säugetier hochkonserviert geblieben ist und es in unterschiedlichen Gewebearten nachgewiesen werden konnte, geht man davon aus, dass ihm eine wichtige physiologische Funktion zukommt (White et al. 1998, Urbanski et al. 1999).

GnRH-I:

pGlu-His-Trp-Ser-Tyr-Gly-Leu-Arg-Pro-Gly-NH2

GnRH-II:

pGlu-His-Trp-Ser-His-Gly-Trp-Tyr-Pro-Gly-NH2

Abb. 1.5: Aminosäuresequenzen der Gonadotropin-Releasing Hormone Typ I und Typ II (GnRH-I, GnRH-II). Die Aminosäuresubstitutionen in der GnRH-II Sequenz sind,fett” hervorgehoben.

\subsubsection{Der GnRH-II Rezeptor}

Das GnRH-II Rezeptorgen ist auf Chromosom eins lokalisiert und besteht ebenfalls aus drei Exons und zwei Introns. Das Protein besteht aus 379 Aminosäuren. Der GnRH-II Rezeptor besitzt im Gegensatz zum GnRH-I Rezeptor einen C-terminalen cytoplasmatischen Schwanz und wird somit nach der Ligandenbindung schneller internalisiert (Tensen et al. 1997, Blomentrohr et al. 1999) (Abb. 1.6).

Die DNA- sowie die Proteinsequenz konnten bisher nur bis zum Primaten charakterisiert werden (Neill et al. 2001, Millar et al. 2001). Die Existenz des GnRH-II Rezeptors wird beim Menschen vermutet, allerdings erschwert ein Stopcodon im zweiten Exon, sowie eine ,Frameshift'-Mutation die Identifikation der Sequenz, so dass 
noch kein vollständiges humanes Transkript nachgewiesen werden konnte (Millar et al. 1999, Neill et al. 2001, Millar 2003).

In den untersuchten Endometrium- und Ovarialkarzinomzellen konnte mittels Reverse Transkriptase (RT)-PCR die GnRH-II Rezeptor-mRNA Expression ermittelt werden. Ausserdem fand man heraus, dass GnRH-II stark antiproliferativ auf die Tumorzellen wirkt. Durch Die Behandlung der Tumorzellen mit GnRH-II und dessen Agonisten, konnten größere antiproliferative Effekte erzielt werden, als durch GnRH-I und dessen Agonisten (Gründker et al 2002).

In früheren Experimenten konnte bereits gezeigt werden, dass GnRH-I Antagonisten wie z.B. Cetrorelix, die in gonadotropen Hypophysenzellen ihren Rezeptor blockieren, also wie echte Antagonisten reagieren, in Endometrium- und Ovarialkarzinomzellen wie Agonisten wirken und antiproliferative Effekte erzeugen (Emons et al. 1997). Neben der hochaffinen Bindungsstelle für GnRH-I in Ovarial- und Endometriumkarzinomen existiert eine weitere niederaffine Bindungsstelle (Pahwa et al. 1991, Emons et al. 1989, 1993a, 1993b). Bei dieser könnte es sich möglicherweise um den GnRH-II Rezeptor handeln, mit dem das GnRH-I niederaffin kreuzreagiert. GnRH-I Rezeptor Knock-Down Versuche, ebenfalls mit gynäkologischen Tumorzellen, zeigen nach der Stimulation mit 1nM des GnRH-II Analogs [D-Lys6]GnRH-II wachstumshemmende Effekte. Es konnten allerdings keine Effekte mehr mit dem GnRH-I Agonisten Triptorelin nach dem GnRH-I Rezeptor Knock-Down beobachtet werden (Gründker et al. 2004). Durch diese Daten liegt die Vermutung nahe, dass neben dem GnRH-I Rezeptorsystem ein GnRH-II Rezeptorsystem in gynäkologischen Tumoren existiert. 


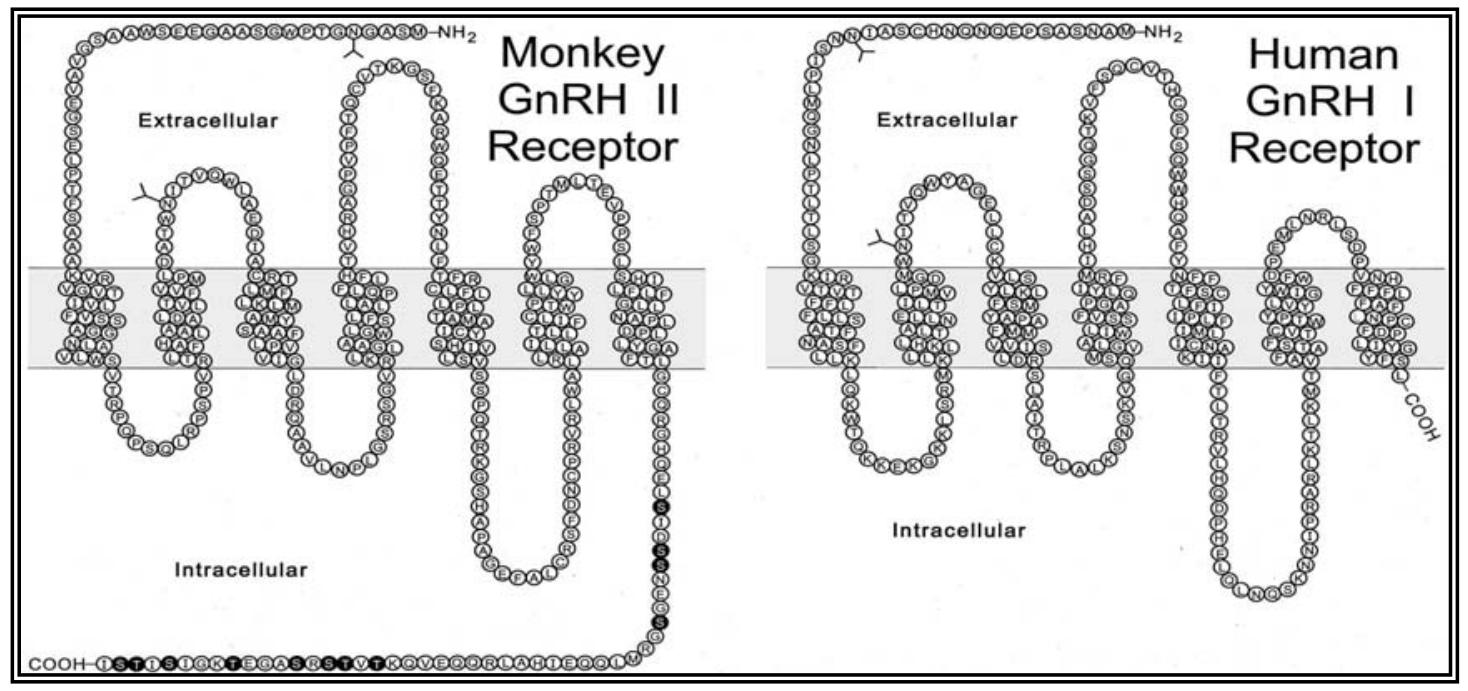

Abb. 1.6: Struktur des GnRH-II Rezeptors vom Affen (links) und des humanen GnRH-I Rezeptors (rechts). Die bekannten Glykosilierungsorte sind mit (Y) markiert. (nach Neill et al .2002)

\subsection{Fragestellung}

Der Mechanismus des GnRH-I Systems in Ovarial- und Endometriumkarzinomen ist weitestgehend aufgeklärt worden, einschließlich der Signalkaskade über die die Zellproliferation in gynäkologischen Karzinomen gehemmt wird. Im Gegensatz dazu ist der humane GnRH-II Rezeptor bisher weitestgehend unbekannt. Deshalb galt es in dieser Arbeit zu klären, welche Rolle das GnRH-II System in gynäkologischen Karzinomen einnimmt bzw. wie das System in der Zelle reguliert wird.

In Vorversuchen konnte bereits die hohe antiproliferative Wirkungsweise des GnRH-II sowie dessen Agonisten auf gynäkologische Tumorzellen, insbesondere bei Ovarialund Endometriumkarzinomzellen, nachgewiesen werden (Gründker et al 2002). In den nachfolgend aufgeführten Untersuchungen sollte erarbeitet werden, ob das putative GnRH-II System in Ovarial- und Endometriumkarzinomzellen dem des GnRH-I Systems ähnelt und ob die Reduktion der Zellzahl ebenfalls über die Wachstumsfaktorrezeptorsignalkaskade reguliert wird. GnRH-I und seine Analoga aktivieren eine PTP und inhibieren dadurch die Tyrosin-Autophosphorylierung des EGF-Rezeptors und somit dessen mitogene Signaltransduktion. Es sollte untersucht werden, ob auch GnRH-II über diese Mechanismen antiproliferativ wirkt. 
Da Knock-Down Versuche der GnRH-I Rezeptor-mRNA gezeigt haben, dass das GnRH-II nicht primär über den GnRH-I Rezeptor wirkt, galt es unter anderem zu klären, ob es sich bei diesem putativen Rezeptor tatsächlich um den humanen GnRH-II Rezeptor handelt.

Wie eingangs beschrieben wurde, stellen gerade die Ovarialkarzinome, ebenso wie die Endometriumkarzinome für die Frau ein hohes Krebsrisiko dar. GnRH-I und seine Analoga werden schon seit Jahren in die Hormontherapie eingesetzt. Mit den Erkenntnissen und der Demonstration des autokrinen, auf GnRH-I basierenden Regulationssystems in diesen Tumorarten, ist bereits ein Beitrag für die Entwicklung neuer therapeutischer Konzepte zur Behandlung dieser Malignome geleistet worden. Aufgrund seiner starken antiproliferativen Effekte ist das GnRH-II Rezeptorsystem möglicherweise besser geeignet für neue Tumortherapien, als das GnRH-I Rezeptorsystem. 


\section{Materialien}

\subsection{Geräte}

Autoklav, 2540 EL

Analysenwaage

Biofuge pico, Labofuge 400R

Brutschrank, Model 3121 S/N 28439532

Elektrophoresekammer, DNA

Elektrophoresekammer, Protein

Gene Amp PCR-System 2400 und 9700

Multi-Detection Microplate Reader, KC 4 Synergy

Magnetrührer MR3000

Mikrotom

Nitrocellulosemembran, ECL ${ }^{\mathrm{TM}}$ Hybond

Phasenkontrastmikroskop, axiovert 25

pH-Meter

Polaroid Land-Kamera, MP 4

Polaroid-Film Typ 665 (50 ASA)

Power Supply, EC 250-90, EC Apparatus

Corporation Standard Power Pack p25

Spektralphotometer (Biophotometer)

Sterilwerkbank, LaminAir ${ }^{\circledR}$ HA 2448 GS

Thermomixer compact

Ultrazentrifuge $\left(\mathrm{UZ}^{6}\right)$
Tuttnauer

Sartorius

Heraeus Holding

Forma Scientific

OWL Separation Systems

Biorad

Amersham Bioscience

BIO-TEK

Heidolph

Leika

Amersham Bioscience

Zeiss

Hanna

Polaroid

Polaroid

Biometra

Eppendorf

Heraeus Holding

Eppendorf

Sorvall 
UV-Transilluminator

Vortex Genie 2 ${ }^{\mathrm{TM}}$

Waage, Kern 440-47

Wasserbad
Biometra

Bender \& Hobein

Kern

Memmert

\subsection{Verbrauchsmaterialien}

Die verwendeten Verbrauchsmaterialien wurden von den Firmen Biozym, Brand, Eppendorf, Greiner bio-one, Merck, Nunc und Sarstedt bezogen, sofern es in der Arbeit nicht anders angegeben wurde.

\subsection{Chemikalien}

Soweit nicht anders angegeben, wurden die in dieser Arbeit verwendeten Chemikalien von den folgenden Firmen bezogen: Invitrogen, Merck, Roth, Serva und Sigma. Alle Chemikalien entsprachen den höchsten Reinheitsgrad, soweit nicht anders vermerkt.

\subsection{Lösungen und Puffer}

Alle Lösungen und Puffer wurden mit autoklavierten Aqua bidest. hergestellt und der $\mathrm{pH}-$ Wert, wenn notwendig, eingestellt.

Anodenpuffer:

0.03M Tris/HCL, 20\% Methanol, $\mathrm{pH} 10.4$

Assaypuffer:

$10 \mathrm{mM}$ Tris/HCL, $0.2 \% \mathrm{NaN}_{3}, 0.2 \%$ BSA, $1 \mathrm{mM}$ DTT, pH 7.6

Binding-Puffer:

$25 \mathrm{mM}$ Tris/HCL, $5 \mathrm{mM} \mathrm{MgCl}_{2}, 100 \mathrm{mM} \mathrm{NaCl}, 1 \%$ BSA, 0.01\% Bacitracin, $\mathrm{pH} 7.4$

Blocking-Lösung:

5\% Magermilchpulver, 100\% TBST

Citratpuffer:

0.01M Citratacetat, 0.01M Zitronensäure, pH 6.0

Elektrophoresepuffer (10x): 25mM Tris/HCL, 192mM Glycin, 0.1\% SDS

Ethidiumbromidbad: $\quad 0.007 \%$ Ethidiumbromid, $100 \%$ Aqua bidest. 
Extraktionspuffer:

Kathodenpuffer:

Konz. Anodenpuffer:

Laemmli-Probenpuffer:

Lysispuffer:

(Membranisolierung)

Lysispuffer:

(PTP-Assay)

Transferpuffer:

Trenngel (10\%):

TBE (10x):

TBST:

Trypsin/EDTA:

PBS:

Phosphatstandard:

Probenpuffer :

Puffer B :

Sammelgel (5\%):

Waschpuffer:
$15 \mathrm{mM} \mathrm{KH}_{2} \mathrm{PO}_{4}, 10 \mathrm{mM} \mathrm{NaN}, 1,5 \mathrm{mM}$ EDTA, $11.5 \%$

Glycerin, $\mathrm{pH} 7.5$

0.04M Amino-u-Capronsäure, 0.025M Tris/HCL, 20\% Methanol, pH 9.4

0.2M Tris/HCL, 20\% Methanol, $\mathrm{pH} 10.4$

519mM DTT, 69mM SDS, 0.1\% Triton X-100, 62.5mM Tris/HCl, 0.05\% Bromphenolblau, $\mathrm{pH} 6.8$

1mM EGTA, 1mM DTT,10mM Tris/HCL, pH 7.4

$60 \mathrm{mM}$ Natriumacetat, $5 \mathrm{mM}$ B-Mercaptoethanol 1\% Triton X-100, pH 5.2

0.025M Tris/HCL, 0.192 Glycin, 20\% Methanol, $\mathrm{pH} 8.3$ $10 \%$ Pro Sieve ${ }^{\circledR}$ 50, 15M Tris/HCL, $10 \%$ SDS, $0.5 \%$ TEMED, 10\% APS, pH 8.8

0.1M Tris/HCL, 5.5\% Borsäure, 0.5M EDTA, $\mathrm{pH} 8.0$

$0.15 \mathrm{M} \mathrm{NaCl}, 0.01 \mathrm{M}$ Tris/HCL, $0.001 \mathrm{M} \mathrm{NaN}, 0.05 \%$ Tween ${ }^{\circledR} 20$, pH 7.4

0.05\% Trypsin, 5mM EDTA, 100\% PBS/BSA

$137 \mathrm{mM} \mathrm{NaCl}, 2.7 \mathrm{mM} \mathrm{KCl}, 8.0 \mathrm{mM} \mathrm{Na}_{2} \mathrm{HPO}_{4}, 1.5 \mathrm{mM}$ $\mathrm{KH}_{2} \mathrm{HPO}_{4}, \mathrm{pH} 7.4$

$1 \mathrm{mM} \mathrm{KH}_{2} \mathrm{PO}_{4}$

0.5M Tris/HCL, 5\% Glycerin, 10\% SDS, $1 \mathrm{mM}$ DTT 0.05\% Bromphenolblau, pH 6.8

$10 \mathrm{mM}$ Tris/HCL, $1 \mathrm{mM}$ EDTA, $0.02 \% \mathrm{NaN}_{3}$, pH 7.5

5\% Pro Sieve ${ }^{\circledR} \quad 50,15 \mathrm{M}$ Tris/HCL, 10\% $\quad$ SDS, 1\% TEMED, $10 \%$ APS, $\mathrm{pH} 8.8$

25mM Tris/HCL, 5mM $\mathrm{MgCl}_{2}, 100 \mathrm{mM} \mathrm{NaCl}, \mathrm{pH} 7.4$ 


\subsection{Nährmedien}

Tab. 2.1: Medien zur Kultivierung der Zellinien

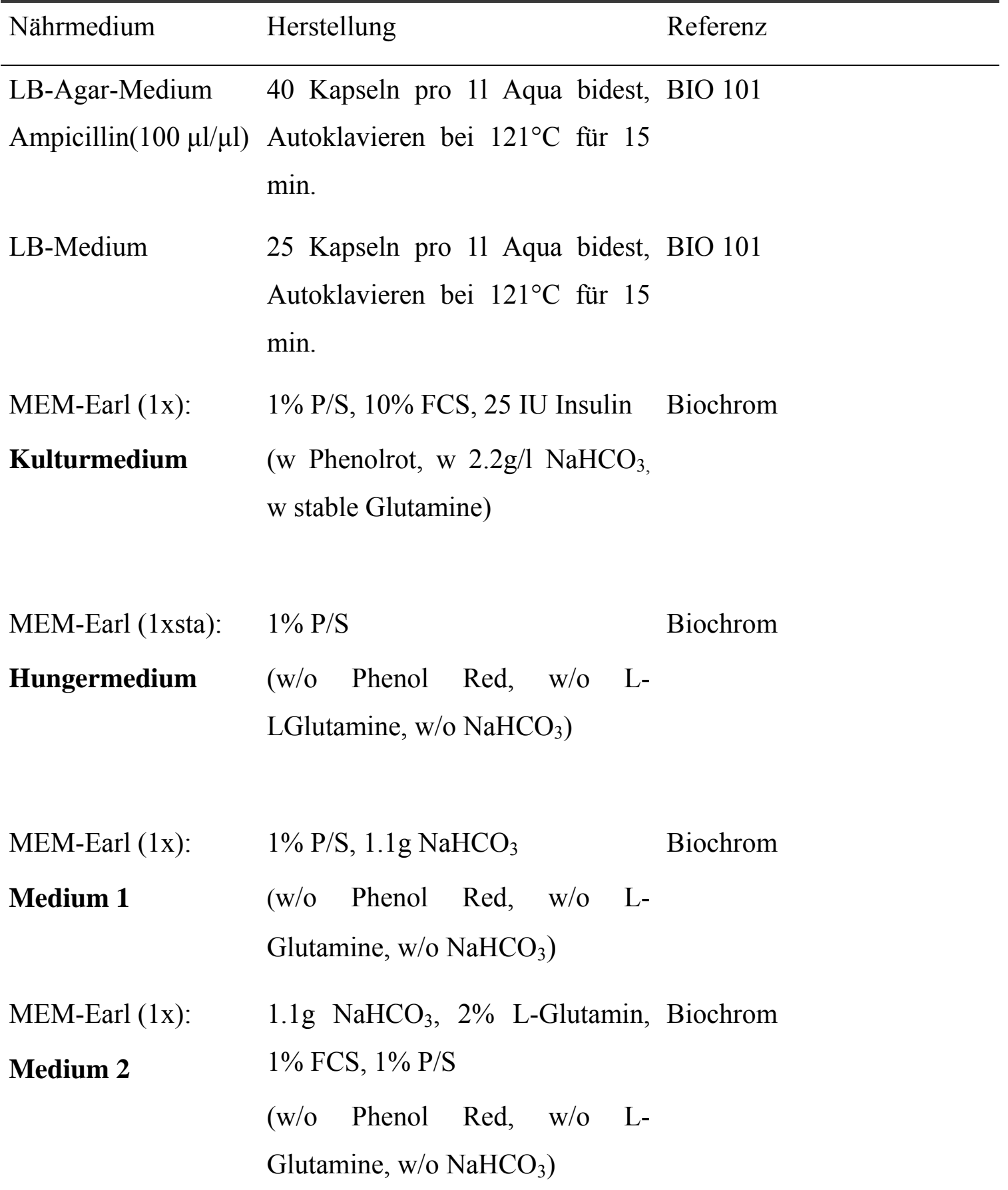




\subsection{Kits und Assays}

Tab.2.2: Verwendete Kits und Assays

\begin{tabular}{|c|c|}
\hline Kits & Referenz \\
\hline ECL ${ }^{\text {TM }}$ Western Blotting Detection & Amersham Bioscience \\
\hline \multicolumn{2}{|l|}{ Reagents and Analysis System } \\
\hline EndoFree ${ }^{\circledR}$ Plasmid Maxi Kit & QIAGEN \\
\hline Enzymatic Protein Deglycosylation Kit & Sigma \\
\hline Histostain ${ }^{\circledR}$ Bulk Kit & Zymed \\
\hline Tyrosin Phosphatase Assay System & Promega \\
\hline RNAeasy ${ }^{\circledR}$ Mini Kit & QIAGEN \\
\hline QIAquick ${ }^{\circledR}$ Gel Extraction Kit & QIAGEN \\
\hline
\end{tabular}

\subsection{Antikörper}

Tab. 2.3: Primärantikörper für Immunblot

Antikörper

Referenz

Anti-active MAPK, polyclonal, rabbit Promega

Anti-c-Fos, polyclonal, rabbit Abcam

GnRH-II Rezeptor Antiserum Eicke et al. 2005

\subsection{Enzyme}

Tab. 2.4: Eingesetzte Enzyme

\begin{tabular}{lll}
\hline \hline Enzym & Methode & Referenz \\
\hline DNase I, RNase-free & cDNA-Synthese & Roche \\
Recombinant RNasin, & cDNA-Synthese & Promega \\
Ribonuklease Inhibitor & &
\end{tabular}


SuperFect ${ }^{\circledR}$

Transfektion

QIAGEN

Transfection Reagent

SuperScript ${ }^{\mathrm{TM}}$

cDNA-Synthese

Invitrogen

RNase H Reverse

Transkriptase

Taq DNA Polymerase

T4 DNA-Ligase

Ligation

Roche

GIBCO

\subsection{Restriktionsendonukleasen}

Tab. 2.5: Verwendete Typ II Restriktionsendonukleasen

\begin{tabular}{lll}
\hline \hline Restriktionsenzym & Erkennungssequenz (5`-3`) & Referenz \\
\hline BamH I & G $\downarrow$ GATCC & Amersham Pharmacia \\
Nhe & G $\downarrow$ CTAGC & Amersham Pharmacia \\
Not I & GC $\downarrow$ GGCCGC & Amersham Pharmacia \\
Sal I & G $\downarrow$ TCGAC & Amersham Pharmacia
\end{tabular}

\subsection{GnRH Analoga}

Tab. 2.7: Verwendete GnRH-I und II Analoga

\begin{tabular}{lll}
\hline \hline GnRH Analoga & Struktur & Referenz \\
\hline $\begin{array}{l}\text { Cetrorelix } \\
\text { (GnRH-I Antagonist) }\end{array}$ & SB-75; [Ac-DNal(2)1, D- & Zentaris \\
& $\begin{array}{l}\text { Phe(4Cl)2,D-Pal(3)3, D-Cit6, } \\
\text { D-Ala10]GnRH-I }\end{array}$ & \\
& pGlu-His-Trp-Ser-Tyr-D-Trp- & Ferring Pharmaceutics \\
Triptorelin & Leu-Arg-Pro-Gly-NH2 & \\
$\begin{array}{l}\text { ([D-Trp6]GnRH-I, } \\
\text { GnRH-I Agonist) } \\
\text { [D-Lys6]GnRH-II } \\
\text { (GnRH-II Agonist) }\end{array}$ & $\begin{array}{l}\text { pGlu-His-Trp-Ser-His-D-Lys- } \\
\text { Trp-Tyr-Pro-Gly-NH2 }\end{array}$ & \\
& &
\end{tabular}




\subsection{Oligonukleotide}

Tab. 2.6: Verwendete Oligonukleotide

\begin{tabular}{|c|c|c|}
\hline Oligonukleotid & Sequenz $\left(5^{\prime}-3^{\prime}\right)$ & Referenz \\
\hline c-fos-for & $\begin{array}{l}\text { GAG ATT GCC AAC CTG } \\
\text { CTG AA }\end{array}$ & MWG Biotech \\
\hline c-fos-rev & $\begin{array}{l}\text { AGA CGA AGG AAG ACG } \\
\text { TGT AA }\end{array}$ & MWG Biotech \\
\hline GABDH-for & $\begin{array}{l}\text { CAT CAC CAT CTT CCA } \\
\text { GGA GCG AGA }\end{array}$ & MWG Biotech \\
\hline GABDH-rev & $\begin{array}{l}\text { GTC TTC TGG GTG GCA } \\
\text { GTG ATG G }\end{array}$ & MWG Biotech \\
\hline GnRH-I as-Plasmid & $\begin{array}{l}\text { CTA GAA CCA TGG ACT } \\
\text { GTC CGA CTT TGC TGT } \\
\text { TGC TTT TCA AAG C }\end{array}$ & MWG Biotech \\
\hline GnRH-I s-Plasmid & $\begin{array}{l}\text { TCG AGC TTT GAA AAG } \\
\text { CAA CAG CAA AGT CGG } \\
\text { ACA GTC CAT GGT T }\end{array}$ & MWG Biotech \\
\hline GnRH-IIRez-for & $\begin{array}{l}\text { GCC CTG CTT ATC TTG } \\
\text { CTG AC }\end{array}$ & MWG Biotech \\
\hline GnRH-IIRez-rev & $\begin{array}{l}\text { CTC CTG CCC TTC TTG } \\
\text { ATG TC }\end{array}$ & MWG Biotech \\
\hline
\end{tabular}

\subsection{Bakterienstamm}

Tab. 2.8: Verwendeter Bakterienstamm

\begin{tabular}{|c|c|c|}
\hline Stamm & Genotyp & Referenz \\
\hline E. coli & $\mathrm{F}^{\prime} m c r \mathrm{~A} \Delta(m r r-h s d \mathrm{RMS}-m c r \mathrm{BC}) \Phi 80$ lacZ $\Delta \mathrm{M} 15$ & Invitrogen \\
\hline TOP 10 & $\begin{array}{l}\text { DlacX74recA1araD139 (ara-leu)7697 galU } \\
\text { galK rpsL(StrR)endA1nupG, chem. kompetent }\end{array}$ & \\
\hline
\end{tabular}




\subsection{Vektor}

Tab. 2.9: Eingesetzter Vektor

\begin{tabular}{lll}
\hline \hline Vektor & Beschreibung & Referenz \\
\hline pIRES Vector $(6.1 \mathrm{~kb})$ & Säugetier-Expressionsvektor, & BD Bioscience \\
& enthält internal ribosome entry & \\
& site (IRES) & \\
& &
\end{tabular}
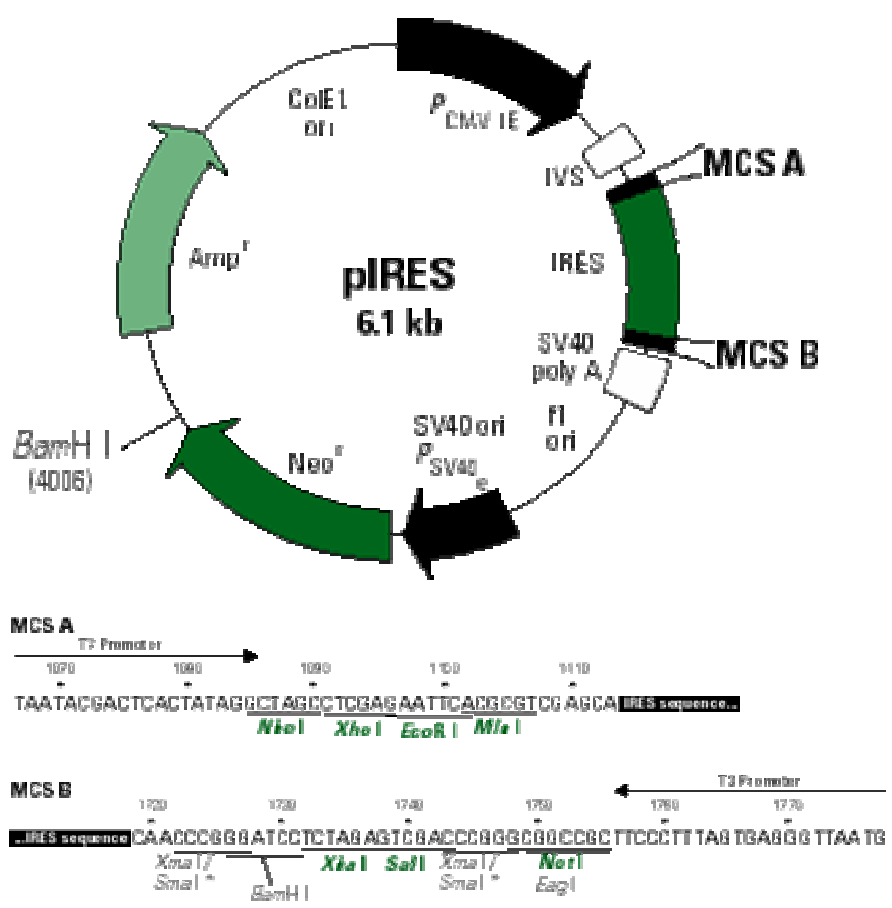

Abb. 2.1: Vektorkarte und Multiple Cloning Site (MCS) von pIRES (6.2 kb): Säugetier-Expressionsvektor. MCS A und B: Es können zwei Gene in den Vektor kloniert und exprimiert werden.Diese sind an beiden Seiten der internal ribosome entry site (IRES) lokalisiert. Die Selektion der rekombinanten Bakterien erfolgt über eine Ampicillin- und Neomycin-Resistenz.

\subsection{Gewebe und Gewebeschnitte}

Die Ovarien des Weißbüschelaffens (Callithrix jacchus) wurden gesunden Tieren, während einer Ovarektomie, entnommen und gesammelt. Durch die freundliche Unterstützung von Frau Dr. Tamara Becker (Deutsches Primatenzentrum, Göttingen) wurde uns dies ermöglicht. 
Die in Paraffin eingebetteten Gewebeschnitte von humaner Plazenta (25ste Woche), sowie von malignen Tumoren reproduktiver humaner Organe (Endometriumkarzinom, Ovarialkarzinom und Prostatakarzinom) wurden von SuperBioChipsLaboratories (Yongdu-Dong, Korea) bezogen.

\subsection{Zellmaterial}

Tab. 2.10: Verwendete Endometrium- und Ovarialkarzinomzellinien

\begin{tabular}{|c|c|c|c|}
\hline Zellinie & Abstammung & Histologie & Herkunft \\
\hline \multicolumn{4}{|c|}{ Endometriumkarzinomzellinien } \\
\hline Ishikawa & Primärtumor & $\begin{array}{l}\text { Adenokarzinom, } \\
\text { gut differenziert }\end{array}$ & $\begin{array}{l}\text { Nishida et al. (1985) } \\
\text { (E.Gurpide, New York) }\end{array}$ \\
\hline HEC-1A & Primärtumor & $\begin{array}{l}\text { Papilläres } \\
\text { Adenokarzinom, } \\
\text { schwach differenziert }\end{array}$ & $\begin{array}{l}\text { Kuramoto et al. (1972a) } \\
\text { (T. Bauknecht, Freiburg) }\end{array}$ \\
\hline \multicolumn{4}{|c|}{ Ovarialkarzinomzellinien } \\
\hline EFO-21 & Aszites & $\begin{array}{l}\text { Seröses Adenokarzinom, } \\
\text { wenig differenziert }\end{array}$ & $\begin{array}{l}\text { Simon et al. (1983) } \\
\text { (F. Hölzel, Hamburg) }\end{array}$ \\
\hline EFO-27 & Netzmetastase & $\begin{array}{l}\text { Seröses Adenokarzinom, } \\
\text { papill., mäßig } \\
\text { differenziert }\end{array}$ & $\begin{array}{l}\text { Simon et al. (1983) } \\
\text { (F. Hölzel, Hamburg) }\end{array}$ \\
\hline $\begin{array}{l}\text { NIH: } \\
\text { OVCAR-3 }\end{array}$ & Ascites & $\begin{array}{l}\text { Adenokarzinom, } \\
\text { schwach differenziert }\end{array}$ & $\begin{array}{l}\text { Hamilton et al. (1983) } \\
\left(\text { ATCC*) }^{*}\right.\end{array}$ \\
\hline SKOV-3 & Aszites & Adenokarzinom & $\begin{array}{l}\text { Fogh et al. (1977) } \\
\left(\text { ATCC*) }^{*}\right.\end{array}$ \\
\hline
\end{tabular}

ATCC*: American Type Culture Collection (Manassas, Virginia, USA), Zellen käuflich erworben 


\section{Methoden}

\subsection{Zellkultur}

Die verwendeten Zellinien wurden bei $37^{\circ} \mathrm{C}$ im Brutschrank (Forma Scientific) bei 5\% $\mathrm{CO}_{2}$ und 95\% Luftfeuchtigkeit in Kultur gehalten. Als Kulturmedium wurde MEM Earl (1x) mit Phenolrot (10\% FCS, 1\% P/S und Insulin 25 IU) von der Firma Biochrom verwendet, welches alle zwei bis drei Tage gewechselt wurde.

\subsubsection{Passagieren adhärenter Zellen}

Die Zellen wurden in bestimmten Zeitintervallen, die sich nach den Wachstumseigenschaften der jeweiligen Zellinie richteten, passagiert. Bei Erreichen einer adhärenten Konfluenz der Zellmonolayer von 80-90\% wurden diese mit Trypsin/EDTA-Lösung (Biochrom) 5 min im Brutschrank bei $37^{\circ} \mathrm{C}$ inkubiert. Das Ablösen der Zellen wurde dabei regelmäßig im Phasenkontrastmikroskop (Zeiss) kontrolliert.

Nach dem Ablösen wurden die Zellen auf neue Zellkulturflaschen $\left(75 \mathrm{~cm}^{2}\right)$ verteilt oder nach Bestimmung der Zellzahl mit der Neubauer-Zählkammer $\left(0,1 \mathrm{~mm} / 0,0025 \mathrm{~cm}^{2}\right.$, Optik-Labor), je nach Versuchsprotokoll auf die entsprechenden Versuchsgefäße ausgesät. Überschüssige Zellen konnten für die Langzeitkonservierung tiefgefroren werden oder wurden verworfen.

\subsubsection{Kryokonservierung}

Für die Langzeitkonservierung wurden die Zellen entweder in einer Kühleinheit bei $-80^{\circ} \mathrm{C}$ oder in flüssigen Stickstoff bei $-196^{\circ} \mathrm{C}$ tiefgefroren. Hierzu wurde der Zellrasen zunächst mit Trypsin/EDTA-Lösung abgelöst, mit dem gleichen Volumenanteil Kulturmedium versetzt und in ein steriles Zentrifugenröhrchen überführt. Nach der Zentrifugation für $10 \mathrm{~min}$ bei $1200 \mathrm{rpm}$ wurde der Überstand verworfen. Das Zellpellet 
wurde in 1,5 ml Wachstumsmedium mit 10\% DMSO resuspendiert und in ein Kryoröhrchen überführt. Danach erfolgte das langsame Einfrieren, erst bei $-20^{\circ} \mathrm{C}$ und dann bei $-80^{\circ} \mathrm{C}$. Bei Bedarf wurden die Zellen aufgetaut, in eine Zellkulturflasche $\left(75 \mathrm{~cm}^{2}\right)$ mit $10 \mathrm{ml}$ Medium überführt und im Brutschrank bei $37^{\circ} \mathrm{C}$ angezüchtet.

\subsubsection{Herstellung von Zellmembranen aus Zellkulturen}

Die Zellen wurden in großen Zellkulturflaschen $\left(150 \mathrm{~cm}^{2}\right)$ ausgesät und bei Erreichen einer 80-90\%igen Konfluenz geerntet. Die Bestimmung der Zellzahl erfolgte mittels Neubauer-Zählkammer. Das Zellpellet wird zwei bis drei mal mit $10 \mathrm{ml}$ eiskaltem PBSPuffer gewaschen und anschließend für $5 \mathrm{~min}$ bei $300 \mathrm{rpm}$ zentrifugiert. Der Überstand wurde abgesaugt und das Pellet in 2,5 ml DTT-Assaypuffer aufgeschwemmt, in einen Glas-Glas-Handpotter (Braun) überführt und für 10-15 min auf Eis homogenisiert. Danach wurde die Suspension in ein Reaktionsgefäß pipettiert und mit DTTAssaypuffer auf $5 \mathrm{ml}$ aufgefüllt. Es erfolgte eine Zentrifugation bei $600 \mathrm{rpm}$ für $15 \mathrm{~min}$ bei $4^{\circ} \mathrm{C}$. Da sich im Pellet die Zellreste befanden, wurde dieses verworfen und der Überstand in ein Zentrifugenröhrchen (Greiner bio-one) überführt und erneut mit DTTAssaypuffer aufgefüllt. Der Überstand wurde nun für $1 \mathrm{~h}$ bei $25.000 \mathrm{rpm}$ und $4^{\circ} \mathrm{C}$ in einer Ultrazentrifuge zentrifugiert. Nach der Zentrifugation wurde der Überstand verworfen und das Zellpellet 2-3mal mit eiskaltem PBS-Puffer gewaschen. Nach einem erneuten Zentrifugationsschritt für $15 \mathrm{~min}$ bei $600 \mathrm{rpm}$ wurde das Pellet entweder in flüssigem Stickstoff schockgefroren und bei $-80^{\circ} \mathrm{C}$ aufbewahrt oder in Lysispuffer aufgenommen und weiterverarbeitet.

\subsection{Molekularbiologische Methoden}

\subsubsection{Isolierung der mRNA}

Um die EGF-induzierte $c$-fos mRNA Expression nachweisen zu können, wurden die Endometrium- und Ovarialkarzinomzellinien für $72 \mathrm{~h}$ in Hungermedium kultiviert. Hierzu wurde, nach Erreichen einer 70-80\% igen Konfluenz, das Kulturmedium abgesaugt und der Zellrasen mit 5 ml PBS-Puffer überspült. Anschließend wurden 
$10 \mathrm{ml}$ Hungermedium in die Kulturflasche pipettiert. Nach einer Inkubationszeit von $72 \mathrm{~h}$ erfolgte eine Stimulation der Zellen mit $100 \mathrm{nM}$ humanen rekombinanten EGF (Sigma) für $30 \mathrm{~min}$. Parallel erfolgte eine zusätzliche Inkubation für $1 \mathrm{~h}$ mit dem GnRH-II Analog [D-Lys ${ }^{6}$ ]GnRH-II $(10 \mu \mathrm{M})$.

Die RNA wurde mit Hilfe des RNeasy ${ }^{\circledR}$ Mini Kit (QIAGEN) isoliert. Das Prinzip der Isolation beruht auf der Bindung von negativ geladenen Nukleinsäuren in Gegenwart von hohen Salzkonzentrationen an Glasfaseroberflächen von Silicagel-Säulen (Vogelstein et al. 1979). Die Bindungsbedingungen für RNA sind optimiert.

Nach der Stimulation wurde das Medium abgesaugt und die Zellen mit $5 \mathrm{ml}$ PBS-Puffer gespült. Zur Lyse der Zellen erfolgte die Zugabe des RLT-Gebrauchspuffers (1,0-1,5 ml je nach Gefäßvolumen). Das Lysat wurde gemäß des Protokolls nach Angaben des Herstellers behandelt. Nach der Aufreinigung wurde die gebundene RNA gewaschen und mit $30 \mu \mathrm{l}$ RNase-freiem $\mathrm{H}_{2} \mathrm{O}$ aus dem Kit von der Silicagel-Membran eluiert. Es folgte die photometrische Bestimmung der mRNA-Konzentration (3.2.2) und die anschließende Lagerung der Proben bei $-80^{\circ} \mathrm{C}$.

\subsubsection{Quantifizierung von Nukleinsäuren}

Nukleinsäuren haben im ultravioletten Licht bei einer Wellenlänge von $260 \mathrm{~nm}$ ihr Absorptionsmaximum. Dies wird durch die Absorption der aromatischen Heterozyklen, der Purin- und Pyrimidinbasen hervorgerufen. Die Breite des Maximums ist ein Indikator für die Reinheit der DNA bzw. RNA und wird durch den Quotient der Extinktionen bei $260 \mathrm{~nm}$ und $280 \mathrm{~nm}\left(\mathrm{OD}_{260 \mathrm{~nm}} / \mathrm{OD}_{280 \mathrm{~nm}}\right)$ bestimmt (Glasel 1995). Proteinverunreinigungen machen sich durch eine Amplitude in der Absorptionskurve bei $280 \mathrm{~nm}$ bemerkbar.

Die Absorption der Proben wurde in einem Gesamtvolumen von $70 \mu \mathrm{l}$ in $1 \mathrm{~cm}$ Quarzküvetten (Quarzglas Suprasil, Hellma) gegen Ampuva (steriles $\mathrm{H}_{2} \mathrm{O}$, Fresenius Kabi) im Spektralphotometer (Biophotometer, Eppendorf) bestimmt. 


\subsubsection{Reverse Transkription}

Bei der Reverse Transkriptase-Polymerase Kettenreaktion (RT-PCR) wird mit Hilfe der RNA-abhängigen DNA-Polymerase Reverse Transkriptase die Gesamt-RNA der zu untersuchenden Zellen, in copy DNA (cDNA) umgeschrieben (Veres et al. 1987).

Zum ,Priming e wurden Oligo-(dT)-Primer verwendet. Die cDNA-Synthese sowie der DNase I Verdau wurden mit dem SuperScript ${ }^{\mathrm{TM}}$ Preamplifikations Kit (Invitrogen) durchgeführt. Um ausschließen zu können, dass die isolierte Gesamt-RNA verunreinigt ist, fand vor der cDNA-Synthese eine Inkubation mit den Enzymen Rnasin (40 U/ $\mu 1$, Promega) und DNase I (10 U/ $\mu$, Roche) statt. Zu $1 \mu$ g RNA wurden jeweils $1 \mu$ der Enzyme hinzugefügt und der Ansatz mit $14 \mu \mathrm{l}$ RNase-freiem $\mathrm{H}_{2} \mathrm{O}$ aufgefüllt. Der Verdau erfolgte im Thermocycler (GeneAmp PCR System 2400, Applied Biosystems) bei $37^{\circ} \mathrm{C}$ für $30 \mathrm{~min}$, mit einer anschließenden Denaturierung bei $70^{\circ} \mathrm{C}$ für $10 \mathrm{~min}$. Danach wurden die Proben bei $4^{\circ} \mathrm{C}$ gekühlt.

Bei der cDNA Synthese wurden Oligo-(dT) ${ }_{15}$ Primer (Roche) eingesetzt, die spezifisch an die Poly(A)-Sequenz der mRNA binden. Durch die Zugabe der Reversen Transkriptase (SuperScript, Invitrogen) wurden die RNA-Moleküle in die entsprechenden DNA-Moleküle umgeschrieben.

Der Reaktionsansatz setzte sich aus folgenden Reagenzien zusammen:

$\begin{array}{lr}\text { Oligo-(dT) }{ }_{15} \text { Primer } & 8,0 \mu \mathrm{l} \\ \text { dNTPs }(10 \mathrm{mM}) & 4,0 \mu \mathrm{l} \\ \text { 5xRT-Puffer } & 8,0 \mu \mathrm{l} \\ \text { 0,1 M DTT } & 4,0 \mu \mathrm{l} \\ \text { SuperScript }(200 \mathrm{U} / \mu \mathrm{l}) & 2,0 \mu \mathrm{l}\end{array}$

Die einzelnen Reagenzien wurden in einem Master-Mix angesetzt und $26 \mu$ davon in die Probe gegeben. Anschließend erfolgte im Thermocycler eine Inkubation für $60 \mathrm{~min}$ bei $37^{\circ} \mathrm{C}$ und eine Denaturierung für $10 \mathrm{~min}$ bei $95^{\circ} \mathrm{C}$. Die cDNA Proben konnten nun bei $-20^{\circ} \mathrm{C}$ gelagert werden. 


\subsubsection{PCR-Amplifikation}

Bei der Polymerase-Ketten-Reaktion (PCR) wird anhand von Oligonukleotiden (Primer), die zu amplifizierende Region beider DNA-Stränge flankiert (Mullis et al. 1986). In sich wiederholenden Zyklen von Denaturierung der Doppelstrang-DNA, Anlagerung der Primer (Annealing) und Verlängerung (Elongation) durch das hitzestabile Enzym Taq-Polymerase (Saiki et al. 1988), wird die Zielsequenz exponentiell vermehrt.

\subsubsection{GAPDH-PCR}

Für den Nachweis, dass die gewonnenen cDNA-Proben intakt sind, wurde eine RT-PCR für das House Keeping Gen GAPDH durchgeführt. GAPDH wird in allen Geweben exprimiert, so dass dessen Amplifikation als Kontrolle dient. Die GAPDH-Primer (MWG Biotech) flankieren ein 342 bp Fragment.

Der Reaktionsansatz setzte sich aus folgenden Reagenzien zusammen:

$$
\begin{array}{lc}
\text { steriles- } \mathrm{H}_{2} \mathrm{O} & 11,025 \mu \mathrm{l} \\
\text { GAPDH-for }(20 \mathrm{pM}) & 0,3 \mu \mathrm{l} \\
\text { GAPDH-rev (20 pM) } & 0,3 \mu \mathrm{l} \\
\text { 10xPCR-Puffer } & 1,5 \mu \mathrm{l} \\
\text { dNTPs (10 mM) } & 1,2 \mu \mathrm{l} \\
\text { Taq-Polymerase }(5 \mathrm{U} / \mu \mathrm{l}) & 0,075 \mu \mathrm{l}
\end{array}
$$

Für jede Probe wurden jeweils $14,4 \mu \mathrm{l}$ des Mastermixes in einem 0,5 $\mathrm{ml}$ Reaktionsgefäß angesetzt. Nach der Zugabe von 0,6 $\mu$ cDNA fand die Amplifikation des Genfragments bei folgenden Parametern im Thermocycler statt: Denaturierung bei $94^{\circ} \mathrm{C}$ für $60 \mathrm{sec}$, Annealing bei $60^{\circ} \mathrm{C}$ für $60 \mathrm{sec}$ und Extension bei $72^{\circ} \mathrm{C}$ für $60 \mathrm{sec}$. Es wurden jeweils 17 Zyklen durchgeführt. 


\subsubsection{2 c-fos-PCR}

Die $c$-fos-mRNA Expression wurde mittels semiquantitativer RT-PCR ermittelt. Hierzu wurden Primer (MWG Biotech) verwendet, die spezifisch an ein 483 bp Fragment der humanen $c$-fos-mRNA binden (Gründker et al. 2000a).

Der Reaktionsansatz setzt sich aus folgenden Reagenzien zusammen:

$$
\begin{array}{lc}
\text { steriles- } \mathrm{H}_{2} \mathrm{O} & 11,025 \mu \mathrm{l} \\
\text { c-fos-for }(20 \mathrm{pM}) & 0,3 \mu \mathrm{l} \\
\text { c-fos-rev (20 pM) } & 0,3 \mu \mathrm{l} \\
\text { 10xPCR-Puffer } & 1,5 \mu \mathrm{l} \\
\text { dNTPs (10 mM) } & 1,2 \mu \mathrm{l} \\
\text { Taq-Polymerase }(5 \mathrm{U} / \mu \mathrm{l}) & 0,075 \mu \mathrm{l}
\end{array}
$$

Es wurden ebenfalls 14,4 $\mu$ l Mastermix für jede Probe angesetzt und 0,6 $\mu 1 \mathrm{cDNA}$ hinzugefügt. Die Reaktion fand im Thermocycler bei folgenden Bedingungen statt. Denaturierung bei $94^{\circ} \mathrm{C}$ für $30 \mathrm{sec}$, Annealing bei $54^{\circ} \mathrm{C}$ für $30 \mathrm{sec}$ und Extension bei $72^{\circ} \mathrm{C}$ für $60 \mathrm{sec}$. Die Anzahl der Zyklen variierte je nach Zellinie. 24 Zyklen wurden für die Amplifikation des $c$-fos-Fragments bei den Ovarialkarzinomzellinien EFO-21 und SKOV-3 verwendet, während für die Endometriumkarzinomzellinien Ishikawa und Hec1A 26 Zyklen notwendig waren, um ein optimales Ergebnis zu erlangen.

Da das GAPDH-Gen in allen Geweben in gleicher Intensität exprimiert wird, wurde dieses als Vergleichswert für die Expressionsstärke der $c$-fos-mRNA verwendet.

\subsubsection{GnRH-II Rezeptor-PCR}

Die Expression der GnRH-II Rezeptor-mRNA Expression wurde ebenfalls mittels semiquantitativer RT-PCR ermittelt. Es wurde ein Primerpaar (MWG Biotech) verwendet, welches eine 313 bp lange DNA-Sequenz des GnRH-II Rezeptor Gens flankiert. 
Der Reaktionsansatz setzte sich aus folgenden Reagenzien zusammen:

$\begin{array}{lc}\text { steriles- } \mathrm{H}_{2} \mathrm{O} & 11,025 \mu \mathrm{l} \\ \text { GnRH-II Rez-for }(20 \mathrm{pM}) & 0,3 \mu \mathrm{l} \\ \text { GnRH-II Rez-rev }(20 \mathrm{pM}) & 0,3 \mu \mathrm{l} \\ \text { 10xPCR-Puffer } & 1,5 \mu \mathrm{l} \\ \text { dNTPs (10 mM) } & 1,2 \mu \mathrm{l} \\ \text { Taq-Polymerase }(5 \mathrm{U} / \mu \mathrm{l}) & 0,075 \mu \mathrm{l}\end{array}$

Es wurde ein Mix von 14,4 $\mu$ l für jede Probe angesetzt und 0,6 $\mu$ l cDNA hinzugefügt. Die Reaktion fand im Thermocycler bei folgenden Bedingungen statt. Denaturierung bei $94^{\circ} \mathrm{C}$ für $30 \mathrm{sec}$, Annealing bei $60^{\circ} \mathrm{C}$ für $30 \mathrm{sec}$ und Extension bei $72^{\circ} \mathrm{C}$ für $60 \mathrm{sec}$. Es wurden 22 Zyklen durchgeführt.

Die Expression des GAPDH-Gens derselben cDNA-Proben wurde wieder als Referenz verwendet.

\subsubsection{Agarose Gelelektrophorese}

Die Auftrennung der DNA-Fragmente im elektrischen Feld erfolgte mittels AgaroseGelelektrophorese. Dies ist eine einfache und effektive Methode DNA-Fragmente verschiedener Größe zu separieren und zu identifizieren, da größere DNA-Moleküle langsamer durch die Gelporen wandern als die Kleineren (McDonell et al. 1977).

Für die Auftrennung wurde bei einer vorhandenen Fragmentgröße von ca. 300-500 bp ein 1,5\%iges Agarose Gel (GIBCO) verwendet. Hierzu wurde die Agarose in TBEPuffer gelöst, aufgekocht und nach kurzem Abkühlen in die entsprechende Gelkammer gegossen. Nach der Auspolimerisation des Gels, konnte dieses mit den PCR-Produkten beladen werden. Hierzu wurden jeweils $10 \mu \mathrm{l}$ des Probenvolumens mit $2 \mu 1$ Probenpuffer versetzt. Der Probenpuffer fungiert als Farbstoffmarker, um die zurückgelegte Probenstrecke charakterisieren zu können, da Bromphenolblau etwa wie ein lineares doppelsträngiges 300 bp DNA-Fragment wandert. Als Referenz diente ein 
DNA-Fragmentlängen-Standard (100bp ladder, MBI Fermentas), von dem $5 \mu \mathrm{l}$ verwendet wurden. Anschließend wurden $10 \mu \mathrm{l}$ eines jeden Ansatzes vorsichtig in die Geltaschen pipettiert. Die elektrische Auftrennung erfolgte konstant bei $100 \mathrm{~V}$ für $1 \mathrm{~h}$. Um die DNA-Fragmente im Gel sichtbar zu machen, wurde dieses für ca. $30 \mathrm{~min}$ in einem Ethidiumbromidbad inkubiert. Nach kurzem Überspülen mit Aqua bidest. wurden die Banden auf einem UV-Transilluminator (Biometra) bei $312 \mathrm{~nm}$ sichtbar gemacht. Zur Dokumentation wird das Ergebnis mit einer Polaroidkamera festgehalten.

\subsection{Herstellung des GnRH-I Rezeptor-'Plasmids}

Um die GnRH-I Rezeptor Expression in Ovarial- und Endometriumkarzinomzellinien zu inhibieren, wurde eine 43 bp lange mRNA-Sequenz des Rezeptors (Tab.2.6) in einen pIRES-Vektor (Abb. 2.1, BD Bioscience) kloniert. Diese mRNA bindet an den komplementären Strang der im Zellkern transkribierten GnRH-I Rezeptor-mRNA und verhindert dadurch die Translation des Proteins. Somit wird die Neusynthese des Rezeptors unterdrückt.

\subsubsection{Bakterien-Medien und Kulturplatten}

Zur Kultivierung von Bakterien wurde LB-Agar-Medium (BIO 101) und SOC-Medium (Invitrogen) verwendet. Alle Bakterienkulturmedien wurden bei $121^{\circ} \mathrm{C}$ für $15 \mathrm{~min}$. hitzesterilisiert. Danach wurden die Gefäße steril verschlossen und bei RT bis zum Gebrauch gelagert. Ampicillin (Ratiopharm), das der Selektion der transformierten Bakterienzellen dient, wurde dem LB-Agar-Medium $(100 \mu \mathrm{g} / \mathrm{ml})$ erst vor Gebrauch zugesetzt.

Zum Gießen von Agarplatten wurden 40 Kapseln des LB-Agar-Mediums in 11 Aqua bidest. während des Autoklaviervorganges gelöst. Erst nach dem Abkühlen des Mediums auf ca. $40-45^{\circ} \mathrm{C}$ wurde das Ampicillin hinzupipettiert, da es hitzeinstabil ist. Es wurden nun jeweils $10 \mathrm{ml}$ des fertigen Mediums auf sterile Petrischalen verteilt und nach dem Erhärten des Agars bei $4^{\circ} \mathrm{C}$ bis zum Gebrauch gelagert. 


\subsubsection{Transformation kompetenter Zellen}

Bakterien nehmen unter normalen Bedingungen DNA nur in begrenztem Umfang auf. Durch eine physikalische und/oder chemische Behandlung der Zellwand wird die Fähigkeit DNA aufzunehemen verstärkt. Die Hitzeschockbehandlung kann E. coliBakterien (Van Die et al. 1983) vorübergehend in den Zustand der ,Kompetenz versetzen, indem sie cDNA-Plamide besser aufnehmen können (Transformation). Plasmide sind doppelsträngig und liegen in zirkulärer Form vor. Es sind kleine DNAMoleküle, die nicht an das Genom der Bakterienzelle gekoppelt sind und sich somit autonom vermehren können. Plasmide tragen meist Gene, die ihnen einen Selektionsvorteil, z.B. Antibiotikaresistenzen verleihen.

Zur Herstellung kompetenter Zellen wurde der E. coli-Stamm TOP10 (Invitrogen) verwendet. $\mathrm{Zu}$ einem Zellaliquot $(50 \mu \mathrm{l})$ wurde $1 \mu \mathrm{g}$ der Plasmid-DNA (pIRES) pipettiert und vorsichtig vermischt. Anschließend wurde die Probe für 15 min auf Eis gestellt, dann $45 \mathrm{sec}$ bei $42^{\circ} \mathrm{C}$ im Wasserbad (Hitzeschock) inkubiert, um dann für 2 min auf Eis abzukühlen. Danach wurden $300 \mu$ vorgewärmtes SOC-Medium in das Reaktionsgefäß gefügt und die Probe für $45 \mathrm{~min}$ bei $37^{\circ} \mathrm{C}$ vorsichtig geschüttelt (ca. 120 rpm). Nach der Inkubationszeit erfolgte das Pipettieren von 50-100 $\mu \mathrm{l}$ der E. coliLösung in die Mitte der Agarplatten. Mit einem Drigalskispatel wurde die Bakterienlösung ausplattiert. Anschließend wurden die Petrischalen kurz luftgetrocknet und für mind. $12 \mathrm{~h}$ bei $37^{\circ} \mathrm{C}$ im Brutschrank bebrütet. Die verbleibenden Bakterienzellen wurden mit gleichem Volumen 87\%igem Glycerin aufgefüllt und bei $-80^{\circ} \mathrm{C}$ gelagert (Glycerol-Stock).

\subsubsection{Amplifikation des pIRES-Vektors}

Da der Vektor ein Ampicillinresistenz-Gen enthält, bilden nur die Bakterien Kolonien auf dem antibiotikumhaltigen Agar, die den Vektor aufgenommen haben. Zur Amplifikation des transformierten pIRES-Vektors, wird eine Kolonie gepickt, in $5 \mathrm{ml}$ Selektionsmedium (LB-Medium, $100 \mu \mathrm{g} / \mathrm{ml}$ Ampicillin) überführt und bei $37^{\circ} \mathrm{C}$ unter Schütteln bei 200-300 rpm für mind. $12 \mathrm{~h}$ inkubiert. Danach wurden $300 \mu \mathrm{lder}$ Bakterienlösung nochmalig mit LB-Medium (BIO 101)auf $150 \mathrm{ml}$ aufgefüllt. Die Replikation fand bei $37^{\circ} \mathrm{C}$, diesmal für mind. $16 \mathrm{~h}$ und $300 \mathrm{rpm}$ statt. 


\subsubsection{Plasmid-DNA-Gewinnung}

Für die Extraktion der amplifizierten Vektoren-DNA aus den Bakterienzellen wurde der Qiagen Plasmid Maxi-Kit® der Firma QIAGEN verwendet. In die Aufarbeitung wurden $450 \mathrm{ml}$ (3 Ansätze) der Bakterienkultur eingesetzt und der Kit nach Angaben des Herstellers verwendet.

Das entstandene Nukleinsäurepellet wurde in $500 \mu$ sterilem $\mathrm{H}_{2} \mathrm{O}$ resuspendiert und die Nukleinsäurekonzentration und der Reinheitsgrad im Spektralphotometer bestimmt (3.2.2).

\subsubsection{Restriktionsanalyse}

Die Hydrolyse von dsDNA-Fragmenten und Plasmid-DNA erfolgt durch Typ II Restriktionsendonukleasen (Fuchs et al. 1983). Diese Enzyme hydrolisieren palindrome Tetra-, Penta- oder Hexanukleotidsequenzen. Dabei entstehen an den 3 '-Enden des gespaltenen DNA-Doppelstranges Hydroxylgruppen, während die 5'-Enden Phosphatgruppen tragen.

Um die IRES (internal ribosome entry site)-Sequenz aus dem Expressionsvektor herauszuschneiden, wurden die Restriktionsendonukleasen Sal I und Nhe I (Amersham Pharmacia) verwendet. In einem Reaktiosvolumen von $10 \mu \mathrm{l}$ wurden $0,5 \mu \mathrm{g}$ der isolierten Plasmid-DNA eingesetzt. Hinzugefügt wurden jeweils $1 \mu \mathrm{l}$ der

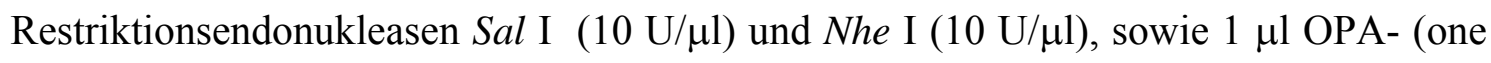
phor all) Puffer, der für alle Endonukleasen der Firma Amersham Pharmacia eingesetzt werden kann. Die Differenz zum Gesamtvolumen wurde mit sterilem- $\mathrm{H}_{2} \mathrm{O}$ aufgefüllt. Der Restriktionsverdau erfolgte bei $37^{\circ} \mathrm{C}$ für $2-3 \mathrm{~h}$.

Als Nachweis für einen erfolgreichen Restriktionsverdau, erfolgte die Auftrennung der Plasmid DNA-Fragmente in einem 0,8\%igen Agarosegel, wie in Methode 3.2.5 beschrieben. 


\subsubsection{Anreicherung der pIRES ${ }^{-}$-DNA}

Um eine effizientere Ausbeute der pIRES-DNA zu erhalten, wurde ein Restriktionsverdau (3.3.5) mit 10fachem Volumen angesetzt. Das gesamte Volumen (ca. $200 \mu \mathrm{l}$ ) wurde nun in einem 0,8\%igem Agarosegel (3.2.5) aufgetrennt. Mittels DNA-Fragment-Längen Standard (100 bp ladder) wurde die ethidiumbromidgefärbte pIRES-DNA bei UV-Licht lokalisiert und mit einem scharfen Skalpell aus dem Gel herausgeschnitten.

Mit Hilfe des Qiaquick® Gel Extraction Kit (QIAGEN) wurde die ausgeschnittene DNA-Agarose-Bande in Puffer gelöst und anschließend an eine Silicagel-Membran zur Aufreinigung gebunden (Vogelstein et al. 1979), gewaschen und eluiert. Der Kit wurde nach den Angaben des Herstellers verwendet.

\subsubsection{Herstellung des GnRH-I Rezeptor-mRNA-Inserts}

Die Oligonukleotide zur Herstellung des GnRH-I Rezeptor-mRNA-Inserts wurden von der Firma MWG Biotech synthetisiert. Die beiden, jeweils 43 bp umfassenden komplementären DNA-Sequenzen, werden im Thermocycler unter folgenden Bedingungen zusammengebracht: Denaturierung bei $94^{\circ} \mathrm{C}$ für 5 min und Anlagerung bei $72^{\circ} \mathrm{C}$ für $10 \mathrm{~min}$.

Für den Ansatz wurden jeweils $9 \mu \mathrm{l}(100 \mathrm{pM})$ des Oligonukleotids und $2 \mu \mathrm{l}$ 10xPCRPuffer (Roche) eingesetzt.

\subsubsection{Ligation}

Zur Ligation der in Methode 3.3.6 gewonnenen Plasmid-DNA mit dem GnRH-I Rezeptor-mRNA-Insert, wurde die Ligase des Bakteriophagen T4 (Weiss et al. 1968) verwendet. Dieses Enzym katalysiert die Verknüpfung von 5'-Phosphat- und 3`-Hydroxylgruppen und kann somit zur Ligation von kompatiblen ,stickye- sowie ,blunt-end'-Fragmenten doppelsträngiger DNA eingesetzt werden. Der Ligationsansatz (40 $\mu \mathrm{l})$ enthielt folgende Komponenten: $20 \mu \mathrm{l}$ Plasmid-DNA $(10 \mu \mathrm{g}), 1,6 \mu 1$ Insert-DNA

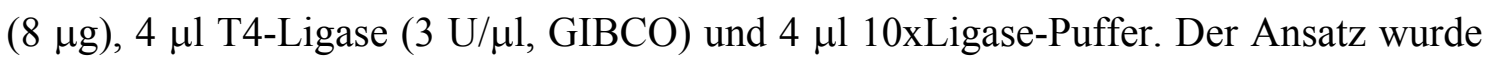


mit sterilem- $\mathrm{H}_{2} \mathrm{O}$ auf $40 \mu \mathrm{l}$ aufgefüllt und für mind. $16 \mathrm{~h}$ bei $14^{\circ} \mathrm{C}$ ligiert. Nach der Ligation konnten die Proben entweder bei $-20^{\circ} \mathrm{C}$ gelagert werden oder sofort für die Transformation in E. coli TOP 10 eingesetzt werden (3.3.2).

Nach der Vervielfältigung des GnRH-I Rezeptor ${ }^{-}$-Konstrukts in kompetenten E. coli TOP 10 wurde wiederum die Vektor-DNA mittels Qiagen Plasmid Maxi-Kit@ der Firma QIAGEN aus den Bakterienzellen extrahiert (3.3.4).

Zur Überprüfung des Konstrukts erfolgte ein Restriktionsverdau (3.3.5) mit den

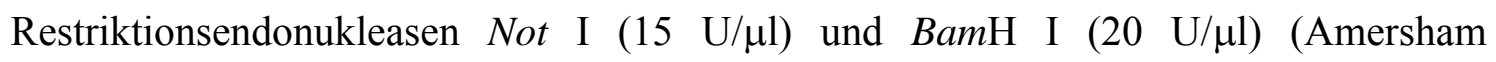
Pharmacia) und anschließender Auftrennung in einem 0,8\%igem Agarosegel (3.3.5). Da sich die Erkennungssequenz von Not I im Insert befindet, können nur dann zwei lineare Fragmente entstehen, wenn das Insert erfolgreich in den Vektor ligiert wurde, d.h. wenn beide Restriktionsenzyme geschnitten haben. Es würde allerdings nur ein Fragment entstehen, wenn keine Insertligation stattgefunden hat.

\subsubsection{Transfektion}

Als Transfektion bezeichnet man das Einbringen von Fremd-DNA in eukaryotische Zellen, so dass die auf dem Vektor liegenden Gene mitrepliziert werden. Man unterscheidet zwischen einer vorrübergehenden (transienten) Expression der transferierten Gene und einer stabilen Transfektion, bei der die Gene in das Genom der Zielzelle integriert werden (Gorman et al. 1986).

Die transiente Transfektion von Endometrium- und Ovarialkarzinomzellinien wurde bei einer Konfluenz von 50-70\% mit dem Transfektionsreagenz SuperFect ${ }^{\circledR}$ (QIAGEN) durchgeführt. Hierbei handelte es sich um eine Lipofektion, bei der das kationische Lipid SuperFect ${ }^{\circledR}$ die Plasmid-DNA bedeckt und ihm eine negative Ladung verleiht. Dieser Komplexe adsorbiert an die Zelloberfläche der Tumorzellen und fusioniert mit der Zellmembran oder wird durch Endozytose aufgenommen, so dass die DNA ins Zytoplasma transportiert werden kann (Felgner et al. 1987).

2-3 h vor der Transfektion wurde das Kulturmedium von den Petrischalen abgesaugt, die Zellen 1mal mit PBS-Puffer gewaschen und mit $5 \mathrm{ml}$ Medium 1 aufgefüllt. Pro Petrischale wurden $5 \mu \mathrm{g}$ des GnRH-I Rezeptor ${ }^{\Theta}$-Konstrukts eingesetzt. Die Plasmid- 
DNA wurde vor Gebrauch 1:100 mit Medium 1 verdünnt und 2-3 min inkubiert. Danach wurden $10 \mu$ l SuperFect ${ }^{\circledR}$ hinzu gegeben, vorsichtig vermischt und für $10 \mathrm{~min}$ bei RT stehen gelassen. Nach der Inkubationszeit wurden $3 \mathrm{ml}$ Medium 2 pro Petrischale zu dem Gemisch gegeben. 3,5 ml der Lösung wurden dann, nach dem Absaugen des Mediums auf jeden Zellrasen pipettiert und für $2-3 \mathrm{~h}$ bei $37^{\circ} \mathrm{C}$ im Brutschrank inkubiert. Anschließend erfolgte zur Erholung der Zellen eine Inkubation mit $5 \mathrm{ml}$ Medium. Am nächsten Tag konnte, je nach Versuchsplanung, mit den Zellen weiter gearbeitet werden.

\subsubsection{Ernten der Zellen nach der Transfektion}

Als Nachweis dafür, dass das GnRH-II Analog [D-Lys ${ }^{6}$ ]GnRH-II nicht über das GnRHI Rezeptor System reguliert wird, wurden die transfizierten Zellen vor dem Ernten mit diesem stimuliert. Zur Internalisierung des GnRH-I Rezeptors, erfolgte vor der Stimulation mit dem GnRH-II Analog eine Inkubation für $6 \mathrm{~h}$ mit dem GnRH-I Analog Triptorelin (100 nM). Danach wurde der Zellrasen mit PBS-Puffer überspült und die Zellen für mind. $12 \mathrm{~h}$ in Hungermedium inkubiert. Anschließend erfolgte die Inkubation mit $\left[\mathrm{D}-\mathrm{Lys}^{6}\right] \mathrm{GnRH}-\mathrm{II}$ in aufsteigender Konzentration $100 \mathrm{pM}, 1 \mathrm{nM}, 100 \mathrm{nM}$ und $10 \mu \mathrm{M}$. Als Kontrolle wurden transfizierte Zellen verwendet, die entweder ganz unbehandelt waren oder nur mit Triptorelin stimuliert wurden. Das Lysieren der Zellen erfolgte entsprechend der nachstehenden Methoden. So wurden die Monolayer entweder mit Lysispuffer (PTP-Assay) oder mit RLT-Puffer (RNA-Isolierung) in Lösung gebracht.

\subsection{Proteinbiochemische Methoden}

Mittels der Western Blot Analyse sollte die MAPK Aktivität, sowie die Expression des C-Fos Proteins nach der EGF-Stimulation mit oder ohne vorherige [D-Lys ${ }^{6}$ ]GnRH-II Zugabe nachgewiesen werden. Damit sollte geklärt werden, ob in Ovarial- und Endometriumkarzinomzellen innerhalb des Signaltransduktionsweges die EGF- 
induzierte Aktivierung beider Signalmoleküle durch Zugabe des GnRH-II Analogs [D-Lys $\left.{ }^{6}\right]$ GnRH-II inhibiert werden kann.

\subsubsection{Proteingewinnung}

Für die Proteingewinnung wurden die Ovarialkarzinomzellinien EFO-21 und SKOV-3 sowie die Endometriumkarzinomzellinien Ishikawa und Hec1A zunächst gleichmäßig in Zellkulturflaschen $\left(75 \mathrm{~cm}^{2}\right)$ ausgesät. Nach dem Erreichen einer $70-80 \%$ igen Konfluenz wurden die Zellen 24 h (MAPK) oder 48 h (C-Fos) in Hungermedium weiterkultiviert. Um die MAPK- und C-Fos-Aktivität zu induzieren, wurden die Zellen mit humanen rekombinantem EGF (100 nM) für 30 min (MAPK) oder 15 min (C-Fos) stimuliert. Eine weitere Stimulation erfolgte mit dem GnRH-II Agonisten [D-Lys ${ }^{6}$ ]GnRH-II $(10 \mu \mathrm{M})$ für entweder $1 \mathrm{~h}$ (MAPK) oder $15 \mathrm{~min}$ (C-Fos). Nach der Stimulation wurde das Medium abgesaugt, die Zellen einmal mit PBS-Puffer überspült und anschließend für $5 \mathrm{~min}$ mit $2,5 \mathrm{ml}$ Trypsin/EDTA-Lösung inkubiert. Zum Abstoppen der Reaktion wurde die Zellsuspension in Kulturmedium aufgenommen und in ein $15 \mathrm{ml}$ Reaktionsgefäß überführt. Nach der Zentrifugation für 5 min bei $1200 \mathrm{rpm}$ wurde der Überstand verworfen und das Pellet ein weiteres Mal mit PBS-Puffer gewaschen. Es erfolgt eine erneute Zentrifugation für 5 min bei $1300 \mathrm{rpm}$. Der Überstand wurde vorsichtig abgesaugt das Pellet bei $-80^{\circ} \mathrm{C}$ gelagert.

\subsubsection{Bestimmung der Proteinkonzentration}

Das aus 3.4.1 gewonnene Pellet wurde in $1 \mathrm{ml}$ Extraktionspuffer aufgenommen, resuspendiert und die Proteinkonzentration mit der Bradford-Methode (Bradford 1976) bestimmt. Um das Aufbrechen der Membranen zu unterstützen wurden die Proben dreimal bei $-80^{\circ} \mathrm{C}$ eingefroren und wieder aufgetaut. Anschließend wurden sie im Ultraschallbad wiederum dreimal für $1 \mathrm{~min}$ beschallt. Der Proteinstandard wurde mit BSA ( $1 \mu \mathrm{g} / \mu \mathrm{l}$, Sigma) in aufsteigender Konzentration (0-500 $\mu \mathrm{g}$ Protein) angesetzt (Tab. 3.1). 


\begin{tabular}{ll} 
Tab. 3.1: Konzentrationen des BSA-Proteinstandards \\
\hline BSA $[\mu 1]$ & Extraktionspuffer $[\mu 1]$ \\
\hline 0 & 1000 \\
50 & 950 \\
80 & 920 \\
100 & 900 \\
200 & 800 \\
300 & 700 \\
400 & 600 \\
500 & 500 \\
\hline
\end{tabular}

Es wurden jeweils $50 \mu \mathrm{l}$ des Standards, sowie $50 \mu \mathrm{l}$ der Proben in beschriftete $15 \mathrm{ml}$ Reaktionsgefäße pipettiert. Bei einer zu hohen Proteinkonzentration der Proben, wurden diese mit dem Extraktionspuffer herunter verdünnt. Jedes Gefäß wurde nun mit 2,5 ml Coomasie-Lösung (Biorad) aufgefüllt. Diese wurde vor Gebrauch 1:5 mit Aqua bidest. verdünnt und filtriert. Es erfolgte eine Inkubation der Proben für 10-50 min bei RT. Zur Proteinkonzentrationsbestimmung wurden $350 \mu \mathrm{l}$ aus jedem Ansatz (die Standards zuerst) in die Wells einer 96-Well-Platte pipettiert. Die Messung der Extinktion erfolgte im Multidetection Microplate Reader (Synergy HAT, KC4, BIO-TEK) bei einer Wellenlänge von $590 \mathrm{~nm}$.

\subsubsection{SDS-Polyacrylamid-Gelelektrophorese}

Die eindimensionale Polyacrylamid-Gelelektrophorese (SDS-PAGE) trennt Proteine der Größe nach auf (Laemmli et al. 1970). Dabei binden die Proteine im Überschuss zugesetztes SDS und erhalten eine negative Ladung. Diese ist proportional zu ihrem Molekulargewicht, weshalb die SDS-Protein-Komplexe in der Gelmatrix der Molmasse nach aufgetrennt werden. 
Die Mini-PROTEAN II Elektrophoresis Cell Apparatur (Biorad) wurde gemäß des BioRad Protokolls aufgebaut. Die verschiedenen Pufferlösungen, sowie die Gele wurden ebenfalls nach den Vorgaben zubereitet. Die 10\%ige Trenngellösung wurde gemischt und luftblasenfrei zwischen die Glasplatten der Gelkammer bis ca. $2 \mathrm{~cm}$ unter den oberen Rand eingefüllt, mit Aqua bidest. überschichtet und $1 \mathrm{~h}$ zum Auspolymerisieren stehen gelassen. Anschließend wurde die Lösung für das 5\%ige Sammelgel angesetzt und nachdem das Aqua bidest. entfernt wurde bis zum oberen Rand der Gelkammer eingegossen. Danach wurde sofort der Gelkamm eingesetzt und ebenfalls auspolymerisieren lassen für 30-45 min. Anschließend wurde der Kamm vorsichtig entfernt, das Gel in die Elektrophoresekammer eingesetzt und diese mit Elektrophorese-Puffer befüllt. In der Zwischenzeit wurden die Proteinproben auf Eis aufgetaut. $5 \mu \mathrm{g}$ des Proteins wurden mit Laemmli-Puffer (2x) 1:1 verdünnt und für 5 min bei $95^{\circ} \mathrm{C}$ denaturiert. Anschließend erfolgte eine Zentrifugation für 5 min bei $13000 \mathrm{rpm}$. Es wurde ein Volumen von $40 \mu \mathrm{l}$ in die Geltaschen pipettiert. Als Molekulargewichtsstandard wurden $15 \mu$ des Full Range Rainbow Markers (Amersham life science) aufgetragen. Anschließend erfolgte die elektrophoretische Auftrennung der Proteine für 30 min bei konstant $80 \mathrm{~V}$ und nachfolgend für 45 min bei konstant $150 \mathrm{~V}$.

\subsubsection{Western Blot (Semi-Dry-Immunblot)}

Der Transfer der aufgetrennten Proteine auf eine Nitrocellulosemembran (HybondECL ${ }^{\mathrm{TM}}$, Amersham Bioscience) erfolgte mit Hilfe des Semi-Dry-ImmunoblotVerfahren, welches den schnellen und vollständigen Transfer ermöglicht (Towbin et al. 1979).

Zunächst wurden die Nitrocellulosemembran und das Whatman 3MM-Filterpapier (12 Streifen pro Membran) auf die entsprechende Gelgröße zugeschnitten. Vor dem Blotten wurde die Membran für $10 \mathrm{~min}$ in $20 \mathrm{ml}$ Transferpuffer inkubiert. Durch den Methanolgehalt werden die Membranporen geöffnet.

Als unterste Schicht dienten vier, in konzentriertem Anodenpuffer getränkte Filterpapiere, worüber vier in Anodenpuffer getränkte Filterpapiere gelegt wurden. Der Filterpapierstapel wurde dann auf die Graphit-Anode gebracht und die Nitrocellulosemembran aufgelegt. Nach der Elektrophorese wurde das Sammelgel 
verworfen. Das Trenngel wurde mit Aqua bidest. gespült, kurz in Transferpuffer geschwenkt und luftblasenfrei auf die Nitrocellulosemembran gelegt. Danach mit vier in Kathodenpuffer getränkten Filterpapieren bedeckt und mit der Graphit-Kathode die Apparatur geschlossen. Das Blotting erfolgte für 90 min bei $4^{\circ} \mathrm{C}$ und $90 \mathrm{~V}$ bei konstanter Voltzahl. Nach Beendigung des Transfers wurde die Membran vorsichtig mit einer Pinzette vom Gel und Filterpapier abgelöst und mit TBST-Puffer gespült. Zur Absättigung unspezifischer Bindungsstellen wurde die Membran nach dem Transfer für 45 min bei RT auf dem Rotationsschüttler mit Blocking-Solution (Naturaflor) inkubiert.

\subsubsection{Immunreaktion und Detektion}

Nach dem Absättigen der Nitrocellulosemembran wurde die Immunreaktion nach den Angaben des Herstellers mit dem ECL ${ }^{\mathrm{TM}}$ plus Western Blotting Analysis System (Amersham Bioscience) durchgeführt. Als Erstantikörper wurde entweder der polyclonal anti-ACTIVE ${ }^{\mathrm{TM}}$ MAPK pAb, rabbit (Promega) oder der polyclonale Anti-c-Fos, rabbit (Abcam) verwendet. Die optimale Antikörper-Konzentration lag bei einer Verdünnung in TBST-Puffer von 1:5000 bzw. 1:200. Nach wiederholtem Waschen mit TBST-Puffer erfolgte die Inkubation mit dem Horseraddish Peroxidasegekoppelten Sekundärantikörper (anti-rabbit IgG, Amersham Bioscience) in einer 1:10000 Verdünnung, ebenfalls für $1 \mathrm{~h}$ bei RT. Durch die Zugabe der im Kit enthaltenen chemilumineszenten Reagenzien konnte der gebundene Sekundärantikörper detektiert werden. Das Signal auf der Nitrocellulosemembran konnte auf einen Röntgenfilm (Kodak) übertragen werden, wobei die Belichtungszeit zwischen 5 und $60 \mathrm{sec}$ variierte.

\subsubsection{Deglykosilierung von Proteinen}

Kohlenhydrate in Form von Asparagin-gekoppelten (N-linked) oder Serin/Threoningekoppelten (O-linked) Oligosacchariden treten häufig als strukturelle Komponenten in eukaryotischen Proteinen auf. Diese bestimmen die biologischen Funktionen (Immunantwort, Rezeptorbindung, Pathogenität u.a.) sowie die Masse und die Ladung der Proteine. Für die Untersuchungen zur Struktur und Funktion von Glykoproteinen, ist 
es oft notwendig alle oder einen Teil der Oligosaccharide vom Protein abzuspalten (Sojar et al. 1987).

Zur Deglykosilierung von Proteinen wurde das Enzymatic Protein Deglycosylation Kit von der Firma Sigma verwendet und nach den Angaben des Herstellers durchgeführt. Die gewonnenen Proteine wurden zum Nachweis der Deglykosilierung in der SDSPAGE (3.4.3) aufgetrennt.

\subsubsection{Prinzip der Photoaffinitätsmarkierung}

Photoaffinitätsmarkierungen werden zur Untersuchung von Wechselwirkungen eines Rezeptors mit bestimmten Liganden durchgeführt (Chiara et al. 2003). Entsprechend derivatisierte Wirkstoffe können nach Erreichen der Bindungsstelle ihres Zielproteins durch Bestrahlung mit UV-Licht zum Eingehen einer irreversiblen Bindung mit benachbarten Aminosäuren angeregt werden. Dies führt zu einer Fixierung zwischen Rezeptor und Ligand. Durch eine anschließende denaturierende Elektrophorese kann die betroffene Protein-Untereinheit direkt detektiert werden. Für detailliertere Studien empfiehlt sich das Einbringen einer zusätzlichen Markierung durch radioaktive Isotope oder fluoreszierende Gruppen.

\subsection{8 [D-Lys6- $N^{\mathrm{e}}$-azidobenzoyl]-GnRH-Il Synthese}

Zur Durchführung der Photo-Affinity-Labeling Methode wurde ein spezielles GnRH Derivat synthetisiert. Das Photoaffinitätsreagenz [D-Lys ${ }^{6}-N^{\mathrm{c}}$-Azidobenzoyl]-GnRH-II hat eine hohe Bindungsaffinität zum GnRH Rezeptor und nach der Photoaktivierung bindet es kovalent an die Zellmembranfraktionen der Tumorzellen (Hazum 1981). Zuerst wurden $0.26 \mathrm{mg}$ (4-Azidobenzoyl)-N-Hydroxysuccinimide mit $1 \mathrm{ml}$ Methanol und 5,6 $\mu \mathrm{l}$ Triethylamin in Lösung gebracht. Anschließend wurden $0.6 \mathrm{mg}$ [DLys $\left.^{6}\right]$ GnRH-II dazugegeben und lichtgeschützt für $3 \mathrm{~h}$ bei RT inkubiert. Danach erfolgte die Präzipitation mit Diethylether und eine Zentrifugation bei $1300 \mathrm{rpm}$ für 1 min. Es folgten drei Waschschritte mit Ethylacetat, wobei die Lösung nach jedem Waschschritt zentrifugiert wurde, um die nichtgebundenen (4-Azidobenzoyl)-NHydroxysuccinimide Moleküle herauszubekommen. Das erhaltene [D-Lys ${ }^{6}-N^{\epsilon}-$ 
Azidobenzoyl]-GnRH-II Derivat konnte in die Photoaffinitätsmarkierung eingesetzt werden.

\subsubsection{Methode der Photoaffinitätsmarkierung}

Für die Photoaffinitätsmarkierung wurden die Zellmembranfraktionen (Methode) verwendet. Vor der Inkubation mit den Tumorzellen wurde das [D-Lys ${ }^{6}-N^{\epsilon}-$ Azidobenzoyl]-GnRH-II Derivat mit dem radioaktivem Isotop ${ }^{125} \mathrm{I}$ markiert. Danach erfolgte die Inkubation der Membranfraktionen mit dem photoreaktiven Radioliganden ${ }^{125}$ I-[D-Lys ${ }^{6}-N^{\mathrm{e}}$-Azidobenzoyl]-GnRH-II $(1 \mathrm{nM})$ in $1 \mathrm{ml}$ Binding-Puffer für $1 \mathrm{~h}$ bei RT. In drei weiteren Ansätzen wurde, unter den selben Bedingungen, zusätzlich mit jeweils ungelabeltem [D-Lys ${ }^{6}$ ]-GnRH-II $(100 \mathrm{nM})$, ungelabeltem Cetrorelix (100 nM) oder ungelabeltem Triptorelin (100 nM) stimuliert. Nach der Inkubationszeit wurden die Zellen mit eiskaltem Waschpuffer gewaschen und danach bei $0^{\circ} \mathrm{C}$ für $10 \mathrm{~min}$ in einem Abstand von $25 \mathrm{~cm}$ mit einer $6 \mathrm{~W}$ Lampe bei $254 \mathrm{~nm}$ bestrahlt. Es folgte eine Zentrifugation bei $600 \mathrm{rpm}$ für $10 \mathrm{~min}$ bei $4^{\circ} \mathrm{C}$, nach der das Pellet gelöst wurde (100 mM Na $2 \mathrm{HPO}_{4}, 25 \mathrm{mM}$ EDTA, 0,1 M Trypsin Inhibitor, 1\% Nonidet P-40). Die gelösten gelabelten GnRH-II Rezeptoren wurden mit gleichem Volumen LaemmliPuffer versetzt und in der SDS-PAGE (10\%) elektrophoretisch aufgetrennt (3.4.3). Zur Detektion wurde das anti-human GnRH-II Rezeptor Antiserum (3.5.1.2) verwendet.

\subsubsection{Phosphotyrosin-Phosphatase Assay}

Das GnRH System aktiviert eine Phosphotyrosin-Phosphatase (PTP), die dann ihrerseits die Tyrosinkinase-Autophosphorylierung von Wachstumsfaktor Rezeptoren beeinflusst. Durch die Dephosphorylierung der Tyrosinkinase reichert sich demnach freies Phosphat in der Zelle an. Das Phosphat steht proportional zur PTP-Aktivität und kann über einen Farbnachweis photometrisch quantifiziert werden (Daum et al. 1993).

Für die Stimulation wurden die Ovarialkarzinomzellinien EFO-21 und SKOV-3, sowie die Endometriumkarzinomzellinien Ishikawa und Hec1A in $75 \mathrm{~cm}^{2}$ Zellkulturflaschen ausgesät. Nach ca. 3-4 Tagen, nachdem die Zellen eine Konfluenz von 90\% erreicht hatten, wurden sie mit Hungermedium für 48 h inkubiert. Dann erfolgte die Stimulation 
mit dem GnRH-II Analog [D-Lys ${ }^{6}$ GnRH-II in aufsteigender Konzentration 100 pM, $1 \mathrm{nM}, 100 \mathrm{nM}$ und $10 \mu \mathrm{M}$ für jeweils $1 \mathrm{~h}$. Die Reaktion wurde mit $5 \mathrm{ml}$ eiskaltem PBSPuffer gestoppt. Die Zellen wurden geerntet und in Lysispuffer $\left(3 \times 10^{6}\right.$ Zellen pro $1 \mathrm{ml}$ Lysispuffer) aufgenommen. Das endogene Phosphat wurde durch das Nutzen von Sephadex G-25 Spin Colums (Promega) herausgewaschen. Die Tyrosin-Phosphatase Aktivität wurde mit dem Tyrosin-Phosphatase Assay System (Promega) bestimmt (Harder et al. 1994). Das synthetische im Assay enthaltene PTP-spezifische Phosphopeptid, ist END(pY)INASL. Der Assay wurde mit $10 \mu$ g Protein gemäß den Angaben des Herstellers durchgeführt. Die Extinktion wurde im Multidetection Microplate Reader bei einer Wellenlänge von $630 \mathrm{~nm}$ gemessen. Die Ergebnisse wurden als Prozent zur unstimulierten Kontrolle $(=100)$ dargestellt.

\subsection{Immunhistochemische Mehoden}

\subsubsection{Gewinnung des anti-human GnRH-II Rezeptor Antiserum}

\subsubsection{Immunisierung}

Bei der Herstellung von Antkörpern wird die natürliche Abwehrreaktion des Organismus gegenüber Antigenen ausgenutzt. Zur Gewinnung des poyklonalen Antiserums gegen den humanen GnRH-II Rezeptor wurde ein Peptid (YSPTMLTEVPPC) synthetisiert (Peptide Specialty Laboratories), welches gegen die dritte extrazelluläre Domäne des Rezeptors gerichtet ist. Das Peptid ist über ein CysteinRest an das Haemocyanin der gewöhnlichen Napfschnecke (Patella coerulea) gebunden. Als Organismus wurde das Kaninchen gewählt. Für die Erstimmunisierung wurden jeweils $2 \mathrm{mg}$ des Peptids in $400 \mu \mathrm{l}$ Freund`s inkomplettes Adjuvans (FIA) verwendet (Hanley et al. 1995, Animal Welfare Center 1997). Nach der Emulgation des Gemisches wurden jedem Kaninchen die Antigenemulsion intramuskulär injiziert. Die folgenden Boosterimmunisierungen erfolgten im Abstand von drei Wochen, wobei ebenfalls FIA als Adjuvans verwendet wurde (Peptide Specialty Laboratories). 


\subsubsection{Antiserum-Gewinnung}

In zwei bis drei wöchigem Abstand wurden den Kaninchen 10-20 ml Blut entnommen und für $4 \mathrm{~h}$ bei $37^{\circ} \mathrm{C}$ inkubiert. Nachdem das Blut für mind. $12 \mathrm{~h}$ gelagert wurde und somit eine Sedimentation der Erythrozyten statt gefunden hat, erfolgte die sterile Entnahme des Serums. Anschließend wurde das Serum bei $1200 \mathrm{rpm}$ für $10 \mathrm{~min}$ zentrifugiert und nach dem Aliquotieren bis zur weiteren Verwendung bei $-20^{\circ} \mathrm{C}$ gelagert.

Um mögliche Kreuzreaktionen mit den ähnlichen Aminosäuresequenzen LTEVPP und PSMATEAPPC zu vermeiden, wurde eine Säulenchromatographie durchgeführt. Die beiden Peptide waren an der Säule gebunden. Vor dem Gebrauch wurde das Antiserum auf diese Säule gegeben und aufgereinigt.

\subsubsection{Einbettung der Gewebe in Paraffin}

Direkt nach der Entnahme des Affenovars, erfolgte die Fixierung mit einer 4\%igen Paraformaldehydlösung in PBS-Puffer für $24 \mathrm{~h}$ bei $4^{\circ} \mathrm{C}$. Zur Dehydrierung wurde das paraformaldehydgetränkte Gewebe in einer aufsteigenden Alkoholreihe (30\%, 50\%, $70 \%, 90 \%$ und Alkohol absolut) für jeweils zweimal $2 \mathrm{~h}$ inkubiert. Nach einer ebenfalls zweistündigen Inkubation mit Xylol, erfolgte das Durchtränken des Ovars mit ca. $70^{\circ} \mathrm{C}$ heißem Paraffin für $12 \mathrm{~h}$. Anschließend wurde ein Block ausgegossen, in dem sich das Gewebe befand und durch Abkühlen gehärtet. Die Blöcke konnten entweder bei $4^{\circ} \mathrm{C}$ gelagert oder die Schnitte auf Objektträger fixiert werden. Hierzu wurden die Paraffinblöcke am Mikrotom (Leika) geschnitten (Schnittdicke $4 \mu \mathrm{m}$ ). Diese wurden im Wasserbad bei $37^{\circ} \mathrm{C}$ gestreckt und faltenfrei auf einen Objektträger gezogen. Es erfolgte das Trocknen der Schnitte im Brutschrank bei $42^{\circ} \mathrm{C}$ für $24 \mathrm{~h}$.

\subsubsection{Immunfärbung der Gewebeschnitte}

Um die Gewebeschnitte für Färbungen verwenden zu können, mussten diese vorerst entparaffiniert werden. Hierfür wurden die Objektträger zweimal in Xylol und anschließend zweimal in Propanol für jeweils 5 min inkubiert. Um die endogene Peroxidase $\mathrm{zu}$ blocken, erfolgte die Behandlung mit einer 3\%igen $\mathrm{H}_{2} \mathrm{O}_{2}$-Lösung in 
Methanol für 20 min. Danach wurden die Schnitte mit Aqua bidest. gewaschen und zur Demaskierung des Antigens dreimal für $5 \mathrm{~min}$ in der Mikrowelle bei $600 \mathrm{~W}$ in Citratpuffer aufgekocht.

Für die Immunfärbung wurde das Histostain ${ }^{\circledR}$ Bulk Kit der Firma Zymed verwendet. Zuerst erfolgte das Beschichten des Schnitte mit $100 \mu \mathrm{l}$ der im Kit enthaltenen Serum Blocking Solution für 10 min. Die Blocking Solution wurde vorsichtig abpipettiert, aber nicht abgewaschen und das rabbit anti-human GnRH-II Rezeptor Serum (1. Antikörper) in einer Verdünnung von 1:10000 in PBS-Puffer hinzu gegeben und für $12 \mathrm{~h}$ bei $4^{\circ} \mathrm{C}$ in einer feuchten Kammer inkubiert (alternativ $1 \mathrm{~h}$ bei $37^{\circ} \mathrm{C}$ ). Es erfolgte das dreimalige Waschen für jeweils 10 min mit PBS-Puffer, bevor der biotinylierte zweite Antikörper für 30 min auf die Schnitte gegeben wurde. Wiederum wurden die Objektträger dreimal für jeweils 10 min mit PBS-Puffer gewaschen. Danach wurden $100 \mu 1$ der StreptavidinPeroxidase für 10 min hinzugefügt, um das Signal der Farbreaktion zu verstärken. Wiederum erfolgte ein Waschschritt unter den selben Bedingungen wie zuvor. Anschließend erfolgte die Inkubation im Dunkeln mit dem Chromogen Diaminobenzidin (DAB, DakoCytomation) für 2-30 min. Hierzu wurde das DABChromogen 1:5 mit seinem Substrat Puffer verdünnt und $100 \mu 1$ der Verdünnung auf die Gewebeschnitte pipettiert. Nach der Inkubationszeit wurde die Reaktion als Braunfärbuung sichtbar.

Um die Kerne der einzelnen Zellen anzufärben, wurde Meyer`s Haemalaun (Merck) verwendet. Vor Gebrauch wurde das Reagenz 1:10 mit Aqua bidest. verdünnt. In diese Verdünnung wurde der Objektträger für $10 \mathrm{sec}$ eingetaucht und dann 5-10 min mit Aqua bidest. inkubiert. Danach erfolgte eine Inkubation für 10 min mit Leitungswasser. Durch die pH-Wert Änderung von 6,8 auf 7,4 kommt es zur Blaufärbung der Kerne (,Bläuen').

Zur Konservierung der Gewebeschnitte, wurden diese in einer aufsteigenden Alkoholreihe $(30 \%, 50 \%, 70 \%, 90 \%$ und Alkohol absolut) und Xylol für jeweils zweimal 10 min dehydriert. Danach wurden sie mit DePex Mounting Medium (Gurr) blasenfrei mit Deckgläschen eingedeckt und archiviert. 


\subsection{Statistische Auswertung der Gen- und Protein-Expression}

Die quantitative Auswertung der einzelnen Banden erfolgte mit der Kodak Digital Science 1D Image Analyse Software (Version 2.0.3, Kodak). Durch jeweils drei unabhängige Versuchsdurchführungen pro Zellinie und Stimulation einschließlich Kontrolle wurden die Intensitäten, die proportional zur Expression des untersuchten Gens bzw. Proteins stehen, bestimmt. Für die Erstellung von Diagrammen sowie zur statistischen Auswertung wurde die Software GraphPad Prism (Version 3.0, Prism) genutzt. Als statistische Tests wurden der ,one-way ANOVA'- sowie der ,Newman Keuls'-Test angewendet. 


\section{ERgebnisse}

\subsection{Wirkungsmechanismen des GnRH-II Rezeptor Systems}

Die Wirkungsweise von GnRH-I und seines Rezeptors in gynäkologischen Tumorzellen ist bereits gut untersucht worden. Der GnRH-I Rezeptor interagiert mit der EGFRezeptor Signalkaskade und hemmt darüber die Proliferation der Tumorzellen (Emons et al. 1997, Gründker et al. 2001). Diese wachstumshemmende Eigenschaft konnte ebenso nach der Stimulation mit GnRH-II sowie dessen Analog [D-Lys ${ }^{6}$ ]GnRH-II gezeigt werden (Tab. 4.1). Die antiproliferative Wirkung des natürlichen GnRH-II Hormons ist sogar stärker als die des GnRH-I und seiner Super-Agonisten. Ebenfalls konnte durch Knock-Down Versuche gezeigt werden, dass GnRH-II nicht über den GnRH-I Rezeptor reguliert wird (Enomoto et al. 2004, Gründker et al. 2004).

Der GnRH-I Rezeptor aktiviert nach Ligandenbindung eine PhosphotyrosinPhosphatase (PTP), die wiederum eine Dephosphorylierung der EGF-Rezeptor-TyrosinKinase hervorruft und dadurch die mitogene Signalkaskade unterbrochen wird.

Es wurde die Aktivität der PTP im GnRH-II Rezeptor System untersucht, ebenso wie die Aktivität der mitogen-aktivierten Proteinkinase (MAPK) extrazellulär-regulierte Kinase (ERK 1/2), die durch Phosphorylierung aktiviert werden und in die EGFRezeptorsignaltransduktionskaskade involviert sind. Sie werden durch die Phosphorylierung an Threonin- bzw. Tyronsinresten durch die MAP Kinase Kinase (MEK) aktiviert und dienen der Informationsübermittlung in den Zellkern. Ebenso sind sie an der Regulation von Zelldifferenzierungs- und Proliferationsvorgängen beteiligt. Es wurde ebenfalls die Expression des ,Immediate Early Response Gens c-fos untersucht. Die Expression dieses Onkogens ist die direkte Antwort (10 bis 15 Minuten nach Stimulation) auf die Aktivierung des EGF-Rezeptors, während die Überexpression des regulatorischen Proteins c-Fos z.B. durch Mutation, eine unkontrollierte Zellproliferation zur Folge hat. 
Tab. 4.1. Antiproliferative Effekte mit jeweils $10 \mu M$ des GnRH-I Agonisten Triptorelin, des GnRH-I Antagonisten Cetrorelix, sowie des GnRH-II in Endometrium (1, 2)- und Ovarialkarzinomzellinen (3-5). Die Zellzahl ist bezogen auf die Kontrolle ( $=100 \%)$.

\begin{tabular}{llll}
\hline \hline Zellinie & Triptorelin & Cetrorelix & GnRH-II \\
\hline 1. Ishikawa & $63.0 \pm 1.8$ & $69.7 \pm 2.2$ & $49.2 \pm 5.7$ \\
2. Hec-1A & $64.9 \pm 4.4$ & $70.1 \pm 2.5$ & $44.1 \pm 4.3$ \\
\hline 3. EFO-21 & $58.4 \pm 2.5$ & $66.1 \pm 3.6$ & $47.8 \pm 3.7$ \\
4. EFO-27 & $69.7 \pm 3.1$ & $\mathbf{9 5 . 3} \pm \mathbf{2 . 0}$ & $\mathbf{9 7 . 0} \pm 2.8$ \\
5. SK-OV-3 & $\mathbf{9 7 . 7} \pm 3.5$ & $63.4 \pm 3.7$ & $48.8 \pm 4.1$ \\
\hline
\end{tabular}

Durch die Untersuchungen dieser verschiedenen Schritte der Wachstumsfaktorrezeptorkaskade sollte geklärt werden, ob durch die GnRH-II Stimulation der untersuchten Endometrium- und Ovarialkarzinomzellinien dieselben Mechanismen eingeleitet werden, wie es bei dem GnRH-I Rezeptor System der Fall ist. Damit sollte der Wirkungsmechanismus des GnRH-II Rezeptorsystems auf Signaltransduktionsebene aufgeklärt werden.

\subsubsection{Untersuchungen der PTP-Aktivität}

\subsubsection{Effekte des GnRH-II Agonisten [D-Lys $\left.{ }^{6}\right] \mathrm{GnRH}-\mathrm{Il}$ in verschiedenen Konzentrationen auf die PTP-Aktivität}

Da im GnRH-I Rezeptorsystem eine PTP mit der mitogenen Signaltranduktion von Wachstumsfaktorrezeptoren interagiert und somit die Zellproliferation hemmt (Gründker et al. 2003), sollte diese Eigenschaft ebenfalls für das GnRH-II System untersucht werden. Nach der GnRH-II Rezeptoraktivierung durch den GnRH-II Agonisten [D-Lys ${ }^{6}$ ]GnRH-II wurde die Erhöhung der Phosphataseaktivität über den Phosphatgehalt mittels PTP-Assay bestimmt.

Die Behandlung der Ovarialkarzinomzellinien EFO-21 und SKOV-3, sowie der Endometriumkarzinomzellinien Hec1A und Ishikawa mit einer aufsteigenden Konzentration (10 pM, $1 \mathrm{nM}, 100 \mathrm{nM}$ und $10 \mu \mathrm{M})$ des GnRH-II Analogs [D- 
Lys $^{6}$ ]GnRH-II zeigte eine deutliche Zunahme der PTP-Aktivität in allen untersuchten Zellinien. Abb. 4.1 stellt die PTP-Aktivität in den Zellinien EFO-21 und Hec1A dar. Es wird deutlich, dass eine Behandlung der Zellen mit einer geringen Konzentration von 10 pM des GnRH-II Analogs [D-Lys ${ }^{6}$ ]GnRH-II keine große Aktivitätssteigerung der Phosphatase zur Folge hat. Bei einer Konzentration von $100 \mathrm{nM}$ des Analogs konnte in allen untersuchten Zellinien die höchste Aktivität festgestellt werden. Ausserdem ist die Zunahme der PTP-Aktivität analog zum Anstieg der GnRH-II Konzentration, wobei sie bei einer Konzentration von $10 \mu \mathrm{M}$ wieder leicht abnimmt.

Nach der statistischen Auswertung mittels one-way ANOVA und Newman Keuls Test, konnte für die Endometriumkarzinomzellinie Hec1A für die Konzentrationen $100 \mathrm{nM}$ und $10 \mu \mathrm{M}$ eine hohe statistische Signifikanz beim Vergleich zur Kontrolle ermittelt werden: $100 \mathrm{nM}(165,7 \% \pm 8,2 \% ; \mathrm{P}<0,001$ vs Kontrolle $)$ und $10 \mu \mathrm{M}(171,5 \% \pm 4,4 \%$, $\mathrm{P}<0,001$ vs Kontrolle). Allerdings wurden keine Signifikanzen für die Ovarialkarzinomzellinie EFO-21 ermittelt. Hier war $\mathrm{P}>0,05$ in allen statistischen Berechnungen. Vergleichbare Ergebnisse konnten für die Ovarialkarzinomzellinie SKOV-3 und die Endometriumkarzinomzellinie Ishikawa unter denselben Bedingungen erzielt werden.

A

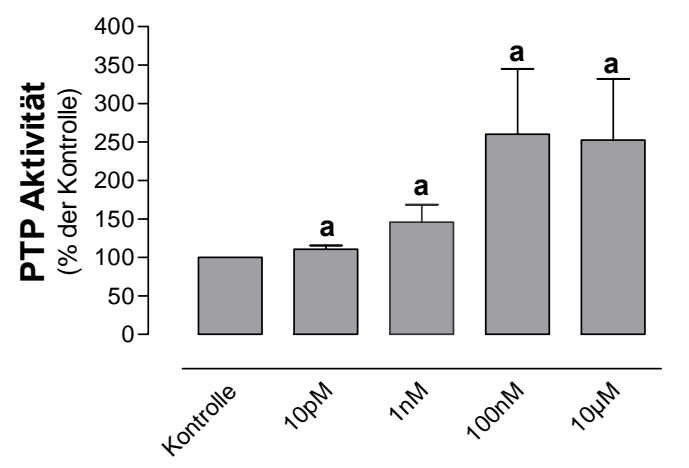

B

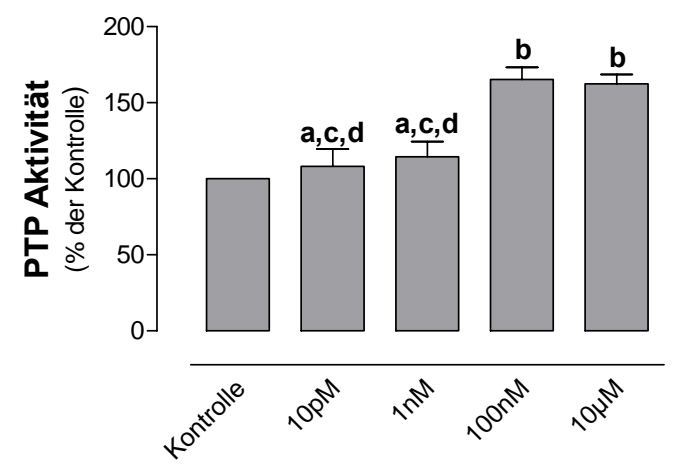

Abb. 4.1: Effekte des GnRH-II Analogs [D-Lys ${ }^{6}$ ]GnRH-II auf die PTP-Aktivität der Zellinien A) EFO-21 (OvarCA) und B) Hec1A (EndoCA). Erster Graph: Kontrolle, zweiter bis fünfter Graph: nach der Stimulation von jeweils 10 pM, 1 nM, 100 nM oder $10 \mu M$ des [D-Lys $\left.{ }^{6}\right] G n R H-I I$ für 1 h. a, P>0,05 vs Kontrolle; $b, P<0,001$ vs Kontrolle; $c, P<0,001$ vs $100 \mathrm{nM}$; $d, P<0,001$ vs $10 \mu M$ (one-way ANOVA und Newman Keuls Test). Die Experimente mit den Zellinien SKOV-3 (OvarCA) und Ishikawa (EndoCA) haben vergleichbare Ergebnisse ergeben. Die Werte leiten sich von drei unabhängigen Versuchen mit jeweils drei unterschiedlichen Passagen ab. 


\subsubsection{Effekte des GnRH-II Analogs [D-Lys ${ }^{6}$ ]GnRH-II in verschiedenen Konzentrationen nach GnRH-I Rezeptor Knock-Down}

Im Gegensatz zu seinem Liganden GnRH-II ist die Existenz des GnRH-II Rezeptors bisher noch nicht geklärt worden. Da das GnRH-II einen stärkeren wachstumsinhibierenden Effekt in gynäkologischen Tumorzellen aufweist als das GnRH-I, kommt ihm eine hohe Bedeutung zu (Gründker et al. 2002). Um festzustellen, ob das GnRH-II bzw. sein Analog [D-Lys ${ }^{6}$ GnRH-II auch einen Einfluss auf die PTPAktivität hat, wenn der GnRH-I Rezeptor nicht mehr auf der Zelloberfäche exprimiert wird, wurde ein Knock-Down des GnRH-I Rezeptors durchgeführt. Zur Internalisierung des Rezeptors erfolgte die Stimulation mit dem GnRH-I Agonisten Triptorelin (100 nM) und eine darauffolgende Behandlung mit [D-Lys $\left.{ }^{6}\right] \mathrm{GnRH}-\mathrm{II}$ in aufsteigender Konzentration (10 pM, $1 \mathrm{nM}, 100 \mathrm{nM})$. In der Ovarialkarzinomzellinie EFO-21 bewirkte die Stimulation mit GnRH-II einen Anstieg der PTP-Aktivität (Abb. 4.2) im Vergleich zur Kontrolle II. Die Aktivität steigt wieder proportional zur GnRH-II Konzentrationszunahme an. Es konnte mit einer Konzentration von $100 \mathrm{nM}$ die maximale PTP-Aktivität erreicht werden. Die Zellen beider verwendeten Kontrollen wurden transfiziert, allerdings fand nur bei der Kontrolle II eine Stimulation mit Triptorelin statt. Keine der Referenzen wurde mit [D-Lys ${ }^{6}$ GnRH-II behandelt.

Die statistische Auswertung ergab für die Zellinie EFO-21, dass mit einer Konzentration von $100 \mathrm{nM}$ [D-Lys ${ }^{6}$ ] GnRH-II eine hohe statistische Signifikanz in der PTP-Aktivität, beim Vergleich zur Kontrolle I und II ermittelt werden konnte (183,6\% \pm $11,6 \%, \mathrm{P}<0,01$ vs Kontrolle I und $\mathrm{P}<0,01$ vs Kontrolle II). Bei einer Konzentration von $100 \mathrm{nM}$ ist die PTP-Aktivität auch im Gegensatz zu den Aktivitäten erhöht, die mit $10 \mathrm{pM}(119,3 \% \pm 2,1 \%)$ und mit $1 \mathrm{nM}(139,5 \% \pm 4,8 \%)$ erreicht werden, hier ist $\mathrm{P}<0,01$ in beiden Fällen. Zwischen den Kontrollen und der Phosphataseaktivität mit $10 \mathrm{pM}$ und $1 \mathrm{nM}$ konnten keine Signifikanzen nachgewiesen werden. Die Experimente mit der Ovarialkarzinomzellinie SKOV-3 und den Endometriumkarzinomzellinien Ishikawa und Hec1A haben vergleichbare Ergebnisse ergeben. 


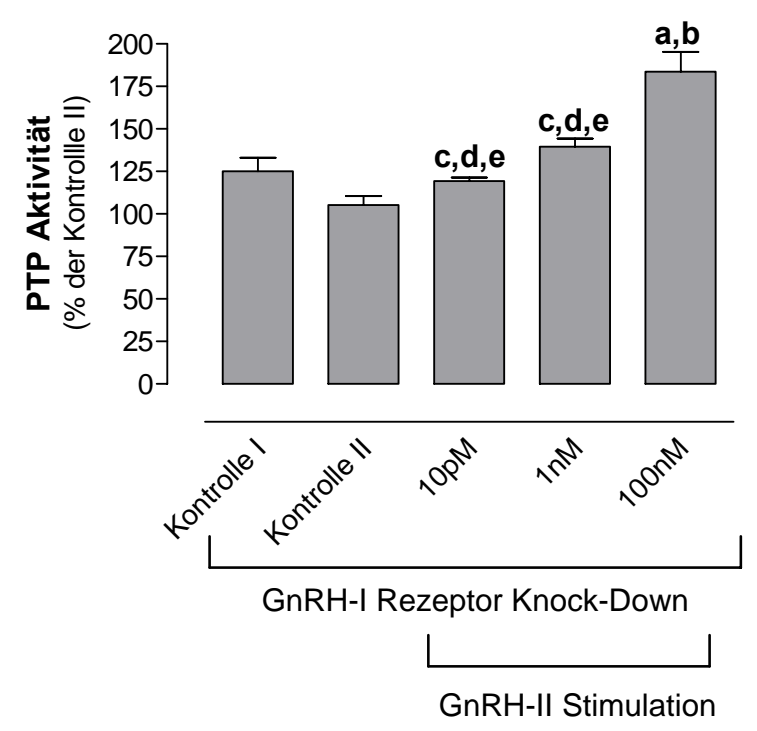

Abb. 4.2: Effekte des GnRH-II Analogs [D-Lys $\left.{ }^{6}\right]$ GnRH-II auf die PTP-Aktivität nach GnRH-I Rezeptor Knock-Down in der Zellinie EFO-21 (OvarCA). Erster Graph: Kontrolle I (Knock-Down), zweiter Graph: Kontrolle II (Knock-Down und GnRH-I Stimulation für $6 \mathrm{~h}$ ), dritter bis fünfter Graph: Knock-Down, GnRH-I Stimulation für $6 \mathrm{~h}$, Stimulation mit jeweils $10 \mathrm{pM}, 1 \mathrm{nM}$ oder $100 \mathrm{nM}$ des [D-Lys $\left.{ }^{6}\right] \mathrm{GnRH}$-II für 1 h. a, $P<0,01$ vs Kontrolle I; $b, P<0,01$ vs Kontrolle II; $c, P<0,01$ vs 100 nM; $d, P>$ 0,05 vs Kontrolle I; $e, P>0,05$ vs 10 Kontrolle II (one-way ANOVA und Newman Keuls Test). Die Experimente mit den Zellinien SKOV-3 (OvarCA),Ishikawa (EndoCA) und Hec1A (EndoCA) haben vergleichbare Ergebnisse ergeben. Die Werte leiten sich von drei unabhängigen Versuchen mit jeweils drei unterschiedlichen Passagen ab.

\subsubsection{Nachweis der GnRH-II Rezeptor-mRNA Expression nach GnRH-I Rezeptor Knock-Down}

Um den Einfluss des GnRH-I Rezeptor Knock-Downs auf die GnRH-II Rezeptor mRNA Expression zu untersuchen, wurden die tranzfizierten Ovarialkarzinomzellinien EFO-21 und NIH:OVCAR-3 sowie die Endometriumkarzinomzellinien Hec1A und Ishikawa verwendet. Die Expression wurde jeweils nach 6, 12, 24, 48, 72 und $96 \mathrm{~h}$ nach der Transfektion und nach Internalisierung des GnRH-I Rezeptors durch die Stimulation mit Triptorelin bestimmt. Ein 313 bp langes Fragment wurde mittels GnRH-II Rezeptor-spezifischen Primern in der PCR amplifiziert. Die quantitative Bestimmung 
der GnRH-II Rezeptor-mRNA Expression erfolgte anhand der Expression des Housekeeping Gens GAPDH in denselben Zellinien. Abb. 4.3 zeigt exemplarisch den zeitabhängigen Verlauf der GnRH-II Rezeptor-mRNA Expression in den Zellinien EFO-21 und Ishikawa. In beiden Diagrammen wird erst nach $48 \mathrm{~h}$ ein leichter Anstieg der Expression im Gegensatz zu den unbehandelten Zellen (Kontrolle) sichtbar. Nach $72 \mathrm{~h}$ ist dieser Anstieg sehr deutlich und nimmt nach $96 \mathrm{~h}$ in der Zellinie Ishikawa nochmals sichtbar zu, während bei EFO-21 wiederum nur eine geringe Erhöhung der Expression zu erkennen ist. NIH:OVAR-3 und Hec1A verhalten sich in ihrer GnRH-II Rezeptor-mRNA Expression ähnlich wie EFO-21. Die statistische Auswertung (oneway ANOVA und Newman Keuls Test) ergab, dass die GnRH-II Rezeptor Expression bis zum Zeitpunkt von 48 h noch keine Signifikanz zeigte ( $\mathrm{P}>0,05$ in allen Fällen). Nach 72 h konnte in beiden Zellinien eine hohe statistische Signifikanz, gegenüber der Kontrolle errechnet werden (Ishikawa/72 h: 176,5\% $\pm 34,8 \%, \mathrm{P}<0,01$ vs Kontrolle; EFO-21/72 h: 207,9\% $\pm 22,7 \%, \mathrm{P}<0,001$ vs Kontrolle). In der Ovarialkarzinomzellinie EFO-21 nahm die Expression nach 96 h nochmals signifikant zu (P $<0,001$ vs 72 h), während bei der Endometriumkarzinomzellinie Ishikawa keine Signifikanz mehr nachgewiesen werden konnte. Die Werte leiten sich von drei unterschiedlichen Versuchen mit jeweils versiedenen Passagen ab.

A

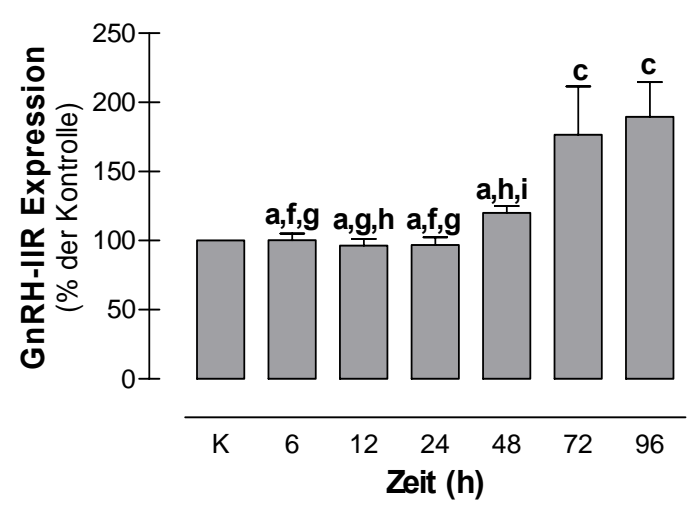

B

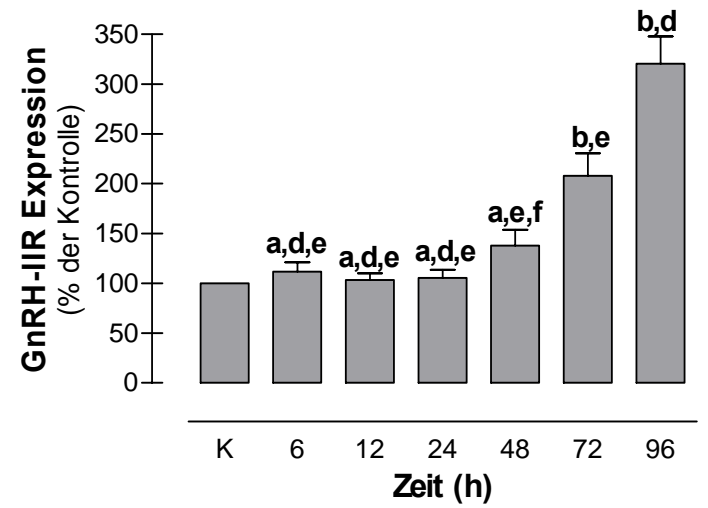

Abb. 4.3: Zeitabhängige GnRH-II Rezeptor-mRNA Expression nach GnRH-I Rezeptor Knock-Down. A) Ishikawa (EndoCA), B) EFO-21 (OvarCA). Erster Graph: GnRH-II Rezeptor-mRNA Expression in unbehandelten Zellen (K), zweiter bis siebter Graph: GnRH-II Rezeptor-mRNA Expression, jeweils 6, 12, 24, 48, 72 und 96 $h$ nach GnRH-I Rezeptor Knock-Down. a, $P>0,05$ vs Kontrolle; b, $P<0,001$ vs Kontrolle; $c, P<0,01$ vs Kontrolle; $d, P<0,001$ vs 72 h; $e, P<0,001$ vs 96 h; $f, P<$ 0,01 vs 72 h; g, $P<0,01$ vs 96 h; $h, P<0,05$ vs 72 h; i, P<0,05 vs 96 h. 


\subsubsection{Effekte des GnRH-II Agonisten [D-Lys $\left.{ }^{6}\right] \mathrm{GnRH}-$ Il auf die EGF- induzierte MAPK (ERK1/2) Aktivität}

Weitere Untersuchungen konzentrierten sich auf die Effekte von [D-Lys ${ }^{6}$ ]GnRH-II auf die EGF-induzierte Aktivität der extrazellulär-regulierten Kinasen 1 und 2 (ERK1/2). In früheren Studien konnten bereits Veränderungen der MAPK Aktivitäten der nach Stimulation mit dem GnRH-I Agonisten Triptorelin nachgewiesen werden (Emons et al. 1996).

Die untersuchten Ovarialkarzinomzellinien EFO-21 und SKOV-3 sowie die Endometriumkarzinomzellinien Ishikawa und Hec1A zeigten nach der Behandlung mit EGF (100 nM) für 15 min einen signifikanten Anstieg der MAPK Aktivität. Dies ist in Abb. 4.4 sowohl im Western Blot Gel, als auch in der grapischen Darstellung deutlich zu sehen. Die anschließende Stimulation mit dem GnRH-II Analog [D-Lys ${ }^{6}$ ]GnRH-II $(10 \mu \mathrm{M})$ für $15 \mathrm{~min}$ induziert die Downregulierung der MAPK Aktivität wie es ebenfalls in der Abb. 4.4 zu erkennen ist. Um die aktive ERK1/2 zu detektieren, wurde ein polyklonaler anti-active MAPK Antikörper eingesetzt, der die phosphorylierte aktive Form von ERK1 (44 kDa) und ERK2 (42 kDa) erkennt. Die Ergebnisse sind exemplarisch für die Zellinien SKOV-3 und Ishikawa in der Abb. 4.4 dargestellt.

Die EGF-Stimulation bewirkt einen signifikanten Anstieg der MAPK Aktivität, sowohl in der Ovarialkarzinomzellinie SKOV-3 (SKOV-3/EGF: 286,0\%+/- 56,9\%, P < 0,05 vs Kontrolle), als auch in der Endometriumkarzinom- zellinie Ishikawa (Ishikawa/EGF: $161,2 \%+/-23,9 \%, \mathrm{P}<0,05$ vs Kontrolle). Die zusätzliche Behandlung der Zellen mit dem GnRH-II Analog [D-Lys ${ }^{6}$ ]GnRH-II bewirkte eine Reduktion dieser Enzymaktivität in beiden Zellinien (SKOV-3/G/E: 133,6\% +/- 21.5\%, P < 0,01 vs EGF; Ishikawa/G/E: $99,1 \%+/-10,2 \%, \mathrm{P}<0,05$ vs EGF). Die statistische Auswertung erfolgte ebenfalls mittel one-way ANOVA und Newman Keuls Test. Die Zellinien EFO-21 und Hec1A zeigten unter denselben Bedingungen vergleichbare Ergebnisse in der MAPK Aktivität. 
A

B
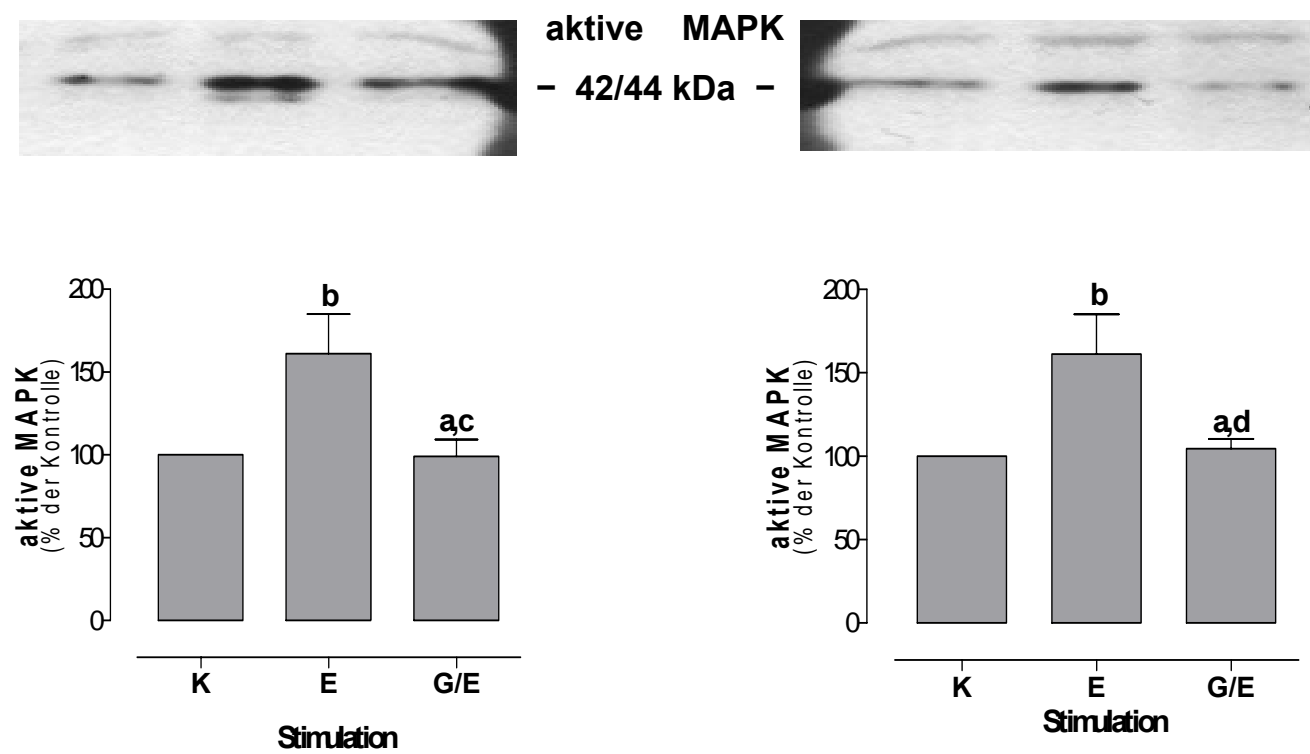

Abb. 4.4: Western Blot Analyse der phosphorylierten MAPKn ERK1/2 in den Zellinien A) Ishikawa (EndoCA) und B) SKOV-3 (OvarCA). Erster Graph: unbehandelte Zellen (K), zweiter Graph: Stimulation mit EGF (100 nM) für 15 min, dritter Graph: Stimulation mit [D-Lys6]GnRH-II (10 $\mu M)$ und EGF (100 nM) für 15 min. Es wurde ein polyklonaler anti-active Antikörper verwendet, der die phosphorylierte aktive Form von ERK1 (44 kDa) und ERK2 (42 kDa) detektiert. a, $P$ $>0,05$ vs Kontrolle; $b, P<0,05$ vs Kontrolle; $c, P<0,05$ vs EGF; $e, P<0,01$ vs EGF (one-way ANOVA und Newman Keuls Test). Alle angegebenen Daten leiten sich von drei unabhängigen Versuchen mit jeweils drei unterschiedlichen Passagen ab. Die Zellinien EFO-21 (OvarCA) und Hec1A (EndoCA) zeigten unter denselben Bedingungen vergleichbare Ergebnisse in der MAP-Kinase Aktivität.

\subsubsection{Effekte des GnRH-II Agonist [D-Lys $\left.{ }^{6}\right] \mathrm{GnRH}-\mathrm{Il}$ auf die EGF-induzierte c-fos Expression}

Frühere Untersuchungen haben bereits ergeben, dass die Behandlung von Ovarial- und Endometriumkarzinomzellinien mit dem GnRH-I Agonisten Triptorelin eine Expressionsabnahme des ,Immediate Early Response` Gens c-fos induziert (Gründker et al. 2000). Aufgrund dieser Tatsache wurde die Expression der c-fos-mRNA, sowie dessen Protein in den Zellinien EFO-21, SKOV-3, Hec1A und Ishikawa, nach der Stimulation mit dem GnRH-II Agonisten [D-Lys ${ }^{6}$ ]GnRH-II und/oder dem EGFRezeptor Liganden EGF, untersucht. 
Nach der Inkubation der Zellinien mit $100 \mathrm{nM}$ des ,Epidermal Growth Factorse (EGF), erfolgte die Behandlung mit $10 \mu \mathrm{M}$ [D-Lys $\left.{ }^{6}\right] \mathrm{GnRH}-\mathrm{II}$, um festzustellen ob der Agonist der EGF-induzierten $c$-fos-Expression entgegen wirken kann und diese inhibiert.

Die Stimulation der Zellen mit EGF für 30 min bewirkte eine bemerkenswerte Zunahme der c-fos-mRNA Expression in allen untersuchten Zellinien, während eine [DLys $^{6}$ ]GnRH-II-bedingte Expressionsabnahme beobachtet werden konnte. Die exprimierte $c$-fos-mRNA wurde mittels semiquantitativer RT-PCR mit $c$-fos spezifischen Primern im Vergleich zu der mRNA Expression des Housekeeping Gens GAPDH durchgeführt (Abb. 4.4A).

In Abb. 4.4 sind exemplarisch die Zellinien Ishikawa und SKOV-3 dargestellt. In der unteren Graphik wird deutlich, dass eine Stimulation mit $10 \mu \mathrm{M}$ [D-Lys $\left.{ }^{6}\right] \mathrm{GnRH}-\mathrm{II}(\mathrm{G})$ keinen signifikanten Anstieg in der c-fos-mRNA Expression induziert (SKOV-3/[DLys $^{6}$ ]GnRH-II: $134.0 \%+/-24.1 \%, \mathrm{P}>0.05$ vs Kontrolle; Ishikawa/[D-Lys ${ }^{6}$ ]GnRH-II: $97.4 \%+/-23.5 \%, \mathrm{P}>0.05$ vs Kontrolle). Nach der Stimulation mit 100 nM EGF (E) ist allerdings eine deutliche Zunahme zu verzeichnen, die in beiden dargestellten Zellinien entweder signifikant oder hoch signifikant im Vergleich zur Kontrolle ist (SKOV3/EGF: $972.4 \%+/-284.0 \%, \mathrm{P}<0.05$ vs Kontrolle und Ishikawa/EGF: 579.2\% +/$131.5 \%, \mathrm{P}<0.001$ vs Kontrolle). Der Vergleich der $c$-fos Expression zwischen [DLys $\left.^{6}\right]$ GnRH-II und EGF behandelten Zellen zeigt ebenfalls eine hohe statistische Signifikanz in beiden Zellinien $\left(\mathrm{P}<0.01\left[{\mathrm{D}-\mathrm{Lys}^{6}}^{6}\right.\right.$ GnRH-II vs EGF in SKOV-3 und $\mathrm{P}<$ 0.001 [D-Lys $^{6}$ ] GnRH-II vs EGF in Ishikawa). Zwischen den Zellen, die nur mit EGF behandelt wurden und denen, die eine zusätzliche Stimulation mit [D-Lys ${ }^{6}$ GnRH-II bekamen, kann in der Ovarialkarzinomzelllinie SKOV-3 zwar keine $(\mathrm{P}>0.05)$, in der Endometriumkarzinomzellinie Ishikawa dafür eine hohe Signifikanz errechnet werden (Ishikawa/[D-Lys $\left.{ }^{6}\right]$ GnRH-II/EGF: $188.1 \%+/-41.2 \%, \mathrm{P}<0.001$ vs EGF). 
A

B
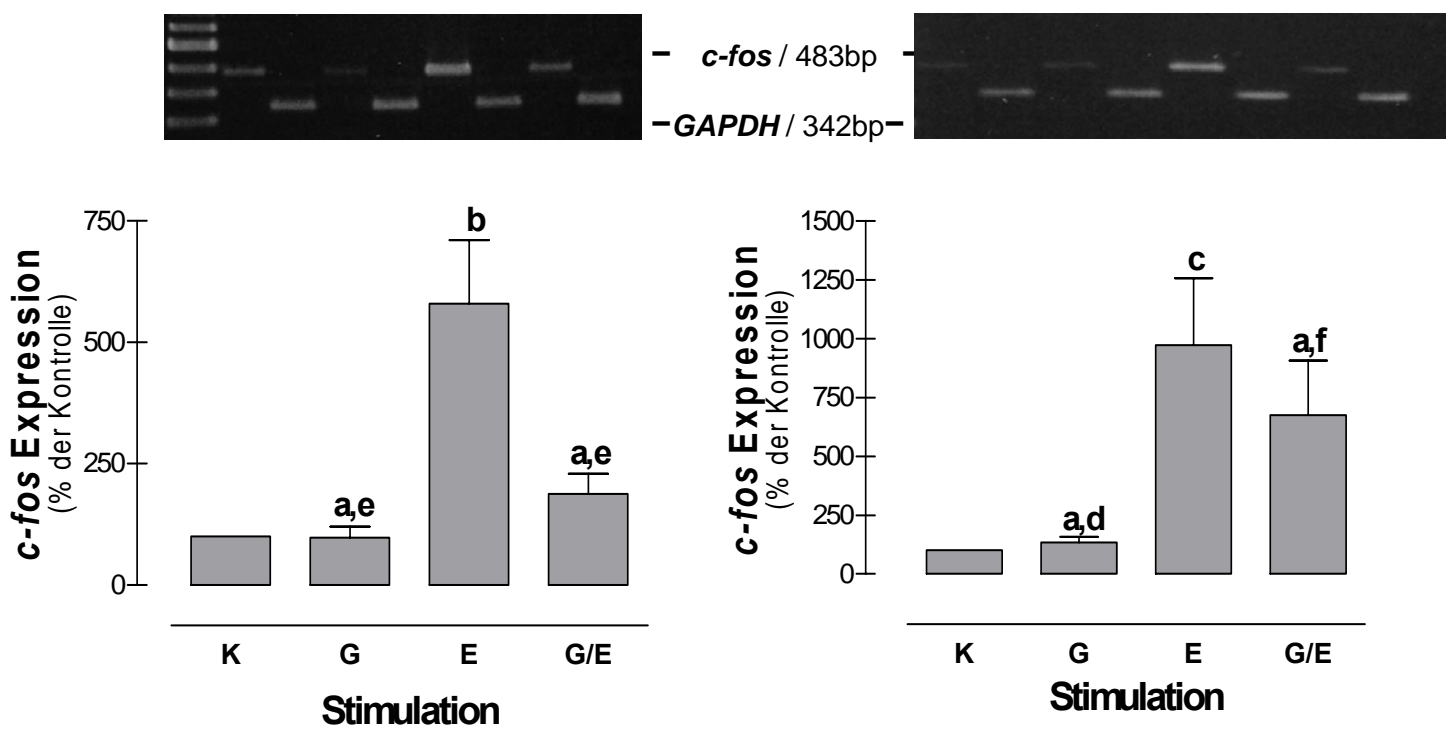

Abb. 4.5: Nachweis der c-fos-mRNA Expession mittels semiquantitativer RT-PCR in den Zellinien A) Ishikawa (EndoCA) und B) SKOV-3 (OvarCA). Erster Graph: unbehandelte Zellen (K), zweiter Graph: Stimulation mit $10 \mu M$ [D-Lys $\left.{ }^{6}\right]$ GnRH-II für $1 \mathrm{~h}$, dritter Graph: Stimulation mit $100 \mathrm{nM}$ EGF für 30 min und vierter Graph: Stimulation mit $10 \mu M$ [D-Lys6]GnRH-II für 1 h und mit 100 nM EGF für 30 min. Die Expression des Housekeeping Gens GAPDH (342 bp) wurde als Standard verwendet. $a, P>0,05$ vs Kontrolle; $b, P<0,001$ vs Kontrolle; $c, P<0,05$ vs Kontrolle; $d, P<0,01$ vs EGF; $e, P<0,001$ vs EGF; $f, P>0,05$ vs EGF (one-way ANOVA und Newman Keuls Test). Alle angegebenen Daten leiten sich von drei unabhängigen Versuchen mit jeweils drei unterschiedlichen Passagen ab, wobei alle untersuchten Zellinien dieselben Tendenzen in der c-fos Expression aufweisen.

Anschließend wurde untersucht, ob sich die Expression des c-Fos Proteins ähnlich verhält, wie die Expression der mRNA in gynäkologischen Tumorzellen. Es wird demnach ein Anstieg nach der Behandlung mit EGF und eine Reduktion der Expression mit dem GnRH-II Analog [D-Lys ${ }^{6}$ ]GnRH-II erwartet.

Zur Detektion des Proteins wurde ein polyklonaler c-Fos spezifischer Antikörper verwendet, der eine Bande bei $62 \mathrm{kDa}$ erkennt (Abb. 4.6). Die Zellinien wurden wie oben beschrieben behandelt. Die Daten der Proteinexpression bestätigen die Daten der c-fos-mRNA Expression. 
Nach der Stimulation der Zellen mit 100 nM EGF für 15 min, konnte ebenfalls ein deutlicher Anstieg in allen untersuchten Zellinien verzeichnet werden (C). Um den Nachweis zu erbringen, dass das [D-Lys $\left.{ }^{6}\right] \mathrm{GnRH}-\mathrm{II}$ eine inhibierende Wirkung auf die EGF-induzierte c-Fos Expression hat, wurden die Zellen vorher mit dem GnRH-II Analog inkubiert (D).

Die Abb. 4.6 stellt die c-Fos Proteinexpressionen nach den verschieden Stimulationen in der Endometriumkarzinomzellinie Ishikawa dar. Nach der statistischen Auswertung konnten allerdings keine statistischen Signifikanzen festgestellt werden $(\mathrm{P}>0,05$ in allen Fällen). Die Ovarialkarzinomzellinien EFO-21 und SKOV-3, sowie die Endometriumkarzinomzellinie Hec1A zeigten die gleichen Tendenzen in der Expression, jedoch wurden auch hier keine Signifikanzen ermittelt.

A

B

C

D
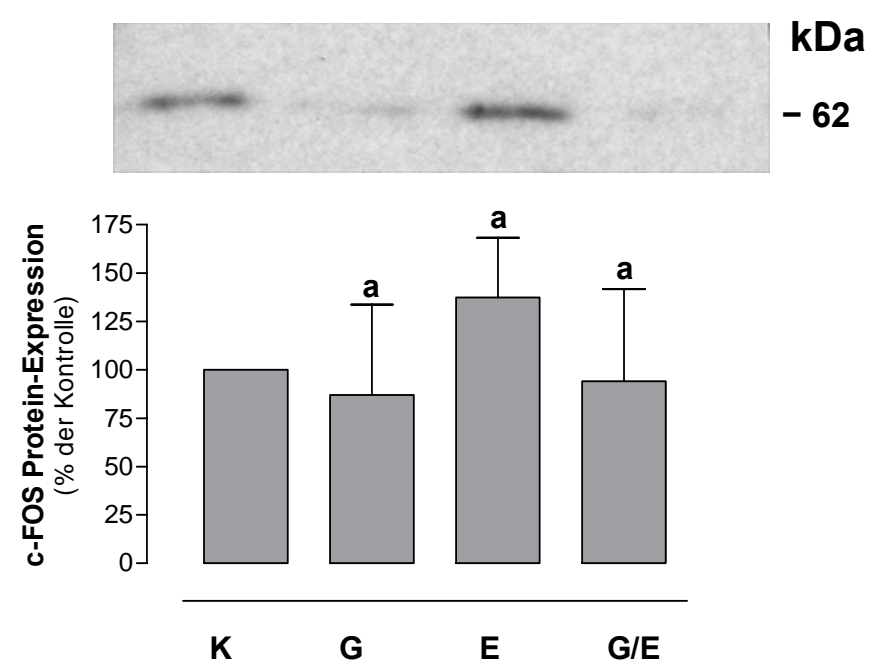

Abb. 4.6: Quantitativer Western Blot der c-Fos Proteinexpression in der Endometriumkarzinomzellinie Ishikawa. Erster Graph: unbehandelte Zellen (K), zweiter Graph: Stimulation mit [D-Lys $\left.{ }^{6}\right]$ GnRH-II (10 $\left.\mu M\right)$ für 1h, dritter Graph: Stimulation mit EGF (100 nM) für 30 min, vierter Graph: Stimulation mit [DLys $^{6}$ JGnRH-II (10 $\left.\mu M\right)$ für 1 h und EGF (100 nM) für 30 min. Zur Detektion wurde ein polyklonales rabbit anti-c-Fos Antiserum verwendet, welches eine Bande bei 62 kDa erkennt. a, P>0,05 in allen Fällen (one-way ANOVA und Newman Keuls Test). Alle angegebenen Daten leiten sich von drei unabhängigen Versuchen mit jeweils drei unterschiedlichen Passagen ab. Die Zellinien EFO-21 (OvarCA), SKOV3 (OvarCA) und Hec1A (EndoCA) zeigten unter denselben Bedingungen vergleichbare Ergebnisse in der Proteinexpression. 


\subsection{Nachweis des GnRH-II Rezeptor Proteins}

Seit 1997 versuchen verschiedene Arbeitsgruppen den GnRH-II Rezeptor zu charakterisieren und ein funktionelles Transkript nachzuweisen (Millar et al. 1999, Millar et al. 2001, Neill et al. 2001, Neill 2002), um seine Funktionen untersuchen zu können. Die vollständige Sequenz konnte bisher allerdings noch nicht identifiziert werden (Millar 2003).

In dieser Arbeit sollte die Existenz des GnRH-II Rezeptor Proteins nachgewiesen werden. Um den Nachweis des Proteins zu erbringen, wurde ein polyklonales Antiserum generiert, welches gegen die hochkonservierte dritte extrazelluläre Domäne des Callithrix jacchus (Weißbüschelaffe) GnRH-II Rezeptors gerichtet ist (Millar et al. 2002). Eine Datenbankanalyse zeigte, dass die Aminosäuresequenz nur eine Homologie zum putativen humanen GnRH-II Rezeptor aufweist. Allerdings wurden zwei Peptide gefunden, die in Teilen eine ähnliche Aminosäuresequenz aufweisen. Um Kreuzreaktionen ausschliessen zu können, erfolgte die Aufreinigung des GnRH-II Rezeptor Antiserums über eine Chromatographiesäule, an die diese Peptide gebunden waren.

\subsubsection{GnRH-II Rezeptor Antiserum Spezifität an Gewebeschnitten des Callithrix jacchus-Ovars}

Die Spezifität des GnRH-II Rezeptor Antiserums wurde an Gewebeschnitten des Callithrix jacchus-Ovars getestet. Im linken Gewebeschnitt (Abb. 4.7) fand eine Inkubation mit dem rabbit anti-human GnRH-II Rezeptor Antiserum für $1 \mathrm{~h}$ statt. Es ist eine starke Braunfärbung des Oberfächenepithels erkennbar, die durch das eingesetzte Chromogen hervorgerufen wird. Als Negativkontrolle wurde die Behandlung desgleichen Gewebes mit dem Serum vor der Immunisierung durchgeführt. Wie im rechten Gewebeschnitt der Abb. 4.7 zu erkennen ist, findet dort keine Farbreaktion statt. Die Färbung ist demnach antikörperspezifisch. 

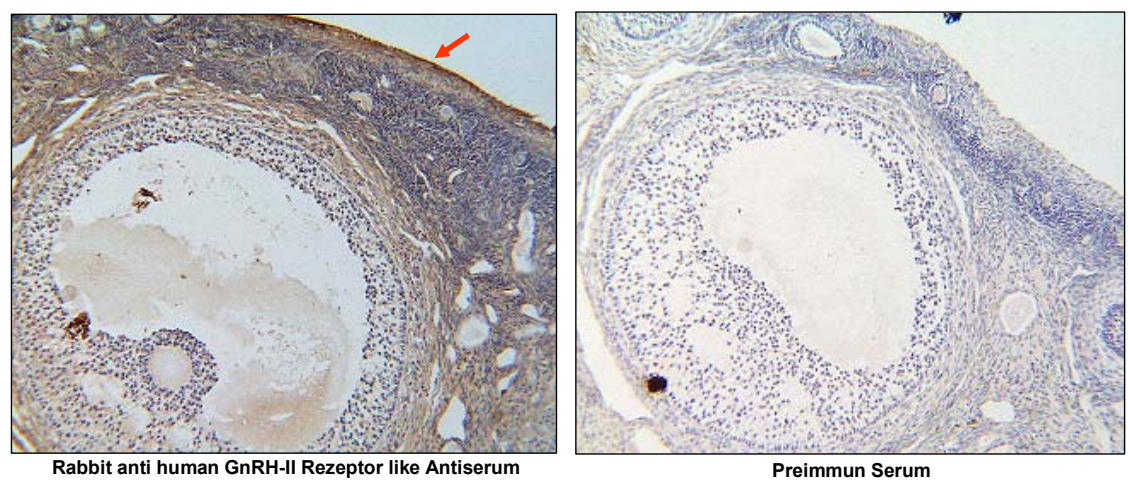

Abb. 4.7: GnRH-II Rezeptor Antiserum Spezifität an Gewebeschnitten des Callithrix jacchus-Ovars. Links: Inkubation für $1 \mathrm{~h}$ mit dem rabbit anti-human GnRH-II Rezeptor Antiserum, rechts: Inkubation für $1 \mathrm{~h}$ mit dem Preimmun-Serum.

\subsubsection{Immunhistochemischer Nachweis der GnRH-II Rezeptor Expression in humanen reproduktiven Geweben}

Zum Nachweis, dass in humanen reproduktiven Geweben der putative GnRH-II Rezeptor exprimiert wird, wurden verschiedene Gewebeschnitte mit dem GnRH-II Rezeptor Antiserum behandelt (Abb. 4.8). Abb. 4.8A zeigt die immunhistochemische Färbung eines Plazentaquerschnittes (25ste Woche). Die Färbung des Chorionepithels (c) ist gut zu erkennen. Ebenso deutlich ist die Braunfärbung der Epithelzellen (e) des Endometriumkarzinoms (B) zu erkennen. Es wird allerdings auch deutlich, dass einige Zellen eine höhere GnRH-II-ähnliche Antigenität aufweisen (Pfeile) als andere. Die Epithelzellen des getesteten Ovarialkarzinomgewebes (C) sind ebenfalls positiv für GnRH-II Rezeptor Antigenität. Das Stroma (s) lässt eine zarte Färbung erkennnen. Im Gegensatz dazu ist im Stroma beim Prostatakarzinom (D) keine GnRH-II Rezeptorähnliche Antigenität erkennbar. Die Epithelzellen dieses Tumorgewebes weisen allerdings eine starke Färbung auf, wobei auch hier wieder einige Zellen stärker GnRH-II Rezeptor-positiv sind, als andere (Pfeile).

Als Kontrollen wurden dieselben Gewebe mit dem Preimmun-Serum desselben Kaninchens behandelt. In allen untersuchten Geweben, konnte eine Braunfärbung des Epithels ausgeschlossen werden. 

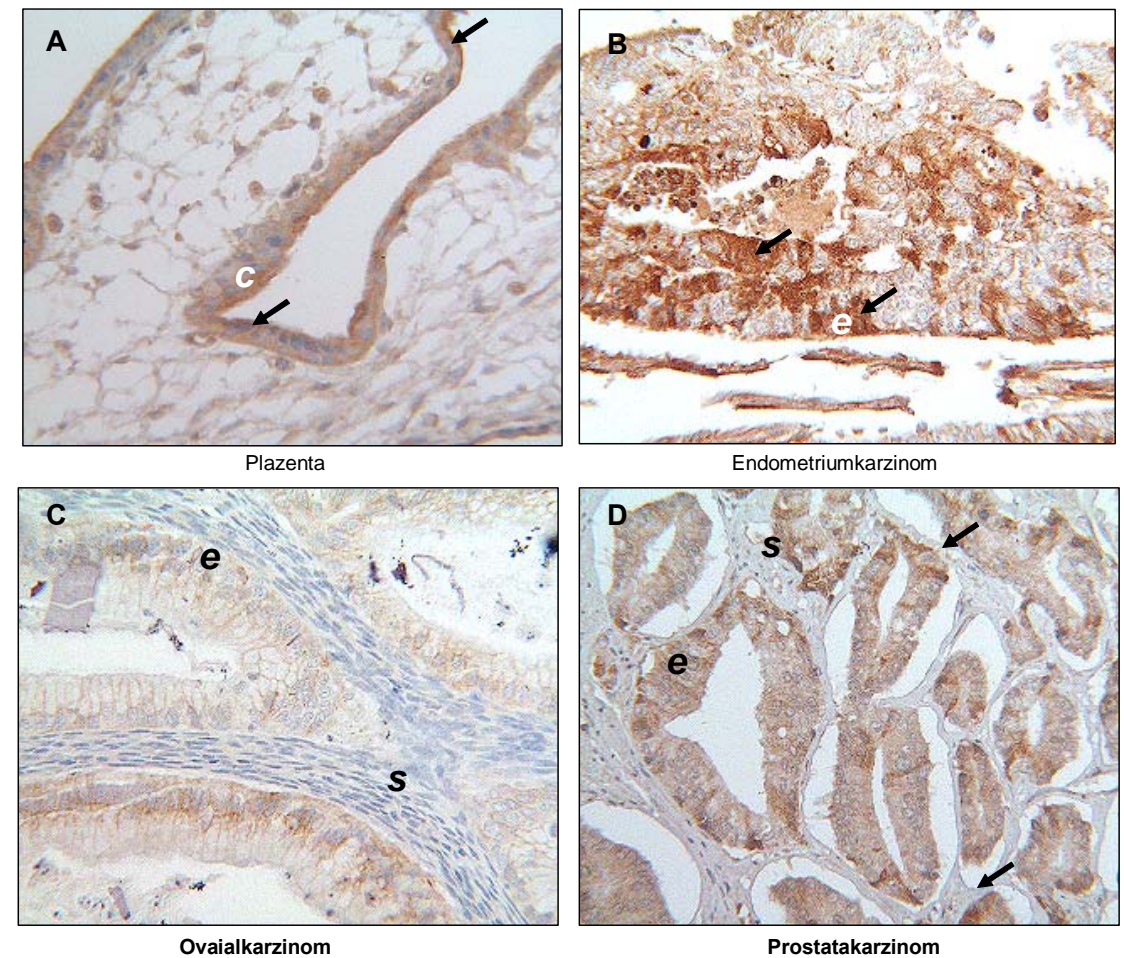

Abb. 4.8: Immunhistochemischer Nachweis der GnRH-II Rezeptor Expression in humanen reproduktiven Geweben mittels rabbit anti-human GnRH-II Rezeptor Antiserum A) Plazenta, B) Endometriumkarzinom, C) Ovarialkarzinom und D) Prostatakarzinom

\subsubsection{Western Blot Analyse des GnRH-II Rezeptor-ähnlichen Proteins an Zellmembranfraktionen}

Für die Untersuchung der putativen GnRH-II Rezeptorproteinexpression und Proteingröße, wurde eine Western Blot Analyse durchgeführt. Unter Anwendung des rabbit anti-human GnRH-II Rezeptor Antiserums wurden die Membranpräparationen der humanen Endometriumkarzinomzellinien Ishikawa und Hec1A, sowie der Ovarialkarzinomzellinien EFO-21 und SKOV-3 auf ihre Antigenität getestet und in der SDS-PAGE aufgetrennt. In allen untersuchten Zellinien wurde eine Bande bei $43 \mathrm{kDa}$ detektiert (Abb. 4.9). Die Membranpräparationen von Ovarien des Weißbüschelaffens zeigten eine Bande bei $54 \mathrm{kDa}(\mathrm{E})$. 


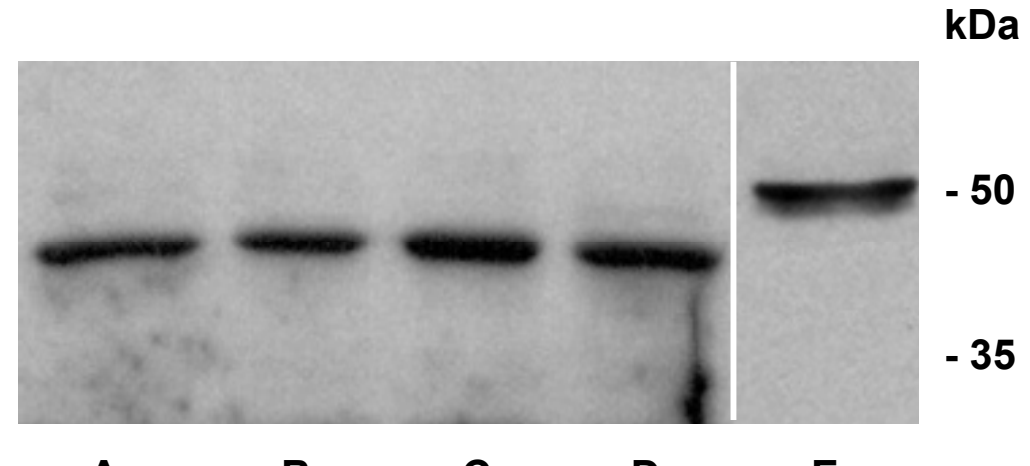

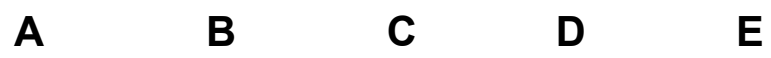

\begin{abstract}
Abb. 4.9: Western Blot Analyse des GnRH-II Rezeptor-ähnlichen Proteins an Zellmembranfraktionen A) Ishikawa (EndoCA), B) Hec1A (EndoCA), C) EFO-21 (OvarCA), D) SKOV-3 (OvarCA) und E) Callithrix jacchus-Ovar. Zur Detektion wurde das rabbit anti-human GnRH-II Rezeptor Antiserum verwendet. Alle angegebenen Daten leiten sich von drei unabhängigen Versuchen mit jeweils drei unterschiedlichen Passagen ab.
\end{abstract}

\title{
4.2.4 Deglykosilierung des putativen GnRH-II Rezeptor Proteins
}

In der Literatur wird das Molekulargewicht des nicht-glykosilierten Callithrix jacchus GnRH-II Rezeptors mit einer Größe von $42 \mathrm{kDa}$ beschrieben (Faurholm et al. 2001). Um nachzuweisen, dass es sich bei dem eingesetzten Protein des Affenovars, um eine glykosilierte Form handelt, wurden mit dem ,Enzymatic Protein Deglykosylation Kit von Sigma mehrere Deglykosilierungsschritte des Glykoproteins durchgeführt. Zur Bestimmung des Molekulargewichts wurden die Proteine jeweils nach jedem Deglykosilierungsschritt in der SDS-PAGE aufgetrennt. Abb. 4.10A zeigt den glykosilierten Zustand des GnRH-II Rezeptorproteins mit einem Molekulargewicht von $54 \mathrm{kDa}$. Nach Zugabe der Glykosidase PNGase F (Chryseobacterium) konnte man eine Reduktion des Molekulargewichtes um ca. $10 \mathrm{kDa}$ erkennen (II). Die darauffolgenden Reaktionen mit den Glykosidasen: $\alpha$-2 Neuraminidase (Arthrobacter ureafaciens) (III), O- Glykosidase (Streptococcus pneumonia) (IV) und $\beta(1-4)$-Galactosidase (Streptococcus pneumonia) (V) verursachten keine weiteren Molekulargewichtsveränderungen des GnRH-II Rezeptorproteins.

In Abb. 4.10B wurden die Membranfraktionen der Ovarialkarzinomzellinie EFO-21 mit den Glykosidasen II, III und IV behandelt und in der SDS-PAGE aufgetrennt. Es konnte keine Veränderung des Molekulargewichtes durch Deglykosilierung festgestellt werden. 
A

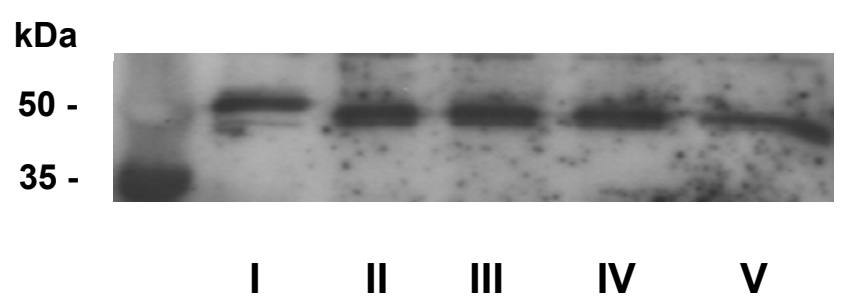

B

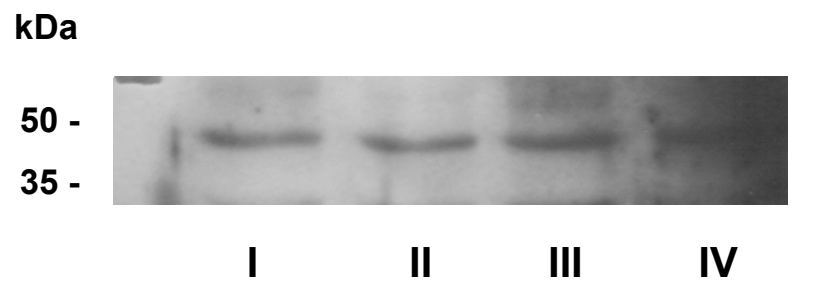

Abb. 4.10: Deglykosilierung des GnRH-II Rezeptorproteins mittels Enzymatic Protein Deglykosylation Kit (Sigma). A) Callithrix jacchus Ovar, B) EFO-21 (OvarCA). I: GnRH-II Rezeptorprotein, II-IV: GnRH-II Rezeptorprotein nach verschiedenen Glykosilierungsschritten. Auftrennung mittels SDS-PAGE.

\subsubsection{Photoaffinitätsmarkierung als Nachweis eines GnRH-II Rezeptor ähnlichen Proteins}

Um nachzuweisen, dass es sich bei dem untersuchten Rezeptor tatsächlich um die Bindungsstelle für das GnRH-II handelt, wurde die Methode der Photoaffinitätsmarkierung durchgeführt (Abb 4.10).

Der Ligand (GnRH-II) wurde mit dem radioaktiven Isotop ${ }^{125} \mathrm{I}$ markiert und danach zusammen mit den Zellmembranfraktionen inkubiert, damit sich ein ${ }^{125}$ I-[D-Lys $\left.{ }^{6}\right]$ GnRH-II - GnRH-II Rezeptor-Komplex bilden konnte. Dieser Komplex wurde mittels SDS-PAGE nachgewiesen. Durch die photochemische Reaktion konnten nur die Rezeptoren nachgewiesen werden, die auch das markierte ${ }^{125} \mathrm{I}-\mathrm{GnRH}-\mathrm{II}$ gebunden haben. Die hierzu untersuchten Ovarialkarzinomzellinien EFO-21 und SKOV-3 wiesen nach der Photoaffinitätsmarkierung ebenfalls eine Bande bei $43 \mathrm{kDa}$, nach der Auftrennung im Gel, auf. In der Ovarialkarzinomzellinie EFO-27 konnte allerdings keine Bande detektiert werden (A). Diese Zellinie ist bereits aus der Literatur dafür bekannt, dass sie keinen GnRH-II Rezeptor zu exprimieren scheint (Gründker et al. 2002). 
In einer Western Blot Analyse desselben Gels mit dem rabbit anti-human GnRH-II Rezeptor Antiserum konnte die Bande von $43 \mathrm{kDa}$ als GnRH-II Rezeptor-ähnliches Protein in den Zellinien EFO-21 und SKOV-3 identifiziert werden. EFO-27 zeigte wiederum keine GnRH-II Rezeptor Antigenität (B).

A

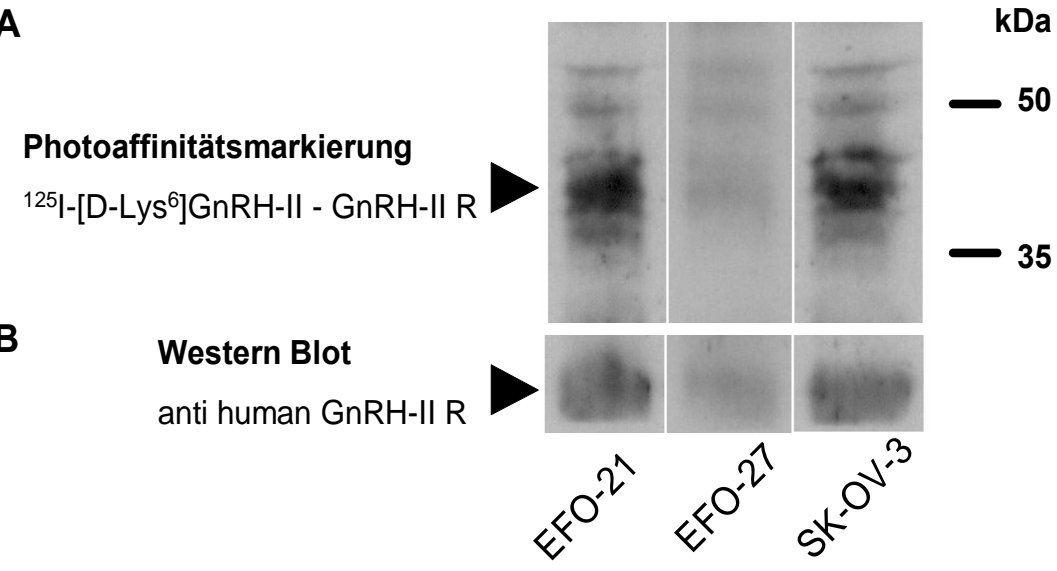

C

Photoaffinitätsmarkierung

${ }^{125}$-[D-Lys $]$ GnRH-II - GnRH-II R

Triptorelin

Cetrorelix

[D-Lys 6 ] $\mathrm{GnRH}-\mathrm{II}$

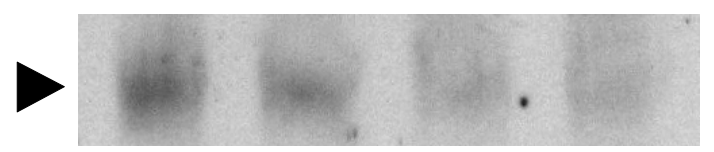

$+$

Abb. 4.10: A) SDS-PAGE des mit ${ }^{125} I-\left[D-L y s^{6}\right] G n R H-I I$ markierten GnRH-II Rezeptors mit den Ovarialkarzinomzellinien EFO-21, EFO-27 und SKOV-3, B) Western Blot Analyse des markierten GnRH-II Rezeptors mittels rabbit antihuman GnRH-II Rezeptor Antiserum und C) Verdrängungsversuch mit jeweils 100 nM unmarkiertem Triptorelin, Cetrorelix und [D-Lys ]GnRH-II. 
Die Verdrängungsversuche mit jeweils $100 \mathrm{nM}$ des unmarkierten GnRH-I Agonisten Triptorelin, des GnRH-I Antagonisten Cetrorelix und des GnRH-II Agonisten [DLys $\left.^{6}\right] \mathrm{GnRH}-\mathrm{II}(100 \mathrm{nM})$ zeigten, dass das [D-Lys $\left.{ }^{6}\right] \mathrm{GnRH}-\mathrm{II}$ die höchste Affinität zum Rezeptor hat. Die Photoaffinitätsbande des ${ }^{125}$ I-[D-Lys ${ }^{6}$ GnRH-II - GnRH-II RezeptorKomplexes war nach der Zugabe des unmarkiertem GnRH-II Analogs fast nicht mehr zu sehen. Nach der Cetrorelixzugabe war ebenfalls eine Reduktion des $\mathrm{I}^{125}$-[DLys ${ }^{6}$ ]GnRH-II zu erkennen, während nach der Zugabe von unmarkiertem Triptorelin die Bande am deutlichsten blieb (C). 


\section{Diskussion}

\subsection{Der GnRH-II Agonist [D-Lys ${ }^{6}$ ]GnRH-II inhibiert die mitogene Signaltransduktion des EGF-Rezeptors}

Durch die EGF-induzierte Rezeptordimerisierung und anschließende Autophosphorylierung verschiedener Tyrosinreste des EGF-Rezeptors können SH2Domänen enthaltende Effektorproteine an den Rezeptor binden und dadurch aktiviert werden. Diese Effektorproteine aktivieren dann ihrerseits unter anderem den MAPKinase-Signalweg. Somit werden wiederum Transkriptionsfaktoren aktiviert, die die Expression von Proteinen wie z.B. c-Fos hervorrufen und $\mathrm{zu}$ einer proliferativen Reaktion der Zelle führen.

Die in dieser Arbeit erhobenen Ergebnisse zeigen, dass mit der Bindung des GnRH-II Agonisten an seinen Rezeptor, die EGF-induzierte Wachstumsfaktorsignalkaskade in den untersuchten Ovarial- und Endometriumkarzinomzellinien inhibiert wird. Es konnte nachgewiesen werden, dass durch die Behandlung der Zellen mit dem GnRH-II Analog [D-Lys $\left.{ }^{6}\right]$ GnRH-II die Aktivität einer Phosphotyrosin-Phosphatase (PTP) gesteigert wird. Da die PTP eine Dephosphorylierung der EGF-Rezeptor-Tyrosin-Kinasen bewirkt, wird durch deren Aktivitätssteigerung der Autophosphorylierung des EGFRezeptors entgegengewirkt. Um zu beweisen, dass diese Dephosphorylierungsprozesse der Tyrosinreste tatsächlich einen Einfluß auf die WachstumsfaktorrezeptorSignalkaskade nehmen, wurde die Aktivität der mitogen-aktivierten Kinase (MAPKINASE) extrazellulär-regulierte Kinasen 1 und 2 (ERK 1/2), sowie die Expression des ,Immediate Early Response ${ }^{e}$ Gens $c$-fos, ebenso wie die des c-Fos Proteins bestimmt. Für diese Untersuchungen erfolgte zuvor die GnRH-II Rezeptorstimulation in den gynäkologischen Tumorzellen mit dem GnRH-II Analog [D-Lys ${ }^{6}$ GnRH-II. Da die Wachstumsfaktorsignalkaskade durch die EGF-Rezeptor Stimulation durch seine Liganden EGF bzw. TGF $\alpha$ stimuliert wird, erfolgte eine zusätzliche Behandlung der Zellen mit EGF. 


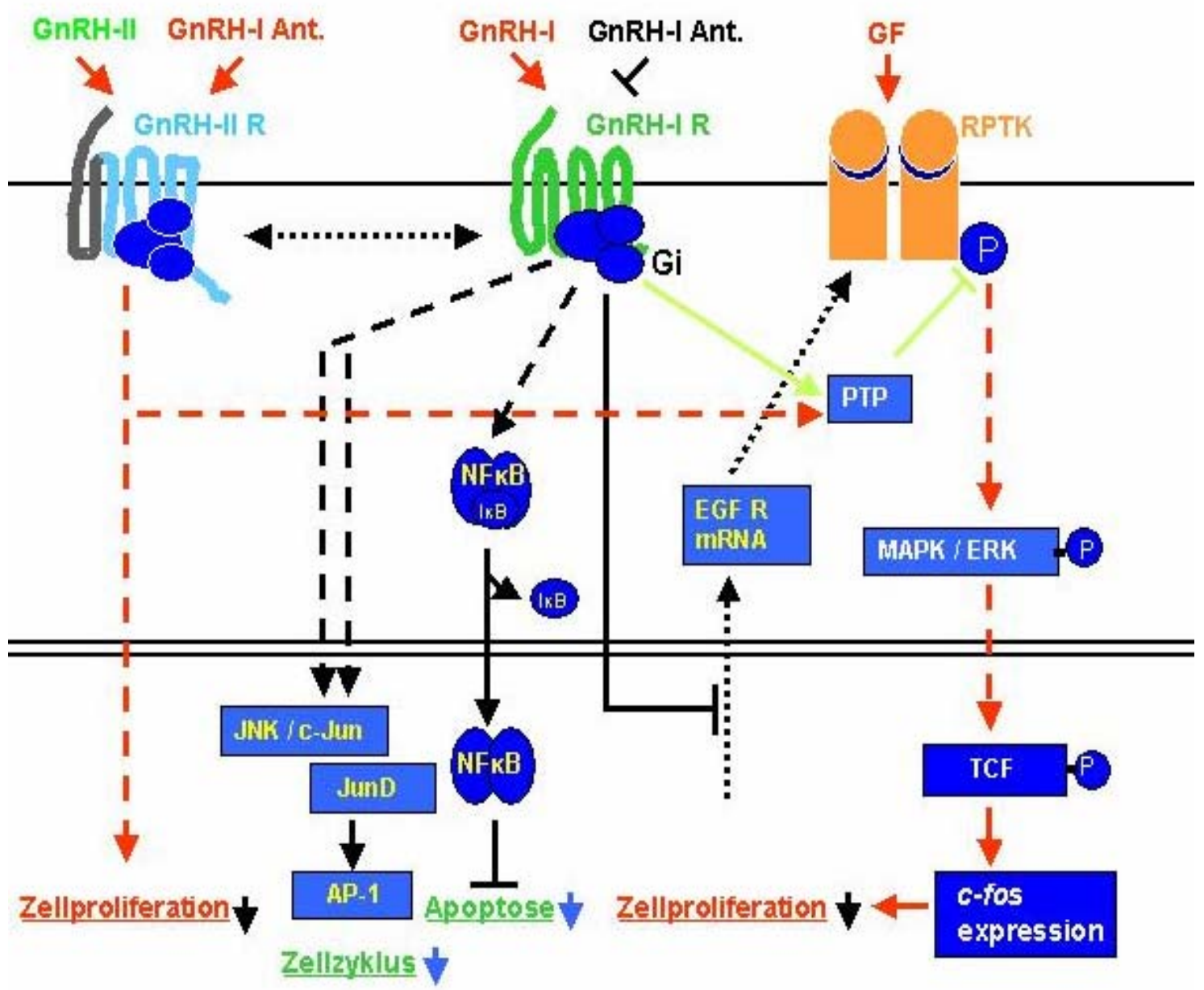

Abb. 5.1: Graphische Darstellung der GnRH-II Rezeptorsignalkaskade und der Interaktion mit der GnRH-I Rezeptor-sowie der EGF-Rezeptor Signalkaskade in gynäkologischen Tumorzellen.

GnRH-I/II (R): Gonadotropin-Releasing Hormone (Rezeptor), GF: growth factor, RPTK: Rezeptor(phospho)-Tyrosin-Kinase (EGF-Rezeptor), NFkB: Nukleus Faktor kappa B, JNK: Janus Kinase, c-Jun: c-Jun N-terminal kinase, AP-1: AktivatorProtein-1, PTP: Phosphotyrosin-Phosphatase, MAP-KINASE: mitogen-activated protein kinase, ERK: extracellulare-regulated kinase, c-fos: immediate early response gene, EGF R: epidermal growth factor receptor, TCF: transcription factor, P:

Phosphat (nach Gründker et al. 2002)

Bei der Betrachtung der Ergebnisse wird es eindeutig, dass die Aktivität der ERK 1/2 nach der Rezeptorstimulation mit dem GnRH-II Analog [D-Lys ${ }^{6}$ GnRH-II inhibiert ist und ebenso ansteigt, wenn eine Aktivierung des EGF-Rezeptors erfolgt. Wird die Aktivität nach der Behandlung der Zellen mit beiden Hormonen gemessen, wobei erst die Stimulation des GnRH-II Rezeptors erfolgen muss, nachdem das EGF-Hormon 
zugegeben wird, kann ebenfalls ein Rückgang der Aktivität nachgewiesen werden. Dies lässt eindeutig darauf schließen, dass der GnRH-II Rezeptor die Wachstumsfaktorrezeptor-Signalkaskade beeinflusst. Die Daten für die Expression des ,Immediate Early Response $e^{e}$ Gens c-fos, ebenso wie die des c-Fos Proteins lassen denselben Schluss zu. Denn auch hier kann eine Erhöhung der jeweiligen Expression durch die EGFRezeptorstimulation hervorgerufen werden, während durch die Behandlung der gynäkologischen Tumorzellen mit dem GnRH-II Analog [D-Lys ${ }^{6}$ GnRH-II diese wieder herabgesetzt werden kann. Die Daten zeigen, dass der Signalweg des GnRH-II Agonisten dem des GnRH-I gleicht (Abb. 5.1).

GnRH-I aktiviert in gynäkologischen Tumorzellen über das G-Protein $\alpha$ i eine PTP und konterkariert ebenso die Tyrosin-Autophosphorylierung von Wachstumsfaktorrezeptoren, so dass die mitogene Signaltransduktion gehemmt wird (Emons et al. 1997, Gründker et al. 2000a, Gründker et al. 2001a). Es weist also alles darauf hin, dass das GnRH-II Rezeptor System über den selben Wirkungsmechanismus wie das GnRH-I System reguliert wird. In Abb. 5.1 ist die mögliche Signalkaskade des GnRH-II Rezeptors nach dessen Stimulation mit GnRH-II oder dem GnRH-I Antagonisten Cetrorelix dargestellt, ebenso wie dessen Kreuzreaktion mit der GnRH-I Rezeptorsowie der EGF-Rezeptorsignalkaskade.

\subsection{Die antiproliferative Wirkung des GnRH-II Agonisten}

Die EGF-Wachstumsfaktor-Signalkaskade steht im direkten Zusammenhang mit der Zellproliferation, als Antwort der c-Fos Proteinaktivierung. Wird diese mitogene Signalkaskade durch die GnRH-II Rezeptoraktivierung supprimiert oder sogar inhibiert, dann kommt es zu einer Reduktion der Zellzahl. Diese Daten stimmen mit denen aus vorherigen Studien überein, in denen gezeigt werden konnte, dass das GnRH-II stark antiproliferativ auf Endometrium- und Ovarialkarzinomzellinien wirkt (Gründker et al. 2002). In diesen Proliferationsversuchen wurde bereits deutlich, dass GnRH-II sowie sein synthetisches Analog [D-Lys ${ }^{6}$ GnRH-II stärker wachstumsinhibierend wirken, als das GnRH-I und seine Analoga. Es konnte kürzlich gezeigt werden, dass die humanen Mammakarzinomzellinien MCF-7 und T47D nach der Stimulation mit dem GnRH-I 
Analog Triptorelin, sowie mit dem GnRH-II Analog [D-Lys ${ }^{6}$ GnRH-II eine Inhibition in ihrer Proliferation aufweisen. Ebenso zeigen die Daten einen GnRH-II-bedingten Rückgang der EGF-induzierten Autophosphorylierung des EGF-Rezeptors und der ERK 1/2-Aktivitäten in denselben Zellinien (Günthert et al. 2005).

\subsection{GnRH-II wird nicht über das GnRH-I Rezeptorsystem reguliert}

Es konnte gezeigt werden, dass der GnRH-II Agonist [D-Lys ${ }^{6}$ ]GnRH-II und der GnRHI Antagonist Cetrorelix, deutliche antiproliferative Effekte in der GnRH-I Rezeptornegativen Zellinie SKOV-3 aufweisen. Ebenso waren nach einem GnRH-I Rezeptor Knock-Down in den Ovarialkarzinomzellinien NIH:OVCAR-3 und EFO-21, sowie in den Endometriumkarzinomzellinien Ishikawa und Hec1A die wachstumsinhibierenden Effekte des Triptorelins nicht mehr erkennbar. Die Effekte des Cetrorelix sowie des GnRH-II Analogs zeigten keine Veränderungen und es konnte in allen untersuchten Endometrium- und Ovarialkarzinomzellinien ein Rückgang der Zellzahl erreicht werden (Gründker et al. 2004) (Abb. 5.2).
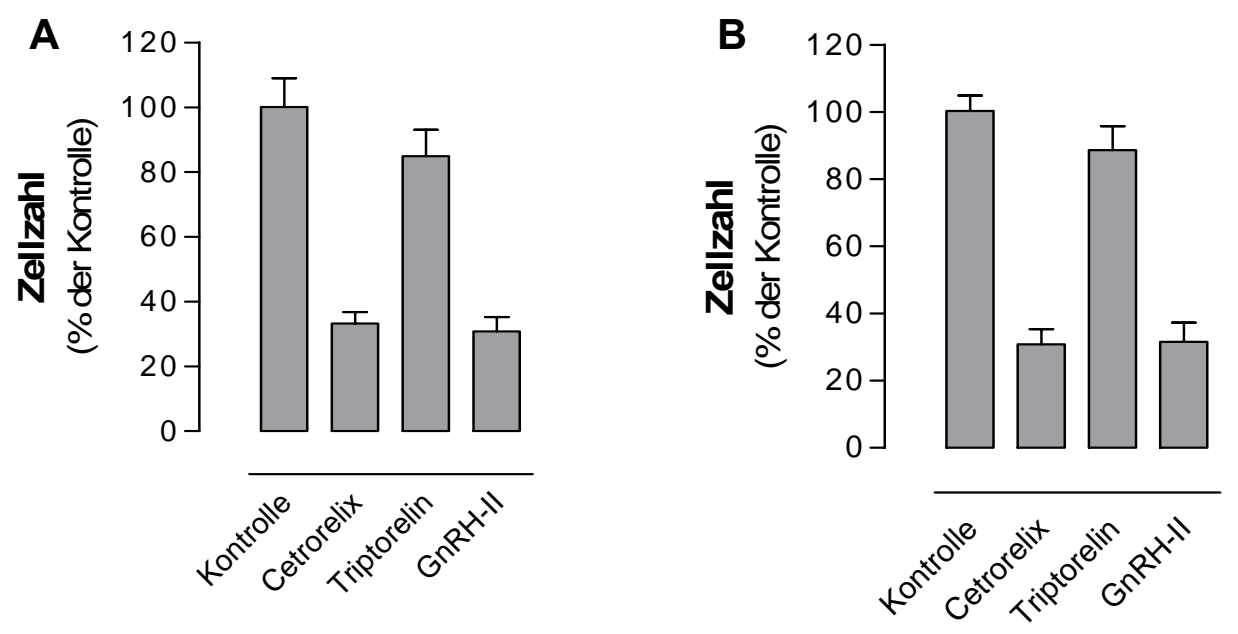

Abb. 5.2: Effekte einer 4-Tages Stimulation auf die Zellzahl nach Knock-Down der GnRH-I Rezepto-mRNA Expression. A) Ishikawa (EndoCA) und B) NIH: OVCAR-3 (OvarCA). Erster Graph: unbehandelte Zellen (Kontrolle), zweiter Graph: GnRH Antagonist Cetrorelix (100 nM), dritter Graph: GnRH-I Agonist Triptorelin (100 nM), vierter Graph: GnRH-II (100 nM) (nach Gründker et al. 2004). 
Da trotz des GnRH-I Rezeptor Knock-Downs keine Veränderungen in der inhibitorischen Wirkung des GnRH-II zu verzeichnen sind, kann davon ausgegangen werden, dass es einen GnRH-II Rezeptor-Liganden Mechanismus oder zumindest ein ähnliches System geben muss, welches über die Hormone GnRH-II und Cetrorelix angeregt wird. Auch, die in der vorliegenden Arbeit gewonnenen Daten sprechen für ein autonomes GnRH-II Rezeptorsystem. Nach dem GnRH-I Rezeptor Knock-Down wurde konzentrationsabhängig die GnRH-II-bedingte PTP-Aktivität bestimmt. Es konnten keine nennenswerten Unterschiede zu den Ergebnissen festgestellt werden, die ohne ein GnRH-I Rezeptor Knock-Down durchgeführt wurden. Auch diese Daten zeigen eindeutig, dass das GnRH-II nicht über den GnRH-I Rezeptor reguliert wird. Durch die bisher erhobenen Daten liegt es allerdings sehr nahe, dass sich die Systeme beider GnRH-Rezeptoren ähneln und über denselben autokrinen/parakrinen Mechanismus antiproliferativ wirken.

\subsection{Nachweis eines GnRH-II Rezeptor-ähnlichen Proteins}

Um das GnRH-II Rezeptor Protein nachweisen zu können, wurde ein polyklonales Antiserum gegen den putativen humanen GnRH-II Rezeptor hergestellt. Hierzu wurde ein Peptid (YSPTMLTEVPPC) eingesetzt, welches gegen die dritte extrazelluläre Domäne des GnRH-II Rezeptors von Callithrix jacchus gerichtet ist. Das Peptid ist über ein Cystein-Rest an das Haemocyanin der gewöhnlichen Napfschnecke (Patella coerulea) gebunden (Millar et al. 2001). Die zwölf Aminosäuren des Peptids sind zwar einzigartig für den GnRH-II Rezeptor, eine Expression sechs dieser Aminosäuren (LTEVPP) konnte allerdings im RLIM Transkriptionsfaktor, einem RING H2 Zinkfinger Protein, nachgewiesen werden. Ebenso wurde eine ähnliche Aminosäuresequenz (PSMATEAPPC) in dem humanen Membranprotein Proteaseinhibitor 16 detektiert. Da diese Sequenzen die Spezifität des Antiserums beeinträchtigt hätten und somit zweifelhafte Ergebnisse erzielt würden, wurde das Antiserum vorher aufgereinigt. Über eine Säulenchromatographie, bei der die Peptide an der Säule gebunden waren, wurde das Antiserum preabsorbiert. Eine Kreuzreaktion zwischen den beiden Peptiden LTEVPP und PSMATEAPPC und dem GnRH-II Rezeptor Antiserum konnte somit ausgeschlossen werden. 
Die Spezifität des Antiserums wurde an Geweschnitten des Callithrix jacchus-Ovars getestet. An ihnen konnte die eindeutige Antigenität des GnRH-II Rezeptor-ähnlichen Proteins nachgewiesen werden. Eine Behandlung desselben Gewebes mit dem Preimmun Serum konnte keine antikörperspezifische Färbung hervorrufen. Dies gilt ebenfalls als Hinweis für die Genauigkeit des GnRH-II Rezeptor Antiserums.

Die Western Blot Analyse des Affenovarproteins mittels GnRH-II Rezeptor Antiserum ließ eine Bande bei $54 \mathrm{kDa}$ erscheinen. In der Literatur ist der GnRH-II Rezeptor des Weißbüschelaffens mit einem Molekulargewicht von $42 \mathrm{kDa}$ beschrieben (Faurholm et al. 2001). Dass es sich bei dem $54 \mathrm{kDa}$ großen Protein um eine glykosilierte Form des GnRH-II Rezeptor handelt, konnte mit der Deglykosilierung dieses Rezeptors bewiesen werden. Nach der Deglykosilierung war eine Reduktion des GnRH-II Rezeptor Molekulargewichts um ca. $10 \mathrm{kDa}$ zu erkennen, womit das entstandene Gewicht von ca. $44 \mathrm{kDa}$ mit dem des in der Literatur angegebenen Gewichts von $42 \mathrm{kDa}$ ungefähr übereinstimmt.

In immunhistologischen Schnitten der Plazenta, humanen Endometrium-, Ovarial- und Prostatakarzinomen konnte ebenfalls eine eindeutige GnRH-II Rezeptor spezifische Färbung mittels rabbit anti-human GnRH-II Rezeptor Antiserum nachgewiesen werden. Diese Ergebnisse beweisen die Existenz des GnRH-II Rezeptor-ähnlichen Proteins in den untersuchten Geweben. Mit der Western Blot Analyse von Membranfraktionen von Endometrium- und Ovarialkarzinomzellinien, ebenfalls unter Anwendung des GnRH-II Rezeptor Antiserums, konnte eine Bande bei ca. $43 \mathrm{kDa}$ detektiert werden. Das Molekulargewicht des humanen GnRH-II Rezeptors, schient mit dem des nichtglykosilierten GnRH-II Rezeptors des Affen zu übereinstimmen.

Um das GnRH-II Rezeptor-ähnliche Antigen als GnRH-II Bindungsstelle identifizieren zu können, wurde die Methode der Photoaffinitätsmarkierung angewendet. Die photochemische Reaktion von ${ }^{125}$ I-[D-Lys ${ }^{6}-N^{\epsilon}$-Azidobenzoyl]-GnRH mit Zellmembranpräparationen von humanen Endometrium- und Ovarialkarzinomzellinien, ergab eine Bande bei $43 \mathrm{kDa}$. Mit dem rabbit anti-human GnRH-II Rezeptor Antiserum konnte diese als GnRH-II Rezeptor-ähnliches Protein nachgewiesen werden. Da GnRH-II in früheren Studien keine Effekte in der Ovarialkarzinomzellinie EFO-27 zeigte wurde davon ausgegangen, dass diese Zellinie GnRH-II Rezeptor-negativ ist. Allerdings konnte mittels Photoaffinitätsmarkierung eine schwache GnRH-II Rezeptor Antigenität 
nachgewiesen werden. Es ist also möglich, dass die GnRH-II Rezeptordichte auf den EFO-27 Zellen sehr gering ist und dadurch keine zellulären Effekte erkennbar sind. Darüber wäre auch zu erklären, warum nur eine geringe Menge des photoreaktiven ${ }^{125}$ I-[D-Lys ${ }^{6}-N^{\mathrm{c}}$-Azidobenzoyl]-GnRH gebunden werden konnte und somit eine extrem schwache Bande detektiert wurde. Vergleichbare Ergebnisse wurden ebenfalls für die Gewebe humaner Plazenten erzielt. Eine ähnliche Situation wurde für die GnRH-I Rezeptorbindung in der Endometriumkarzinomzellinie MFE-296 beschrieben (Völker et al. 2002).

In Verdrängungsexperimenten mit jeweils ungelabeltem [D-Lys $\left.{ }^{6}\right]-G n R H-I I$, ungelabeltem Cetrorelix oder ungelabeltem Triptorelin konnte gezeigt werden, dass das GnRH-II am stärksten mit dem ${ }^{125}$ I-[D-Lys ${ }^{6}-N^{\epsilon}$-Azidobenzoyl]-GnRH um die GnRH-II Rezeptorbindung konkurriert, im Gegensatz zu dem ungelabelten Triptorelin, welches kaum eine Verdrängung gezeigt hat. Diese Daten zeigen, dass das GnRH-II Rezeptorähnliche Protein die spezifische Bindungsstelle für das GnRH-II ist.

Diese Ergebnisse sind die ersten klaren Hinweise für die Existenz eines GnRH-II Rezeptor-ähnlichen Proteins in der menschlichen Plazenta sowie in Tumoren humaner reproduktiver Gewebe.

\subsection{Identifikation des GnRH-II Rezeptors}

Obwohl die in dieser Arbeit erhobenen Daten, sowie die Ergebnisse aus früheren Studien darauf hinweisen, dass ein eigenständiges GnRH-II System vorhanden sein muss und dass ein Rezeptor existiert, der eine hohe Affinität zum GnRH-II besitzt, konnte der humane GnRH-II Rezeptor bisher nicht eindeutig indentifiziert und charakterisiert werden.

Das GnRH-II Rezeptorssystem ist bei einigen Species bereits gut charakterisiert worden, so auch der Primaten GnRH-II Rezeptor, der geklont und in allen untersuchten Geweben und Organen detektiert werden konnte (Millar et al. 2001, Neill et al. 2001). Untersuchungen zur Funktionalität des Affenrezeptors wurden mit GnRH-II Konzentrationen im Nanomolarbereich durchgeführt. Da der Rezeptor auch bei diesen niedrigen Ligandendosen aktiv war, bestätigt dies seine Funktionalität. Dem GnRH-II 
konnte sogar eine 400mal höhere Aktivität nachgewiesen werden als dem GnRH-I, was als Indiz für die Spezifität der Interaktion zwischen GnRH-II und seinem Rezeptor spricht (Neill et al. 2004).

Die Existenz eines eigenständigen GnRH-II Rezeprotsystems in Primaten könnte ein Argument für das Vorkommen eines ähnlichen humanen Systems sein. Allerdings war bisher weder das Klonieren, noch das Sequenzieren eines vollständigen humanen GnRH-II Rezeptortranskripts erfolgreich. (Millar et al. 2003, Millar et al. 1999, Neill et al. 2001, Gründker et al. 2002). Da die humane GnRH-II Rezeptorsequenz im zweiten Exon ein Stopcodon (Aminosäure 181) besitzt und eine Frameshift Mutation nahe des N-terminus (Zwischen Aminosäure neun und zehn) aufweist (Anhang), stellt sich die Identifikation des Transkripts als schwierig dar (van Biljon 2002, Millar et al. 2003, Morgan et al. 2003). Es wird darüber spekuliert, dass der funktionsfähige GnRH-II Rezeptor als eine Reihe von Splicevarianten exprimiert wird, wie sie in Abb. 5.3 dargestellt sind (Neill et al. 2002).

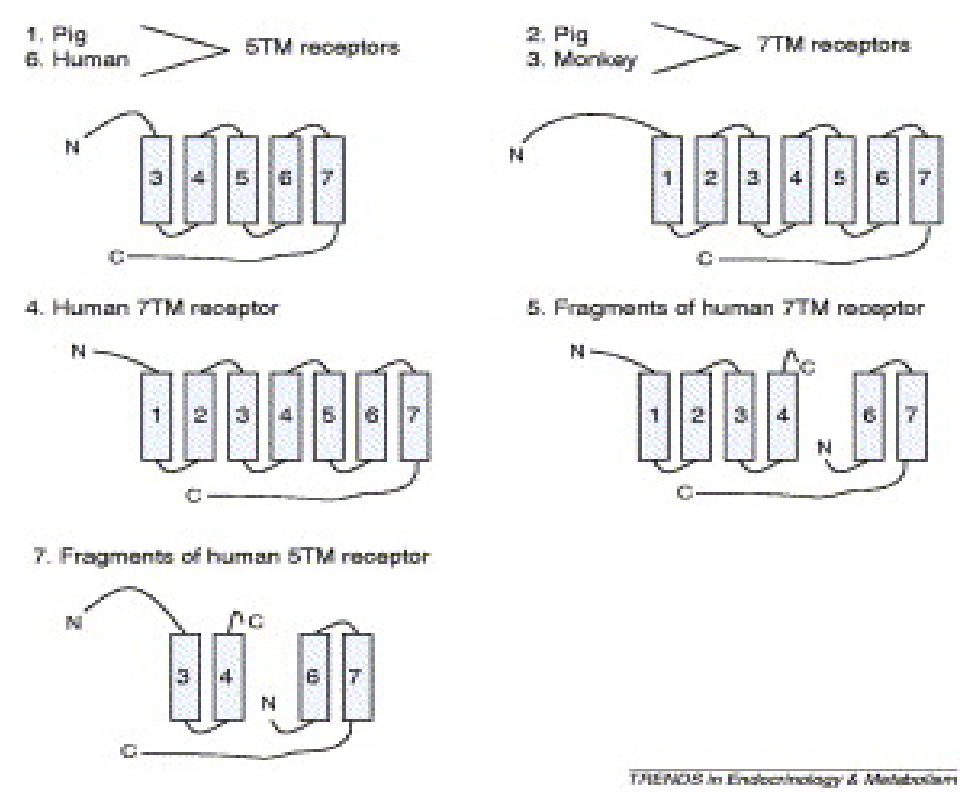

Abb. 5.3: Potentielle Splicevarianten des GnRH-II Rezeptorproteins. 1-7 bezeichnen die Transmembran-Domänen. $N$ und C kennzeichnen den Amino- bzw. Carboxylterminus (nach Neill et al. 2002). 
Es wird vermutet, dass ein funktionsfähiger GnRH-II Rezeptor in humanem Geweben ein 5 Transmembran (TM) Rezeptor ist, dem die TM Regionen I und II fehlen. Es besteht aber auch die Möglichkeit, dass die GnRH-II Rezeptor-mRNA als ganzes Transkript exprimiert wird oder dass sich ein Chimär aus dem GnRH-I Rezeptor und Fragmenten des GnRH-II Rezeptors bildet (Neill et al. 2004). Die Existenz einer funktionsfähigen 5 TM G-Protein gekoppelten Rezeptor (GPCR) Mutante ist bereits vom Chemokin-Rezeptor bekannt. Hier bindet das N-terminale Segment direkt an die TM-Domäne III, so dass eine Deletion der TM-Domänen I und II vorliegt (Ling et al. 1999). Ausserdem konnte ebenfalls im Schwein ein GnRH-II Rezeptor mit nur 5 TMDomänen nachgewiesen werden (Neill et al. 2002) (Abb. 5.3).

Van Biljon konnte vor kurzem ein GnRH-II Rezeptortranskript von humanen Spermien klonieren, welches aus den drei Exons bestand, die für die Translation eines vollständigen Rezeptors notwendig sind. Das Transkript beinhaltete ebenfalls ein Stopcodon und eine ,Frameshifte Mutation (van Biljon et al. 2002). Bevor nicht der endgültige Beweis für die Existenz eines funktionsfähigen humanen GnRH-II Rezeptortranskripts erbracht worden ist, schliessen viele Wissenschaftler die Möglichkeit nicht aus, dass es sich bei dem GnRH-II Rezeptor um ein Pseudogen handelt (Neill et al. 2002, Millar et al. 2003, Morgan et al. 2003). Pseudogene sind im menschlichen Genom nicht ungewöhnlich und es wird geschätzt, dass die Anzahl dieser Gene mit der Anzahl der translatierbaren Gene nicht großartig differiert (Harrison et al. 2002).

Damit die humane GnRH-II Rezeptor-mRNA in ein Protein umgeschrieben werden kann, sind Mechanismen notwendig, die ein Stopcodon als eine Aminosäure erkennen und die die Leserasterverschiebung aufheben. Für beide dieser Mechanismen sind Beispiele für Eukaroyten in der Literatur dokumentiert (Robinson et al. 1997, Bertram et al. 2001, Namy et al. 2004). Das Stopcodon kann zu einem translatierbaren Codon dekodiert werden (,stop-codon readthrough ${ }^{\circledR}$ ). Wenn UGA für das Stopcodon steht, wie es bei dem GnRH-II Rezeptorgen der Fall ist, dann kann dieses Triplett in die 21ste Aminosäure Selenocystein umgeschrieben werden, um somit das Stopcodon zu übergehen (Bertram et al. 2001). Das programmierte ,Frameshiftinge ist allerdings nicht so verbreitet und bei den Säugetieren gibt es bisher nur ein Beispiel in einem Gen retroviralen Ursprungs (Namy et al. 2004). 


\subsection{Fazit}

Durch Proliferations- und Stimulationsversuche an gynäkologischen Tumorzellen mit GnRH-II konnte die antiproliferative Wirkung dieses Hormons gezeigt werden. Ausserdem konnte in verschiedenen Studien nachgewiesen werden, dass das GnRH-II nicht über das GnRH-I System reguliert wird. Die wachstumshemmende Wirkung des GnRH-II wird wie GnRH-I über die Hemmung der mitogenen Signalkaskade des EGFRezeptors vermittelt. Man nimmt daher an, dass es sich auch hier um ein autokrines/parakrines System handelt. Durch die Daten dieser Arbeit konnte ebenfalls gezeigt werden, dass ein humanes GnRH-II Rezeptor Protein existiert, welches eine hohe Affinität zum GnRH-II besitzt. Um die Existenz eines GnRH-II Rezeptors eindeutig bestätigen zu können, fehlen aber noch die Sequenzdaten eines vollständigen Transkripts. Wie bereits beschrieben, gibt es hier einige Schwierigkeiten und es weist alles darauf hin, dass es sich bei dem humanen GnRH-II Rezeptor um einen 5 TM Rezeptor handelt. Man geht davon aus, dass durch die Lesesraterverschiebung zwischen den Aminosäuren neun und zehn, die ersten beiden Domänen nicht exprimiert werden.

Mit dieser Arbeit wurde ein wichtiger Beitrag zur Identifizierung des GnRH-II Rezeptors und seiner Wirkungsmechanismen geleistet. Es sind allerdings weitere Experimente notwendig, um den Rezeptor weiter $\mathrm{zu}$ identifizieren, der durch das GnRH-II aktiviert wird. 


\section{LITERATUR}

Akhmedkhanov A, Zeleniuch-Jacquotte A, Toniolo P (2001): Role of exogenous and endogenous hormones in endometrial cancer. Ann NY Acad Sci. 943: 296-315

Animal Welfare Center (AWIC) (1997): Information resources for adjuvants and antibody production: Comparisons and alternative technologies. US Department of Agriculture, National Agrculture Library, AWIC, USA

Arbeitsgemeinschaft der Wissenschaftlichen Medizinischen Fachgesellschaften (AWMF) (2002): Leitlinie Onkologie/Gynäkologie: Endometriumkarzinom

Arbeitsgemeinschaft der Wissenschaftlichen Medizinischen Fachgesellschaften (AWMF) (2002): Leitlinie Onkologie/Gynäkologie: Ovarialkarzinom

Bernstein L, Deapen D, Cerhan JR, Schwartz SM, Liff J, McGann-Maloney E, Perlman JA, Ford L (1999): Tamoxifen therapy for breast cancer and endometrial cancer risk. J Natl Cancer Inst. 6; 91(19): 1654-1662

Berridge MJ (1993): Inositol triphosphate and calcium signaling. Nature 361: 315-325

Bertram G, Innes S, Minella O, Richardson J, Stansfield I (2001): Endless possibilities: translation termination and stopcodon recognition. Microbiology 147: 255-269

Blomenrohr M, Heding A, Sellar R, Lewis R, Bogerd J, Eidne KA (1999): Pivotal role for the cytoplasmatic carboxyl-terminal tail of a nonmammalian gonadotropin-releasing hormone receptor in cell surface expression, ligand binding, and receptor phosphorylation and internalization. Mol Pharmacol 56: 1229-1237 
Bokhmann JV (1983): Two pathogenic types of endometrial carcinoma. Gynecol Oncol. 15: 10-17

Bramley TA, McPhie CA, Menzies GS (1992): Human placental gonadotropinreleasing hormone $(\mathrm{GnRH})$ binding sites: I. Characterization, properties and ligand specifity. Placenta 13: 555-581

Bradford MM (1976): A rapid sensitive method for the quantitation of microgram quantities of protein utilizing the principle of protein-dye binding. Anal. Biochem. 72: 248-254

Bristow RF (1999): Endometrial cancer. Curr Opin Oncol. 11(5): 388-393

Bruckner HW, Motwani BT (1989): Treatment of advanced refractory ovarian cancer with a gonadotropin-releasing hormone analogue. Am J Obstet Gynecol. 161: 1216

Chegini N, Rong H, Dou Q, Kipersztok C, Williams RS (1996): Gonadotropinreleasing hormone $(\mathrm{GnRH})$ and $\mathrm{GnRH}$ receptor gene expression in human myometrium and leiomyomata and the direct action of GnRH analogs on myometrial smooth muscle cells and interaction with ovarian steroids in vitro. J Clin Endocrinol Metab. 81: 743750

Chen A, Yahalom D, Ben-Aroya N, Kaganovsky E, Okon E, Koch Y (1998): A second isoform of gonadotropin-releasing hormone is present in the brain of human and rodents. FEBS lett 435: 199-203

Chen A, Yahalom D, Laskar-Levy O, Rahimipour S, Ben-Aroya N, Koch Y (2001): Two isoforms of gonadotropin-releasing hormone are coexpressed in neuroal cell lines. Endocrinology 142: 830-837 
Chen HF, Jeung EB, Stephenson M, Leung PC (1999): Human peripheral blood mononuclear cells express gonadotropin-releasing hormone $(\mathrm{GnRH}), \mathrm{GnRH}$ receptor, and interleukin-2 receptor gamma chain messenger ribonucleic acids that are regulated by GnRH in vitro. J Clin Endocrinol Metab. 84: 743-750

Chiara DC, Trinidad JC, Wang D, Ziebell MR, Sullivan D, Cohen JB (2003): Identification of amino acids in the nicotinic acetylcholine receptor agonist binding site and ion channel photolabeled by 4-[(3-trifluoromethyl)-3H-diazirin-3yl]benzoylcholine, a novel photoaffinity antagonist. Biochemestry 42(2): 271-283

Chiu R, Boyle WJ, Meek J, Smeal T, Hunter T, Karin M (1988): The c-fos protein interacts with c-Jun/AP1 to stimulate transcription of AP1 responsive gene. Cell 54: $541-552$

Cohen P (2002): The origins of protein phosphorylation. Nat cell Biol 4: 127-130

Conn PM (1994): The molecular mechanism of gonadotropin-releasing hormone action in pituitary. In: Knobil E, Neill JD (eds.): The Physiology of Reproduction. Raven Press, New York, 1815-1832

Creasman WT, Odicinio F, Maisonneuve P, Beller U, Benedet JL, Heintz APM, Ngan HYS, Sideri M, Pecolli S (2001): FIGO Annual Report on the results of treatment in gynecological cancer. Vol. 24. Carcinoma of the corpus uteri. J Epidemiol Biostat. 6: $45-86$

Curran T, Franza BR (1988): Fos and Jun: The AP1 connection. Cell 55: 395-397

Daum G, Solca F, Diltz CD, Zhao Z, Cool DE, Fischer EH (1993): A general peptide substrate for protein tyrosine phosphatases. Anal Biochem. 211: 50-54 
De Souza PL, Friedlander ML (1992): Prognostic factors in ovarian cancer. Hematol/Oncol Clinics of North America 6: 761-781

Dubois EA, Zandbergen MA, Peute J, Goos HJ (2002): Evolutionary Development of three gonadotropin-releasing hormones (GnRH) systems in vertebrates. Brain Res Bull. 57: $413-418$

Emons G, Pahwa GS, Brack C, Sturm R, Oberheuser F, Knuppen R (1989): Gonadotropin releasing hormone binding sites in human epithelial ovarian carcinomata. Eur J Cancer Clin Oncol. 25: 215-221

Emons G, Ortman O, Pahwa GS, Oberheuser F, Schulz KD (1992a): LH-RH agonists in the treatment of ovarian cancer. In: Höffken (ed.) Peptides in Oncology I, LH-RH agonists ansd antagonists. Springer, Berlin Heidelberg New York Tokio, p 55

Emons G, Ortman O, Pahwa GS, Hackenberg R, Oberheuser F, Schulz KD (1992b): Intracellular actions of gonadotropic and peptide hormones and the therapeutic value of the GnRH-agonists in ovarian cancer. Acta Obstet Gynecol Scand Suppl. 155: 31

Emons G, Ortman O, Schulz KD (1993a): Rolle der endokrinen Therapie beim Ovarialkarzinom. Gynäkologie 26: 123-130

Emons G, Ortmann O, Becker M, Irmer G, Springer B, Laun R, Hölzel F, Schulz KD, Schally AV (1993b): High affinity binding and direct antiproliferative effects of LH-RH analogues in human ovarian cancer cell lines. Cancer Res. 53: 5439-5446

Emons G, Schröder B, Ortmann O, Westphalen S, Schulz KD, Schally AV (1993c): High affinity binding and direct antiproliferative effects of luteinizing hormonereleasing hormone analogs in human endometrial cancer cell lines. J Clin Endocrinol Metab 77: 1458-1464 
Emons G, Schally AV (1994): The use of luteinizing hormone-releasing hormone agonists and antagonists in gynecological cancers. Hum Reprod. 9: 1364-1379

Emons G, Müller V, Ortmann O, Grossmann G, Trautner U, von Stuckrad B, Schulz KD Schally AV (1996): Luteinizing hormone-releasing hormone agonist triptorelin antagonizes signal transduction and mitogenic activity of epidermal growth factor in human ovarian and endometrial cancer cell lines. Int J Oncol. 9: 1129-1137

Emons G, Ortman O, Schulz KD, Shally AV (1997): Growth-inhibitory actions of analogues of lueinizing hormone releasing hormone on tumor cells. Trends Endocrinol Metab. 9: 355-362

Emons G, Weiß S, Ortman O, Gründker C, Schulz KD (2000): Luteinizing hormone releasing hormone (LHRH) acts as a negative autocrine regulator of proliferation of human ovarian cancer. Eur J Endocrinol. 142: 665-670

Enomoto M, Endo D, Kawashima S, Park MK (2004): Human Type II GnRH Receptor mediates Effects of GnRH on Cell Proliferation. Zool Science 21: 763-770

Faurholm B, Millar RP, Katz AA (2001): The genes encoding type II gonadotropinreleasing hormone receptor and the ribonucleoprotein RBM8A in humans overlap in two genomic loci. Genomics 78: 15-18

Fekete M, Wittliff JL, Schally AV (1989): Characteristics and distribution of receptors for [D-Trp]-luteinizing hormone releasing hormone, somatostatin, epidermal growth factor and sex steroids in 500 biopsy samples of human breast cancer. J Clin Lab Anal 3: $137-147$ 
Felgner PL, Gadek TR, Holm M, Roman R, Chan HW, Wenz M, Northrop JP, Ringold GM, Danielsen M (1987): Lipofection: a highly effficient, lipid-mediated DNAtranfection procedure. Proc Natl Acad Sci USA. 84: 413-417

Fuchs R, Blakesley R (1983): Guide to the use of type II restriction endonucleases. Methods Enzymol. 100: 3-38

Fuchtner C, Manetta A, Walker JL, Emma D, Berman M, Di Saia PJ (1992): Radical hysterectomy in the elderly patient: analysis of morbidity. Am J Obstet Gynaecol. 166: 593-597

Glasel JA (1995): Validity of nucleic acid putities monitored by $260 \mathrm{~nm} / 280 \mathrm{~nm}$ absorbance ratios. Biotchniques 18: 62-63

Godwin AK, Testa JR, Hamilton TC (1993): The biology of ovarian cancer development. Cancer 15(71): 530-536

Gorman CM, Lane DP, Rigby PW (1986): High efficiency gene transfer into mammalian cells. Philos Trans R Soc Lond B Biol Sci. 307: 343-346.

Greenberg ME, Ziff EB (1984): Stimulation of neuronal acetylcholine receotors induces rapid gene transcription. Science 234: 80-83

Gründker C, Völker P, Schulz KD, Emons G (2000a): Luteinizing hormone-releasing hormone (LHRH) agonist Triptorelin and antagonist Cetrorelix inhibit EGF-induced cfos expression in human gynaecological cancers. Gynecol Oncol 78:194-202

Gründker C, Schulz KD, Günthert AR, Emons G (2000b): Luteinizing hormonereleasing hormone induces nuclear factor $\kappa \mathrm{B}$ activation and inhibits apoptosis in ovarian cancer cells. J Clin Endocrinol Metab. 85: 3815-3820 
Gründker C, Völker P, Emons G (2001a): Antiproliferative signaling of LHRH in human endometrial and ovarian cancer cells through G-protein $\alpha$ i-mediated activation of phosphotyrosine phosphatase. Endocrinology 142: 2369-2380

Gründker C, Schlotawa L, Viereck V, Emons G (2001b): Protein kinase C (PKC)independent stimulation of activator protein-1 (AP-1) and c-Jun N-terminal kinase (JNK) activity in human endometrial cancer cells by luteinizing hormone-releasing hormone (LHRH) agonist Triptorelin. Eur J Endocrinol. 145(5): 651-658

Gründker C, Günthert AR, Millar RP, Emons G (2002): Expression of GonadotropinReleasing Hormone II (GnRH-II) Receptor in Human Endometrial and Ovarian Cancer Cells and Effects of GnRH-II on Tumor Cell Proliferation. J Clin Endocrinol Metab. 87(3): $1427-1430$

Gründker C, Völker P, Emons G (2003): Antiproliferative signaling of luteinizing hormone-releasing hormone in human endometrial and ovarian cancer cells through $\mathrm{G}$ protein ai-mediated activation of phosphotyrosine phosphatase. Endocrinology 142: $2369-2380$

Gründker C, Schlotawa L, Viereck V, Eicke N, Horst A, Kairies B, Emons G (2004): Antiproliferative effects of the GnRH antagonists cetrorelix and of GnRH-II on human endometrial and ovarian cancer cells are not mediated through the GnRH type I receptor. Eur J Endocrinol. 151: 141-149

Günthert AR, Gründker C, Hollmann K, Emons G (2002): Luteinizing hormone releasing-hormone induces JunD-DNA binding and extends cell cycle in human ovarian cancer cells. Biochem Biophys Res Commun. 294(1): 11-15

Günthert AR, Gründker C, Olata A, Läsche J, Eicke N, Emons G (2005): Analogs of Gonadotropin-Releasing Hormone I (GnRH-I) and GnRH-II inhibit epidermal growth 
factor-induced signal transduction and resensitize resistant human breast cancer cells to 4OH-Tamoxifen. Eur J Endocrinol. 153(4): 613-625

Hacker NF (1991): Surgery for endometrial carcinoma. In: Kleine W, Meerpohl HG, Pfleiderer A, Profous CZ (eds.): Therapie des Endometriumkarzinoms. Springer Verlag, pp. $83-90$

Hamilton TC, Young RC, McKoy WM, Grotzinger KR, Green JA, Chu EW, WhangPeng J, Rogan AM, Green WR, Ozols RF (1983): Characterisation of a human ovarian carcinoma cell line (NIH: OVCAR-3) with androgen and estrogen receptors. Cancer Research 43: 5379-5389

Hanley CW, Artwohl JE, Taylor Bennett B (1995): Rewiev of polyclonal antibody production procedures in mammals and poultry. ILAR Journal 37(3): 93-118

Harari PM (2004): Epidermal growth factor receptor inhibition strategies in oncology. Endocr Relat Cancer 11: 689-708

Harder KW, Owen P, Wong LK, Aebersold R, Clark-Lewis I, Jirik FR (1994): Characterisation and kinetic analysis of the intracellular domain of human protein tyrosine phosphatase $\beta$ (HPTP $\beta$ ) using synthetic phosphopeptides. Biochem J. 298: 395401

Harrison PM, Hegyi H, Balasubramanian S, Luscombe NM, Bertone P, Echols N, Johnson T, Gerstein M (2002): Molecular fossils in the human genome: identification and analysis of the pseudogenes in chromosomes 21 and 22. Genome Res. 12: 272-280

Hatch KD, Beecham JB, Blessing JA, Creasman WT (1991): Responsiveness of patients with advanced ovarian carcinoma to tamoxifen. Cancer 68: 269-271 
Hazum E (1981): Photo-Affinity inactivation of Gonadotropin releasing hormone receptors. FEBS Letters 128: 111-113

Holschneider CH, Berek JS (200): Ovarian Cancer: epidemiology, biology, and prognostic factors. Semin Surg Oncol. 19(1): 3-10

Hsueh AJ, Jones PB (1981): Extrapituitary actions of gonadotropin-releasing hormone. Endocrine Reviews 2: 437-461

Hunter T (1995): Protein kinases and phosphatases: The Yin and Yang of protein phosphorylation and signaling. Cell 80: 225-236

Imai A, Ohno T, Iida K, Fuseya T, Fururi T, Tamaya T (1994): Presence of gonadotropin-releasing hormone receptor and its messenger ribonucleic acid in endometrial carcinoma and endometrium. Gynecol Oncol 55: 114-118

Irmer G, Bürger C, Ortmann O, Schulz KD, Emons G (1994): Expression of luteinizing hormone-releasing hormone and its mRNA in endometrial cancer cell lines. J Clin Endocrinol Metab. 79: 916-919

Irmer G, Bürger C, Müller R, Ortmann O, Peter U, Kakar SS, Neill JD, Schulz KD, Emons G (1995): Expression of the messenger RNAs for luteinizing hormone-releasing hormone (LHRH) and its receptor in human ovarian epithelial carcinoma. Cancer Res. 55(4): $817-822$

Jäger W, Wildt L, Lang N (1989): Some observations on the effects of a GnRH analog in ovarian cancer. Eur J Obstet Gynecol Reprod Biol. 32: 137 
Jelovsec FR, Hammond CB, Woodward BH, Draffin R, Lee KL, Creasman WT, Parker RT (1989): Risk of exogenous therapy and endometrial cancer. Am J Obstet Gynecol. 137: 85-91

Kakar SS, Musgrove LC, Devor DC, Sellers JC, Neill JD (1992): Cloning, sequencing, and expression of human gonadotropin releasing hormone $(\mathrm{GnRH})$ receptor. Biochem Biophys Res Commun. 189: 289-295

Kakar SS, Grizzle WE, Neill JD (1994): The nucleotide sequence of human GnRH receptors in breast and ocarian rumors are identical with that found in pituitary. Mol Cell Endocrinol 106: 145-149

Keizer J, Li YX, Stojilkovic Rinzel J (1995): InsP3-induced Ca2+ excitability of the endoplasmatic reticulum. Mol Bio Cell. 6(8): 945-951

Kim ES, Khuri FR, Herbst RS (2001): Epidermal growth factor receptor biology (IMCC225). Curr Opin Oncol 13: 506-513

Kira S, Nakanishi T, Suemori S, Kitamoto M, Watanabe Y, Kajiyama G (1997): Expression of transforming groth factor alpha and epidermal growth factor receptor in human hepatocellular carcinoma. Liver 17: 177-182

Knobil E (1990): The GnRH pulse generator. Am J Ostet Gynecol 163: 1721-1727

Kouzardes T, Ziff ED (1988): The role of the leucine zipper in the fos-jun interaction. Nature 336: 646-651

Kullander S (1992): Treatment of endometrial cancer with GnRH analogs. Recent Results Cancer Res. 124: 69-73 
Kuramoto H, Tamura S, Notake Y (1972): Establishment of a cell line of human endometrial adenocarcinoma in vitro. Am J of Obstet and Gynecol. 114: 1012-019, 1972

Laemmli UK (1970): Cleavage of structural proteins during the assembly of the head of bacteriophage T4. Nature 227: 680-685

La Vecchia C, Franceschi S (1999): Oral contraceptives and ovarian cancer. Eur J Cancer Prev. 8(4): 297-304

La Vecchia C (2001): Epidemiology of ovarian cancer: a summary review. Eur J Cancer Prev. 10(2): 125-129

Limonata P, Dondi D, Moretti DM, Maggi R, Motta R (1992): Antiproliferative effects of luteinizing hormone-releasing hormone agonists on the human prostatic cancer cell line LNCaP. J Clin Endocrinol Metab 75: 207-212

Lin LS, Roberts VJ, Yen SS (1995): Expression of human gonadotropin-releasing hormone receptor gene in placenta and its functional relationship to human chorionic gonadotropin secretion. . J Clin Endocrinol Metab. 80: 580-585

Lindner H, Lukas P, Willgeroth F, Würschmidt F (2000): Radioonkologische Behandlung. In: Kimmig R, Kürzl R, Höß C, Kolben M, Staub J: Manual, Malignome des Corpus uteri, Empfehlungen zur Diagnostik, Therapie und Nachsorge. Tumorzentrum München, 1-56

Lindt MJ, Cantwell BMJ, Millward MJ, Robinson A, Proctor M, Simmons D, Carmichael J, Harris AL (1992): A phase II trial of goserelin (Zoladex) in relapsed epithelial ovarian cancer. Br J Cancer 65: 621-623 
Ling K, Wang P, Zhao J, Wu Y-L, Cheng Z-J, Wu G-X, Hu W, Ma L, Pei G (1999): Five transmembrane Domains appear sufficient for a $G$ protein-coupled receptor: Functional five-transmembrane domain chemokine receptor. Proc Natl Acad Sci USA 96: 7922-7927

McDonell MW, Simon MN, Studier FW (1977): Analysis of restriction fragments of T7 DNA and determination of molecular weights by electrophoresis in neutral and alkaline gels. J Mol Biol 110:119-146

Merz WE, Erlewein C, Licht P, Harbarth P (1991): The secretion of human chorionic gonadotropin as well as the $\alpha$-and $\beta$-messenger ribonucleic acid levels are stimulated by exogenous gonadoliberin pulses applied to first trimester placenta in a superfusion culture system. J Clin Endocrinol Metab. 73: 84-92

Millar RP, Conklin D, Lofton-Day C, Hutchinson E, Troskie B, Illing N et al.(1999): A novel human GnRH receptor homolog gene: abundant and wide tissue distribution of the antisense transcript. J Endocrinol. 162: 117-126

Millar RP, Lowe S, Conklin D, Pawson A, Maudsley S, Troskie B et al. (2001): A novel mammalian receptor for the evolutionary conserved type II gonadotropinreleasing hormone. Proc Natl Acad Sci USA 98: 9636-9641

Millar RP (2002): Gonadotropin releasing hormones and their receptors. In: Fauser BCJM (ed.): Molecular Biology in clinical reproductive medicine, $2^{\text {nd }}$ edn, Parthenon pp. 199-224

Millar RP (2003): GnRH II and type II GnRH receptors. Trends Endocrinol Metab. 14: $35-43$ 
Minaretzis D, Jakubowski M, Mortola JF, Pavlou SN (1995): Gonadotropin-releasing hormone receptor gene expression in human ovary and granulosa-lutein cells. J Clin Endocrinol Metab. 80: 430-434

Moretti MR, Montagnani Morelli M, Dondi D, Poletti A, Martini L, Motta M, Limonta P (1996): Luteinizing hormone-releasing hormone agonist interfere with the stimulatory action of epidermal growth factor in human prostatic cancer cell lines, LNCaP and DU 145. J Clin Endocrinol Metab 81: 3930-3937

Morgan K, Conklin D, Pawson AJ, Sellar R, Ott TR, Millar RP (2003): A transcriptionally active human type II gonadotropin-releasing hormone receptor gene homolog overlaps two genens in the antisense orientation on chromosome 1q.12. Endocrinology 144: 423-436

Mullis K, Faloona F, Scharf S, Saiki R, Horn G, Erlich H (1986): Specific enzymatic amplification of DNA in vitro: the polymerase chain reaction. Cold Spring Harb Symp Quant Biol. 51 Pt 1 263-273

Namy O, Rousset JP, Napthine S, Brierley I (2004): Reprogrammed genetic decoding in cellular gene expression. Mol Cell. 13: 157-168

Naor Z (1990): Signal transduction mechanisms of Ca2+-mobilizing hormones. The case of gonadotropin-releasing hormone. Endocine Rev. 11: 326-353

Naor Z, Benard O, Seger R (2000): Activation of MAP-KINASE cascades by Gprotein-coupled receptors: the case of gonadotropin-releasing hormone receptor. Trends Endocrinol Metab. 11: 91-99 
Neill JD, Duck LW, Sellers JC, Musgrove LC (2001): A gonadotropin-releasing hormone $(\mathrm{GnRH})$ receptor specific for GnRH-II in primates. Biochem Biophys Res Comm 282: 1012-1028

Neill JD (2002): GnRH and GnRH receptor genes in the human genome. Endocrinology 143: 737-743

Neill JD, Musgrove LC, Duck LW (2004): Newly recognized GnRH-receptor: Function and Relative Role. Trends Endocrinol Metab. 15: 383-392

Nguyen TV, Petereit DG (1998): High-dose-rate brachytherapie for medically inoperable stage I endometrial cancer. Gynecol Oncol. 71: 196-203

Nishida M, Kasahara K, Kaneko M, Iwasaki H (1985): Establishment of a new endometrial adenocarcinoma cell line, Ishikawa cells, containing estrogen and progesterone receptors. Acta Obstet Gynaecol Jpn. 37: 1103-1111

Oberlechner E (2000): Adjuvante medikamentöse Therapie. In: Kimmig R, Kürzl R, Höß C, Kolben M, Staub J: Manual, Malignome des Corpus uteri, Empfehlungen zur Diagnostik, Therapie und Nachsorge. Tumorzentrum München, 1-56

Ozols RF, Rubin SC, Dembo AJ, Robboy S (1992): Epithelial ovarian cancer. In Hoskins WJ, Perez CA, Young RC (eds). Gynecologic Oncology. Philadelphia, Lippincott, pp. 731-781

Pahwa GS, Vollmer G, Knuppen R, Emons G (1989): Photoaffinity labelling of gonadotropin releasing hormone binding sites in human epithelial ovarian carcinomata. Biochem Biophys Res Commun. 161: 1086-1082 
Pahwa GS, Kullander S, Vollmer G, Oberheuser F, Knuppen R, Emons G (1991): Specific low affinity binding sites for gonadotropin releasing hormone in human endometrial carcinomata. Eur J Obstet Gynecol Reprod Biol. 41: 135-142

Parazzini F, Franceschi S, La Veccia C, Fascioli M (1991a): The epidemiology of ovarian cancer. Gynecol Oncol. 43: 9-23

Parazzini F, La Veccia C, Bocciolone L, Franceschi S (1991b): The epidemiology of endometrial cancer. Gynecol Oncol. 41: 1-16

Park RC, Grisby PW, Muss HB, Norris HJ (1992): Corpus: Epithelial tumors. In: Hoskins WJ, Perez CA, Young RC (eds.): Gynecologic Oncology. Philadelphia, Lippincott, pp. 663-693

Peng C, Fan NC, Ligier M, Väänänen J, Leung PCK (1994): Expression and regulation of gonadotropin-releasing hormone $(\mathrm{GnRH})$ and $\mathrm{GnRH}$ receptor messenger ribonucleic acids in human granulosa-luteal cells. Endocrinology 135: 1740-1745

Petterson A (1988): Annual report on the results of treatment in gynecological cancer. Vol. 20, FIGO Stockholm

Piver MS, Baker TR, Piedmonte M, Sandecki AM (1991): Epidemiology and etiology of ovarian cancer. Semin Oncol. 18(3): 177-185

Rao BR, Slotman BJ (1991): Endocrine factors in common epithelial ovarian cancer. Endocrine Rev. 12: 14-26

Rauscher FJ, Voulalas PJ, Franza JR, Curran T (1988): Fos and Jun bind cooperatively to the AP1 site: Reconstruction in vitro. Genes Devel. 2: 1687-1699 
Robinson DN, Cooley L (1997): examination of the function of two kelch proteins generated by stop codon suppression. Development 124: 1405-1417

Rodenburg CJ, Cornelisse CJ, Heintz PAM, Hermans J, Fleuren GJ (1987): Tumor ploidy as a major factor in advanced ovarian cancer. Cancer 59: 317-323

Rose PG, Baker S, Kern M, Fitzgerald TJ, Tak WK, Reale FR, Nelson BE, Hunter RE (1993): Primary radiation therapy for endometrial carcinoma: a case controlled study. Int J Radiat Oncol Biol Phys. 27: 585-590

Rubinfeld H, Seger R (2005): The ERK cascade: A prototype of MAPK signalling. Mol Biotchnol. 31: 151-174

Saiki RK et al. (1988): Primer directed enzymatic amplification of DNA with a thermostable DNA polymerase. Science 239: 487-491

Salomon DS, Brandt R, Ciardiello F, Normanno N (1995): Epidermal growth factorrelated peptides and their recepors in human malignancies. Crit Rev Oncol Hematol. 19: $183-232$

Sambucetti LC, Curran T (1986): The Fos protein complex is associated with DNA in isolated nuclei and binds to DNA cellulose. Science 234: 1417-1419

Serov SF, Scully RE (1973): Histology typing of ovarian tumors. No. 9, Geneva: World Health Organization (WHO)

Schmidt-Matthiesen H, Bastert G (1995): Gynäkologische Onkologie. SchattauerVerlag, Stuttgart 
Schmidt-Rhode P (1991): Kontrolluntersuchungen während und nach einer medikamentösen Tumortherapie-Erkennung und Behandlung von Nebenwirkungen. In: Kaiser R, Schulz KD, Maass H (eds.): Hormonale Behandlung von Genital- und Mammatumoren bei der Frau, Thieme, Stuttgart New York, pp 137

Schueler JA, Cornelisse CJ, Hermans J, Trimbos JB, von der Burg MEL, Fleuren GJ (1993): Prognostic factors in well differentiated early stage epithelial ovarian cancer. Cancer 71: 787-795

Schulz KD, Hofman J, Hackenberg R, Emons G, Schmidt-Rhode P, Sturm G (1991): Palliative hormonal treatment in endometrial carcinoma. In: Kleine W, Meerpohl HG, Pfleiderer A, Profous CZ (eds.): Therapie des Endometriumkarzinoms. Springer Verlag, pp. 119-129

Schulz KD, Emons G (1995): Endometriumkarzinom. In: Zeller WJ, zur Hausen H (eds.): Onkologie. Grundlagen, Diagnostik, Therapie, Entwicklung. Ecomed, Landsberg/Lech, V-2.9, 1-12

Sealfon SC, Weinstein H, Millar RP (1997): Molecular mechanism of ligand interaction with gonadotropin-releasing hormone receptor. Endocr Rev. 18: 180-205

Shally AV, Arimura A, Baba J, Nair RM, Matsuo H, Reeding TW, Debeljuk L (1971): Isolation and properties of the FSH-and LH-releasing hormone. Biochem Biophys Res Commun. 43: 393-399

Shirahige Y, Cook C, Pinski J, Halmos G, Nair R, Schally AV (1994): Treatment with luteinizing hormone-releasing hormone antagonist SB-75 decreases levels of epidermal growth factor receptor and its mRNA in OV-1063 human epithelial ovarian cancer xenograft in nude mice. Int J Oncol. 5: 1031-1035 
Silverberg SG (1984): New aspects of endometrial carcinoma. Clin Obstet Gynec. 11: 189-208

Simon WE, Albrecht M, Hänsel M, Dietel M, Hölzel F (1983): Cell lines derived from human ovarian carcinomas: growth stimulation by gonadotropic and steroid hormones. $\mathrm{J}$ Natl. Cancer Inst. 70: 839-845

Sojar HT, Bahl OP (1987): A chemical method for deglcosylation of proteins. Arch. Biochem. Biophys. 259: 52-57

Srkalovic G, Schally AV, Wittliff JL, Day TG jr., Jenison EL (1998): Presence and characteristics of receptors for [D-Trp6]luteinizing hormone releasing hormone and epidermal growth factor in human ovarian cancer. Int J Oncol 12: 489-498

Standaert FE, Chew BP, De Avila D, Reeves JJ (1992): Presence of luteinizing hormone-releasing hormone binding sites in cultured porcine lymphocytes. Biol Reprod. 46: 997-1000

Stauber M, Weyerstahl T (2005): Gynäkologie und Geburtshilfe. Thieme-Verlag, Stuttgart

Stojilkovic SS, Reinhardt J, Catt KJ (1994): Gonadotropin-releasing hormone receptors: Structure and signal transduction pathways. Endocr Rev. 15: $462-499$

Tensen C, Okuzawa K, Blomenrohr M, Rebers F, Leurs R, Bogerd J (1997): Distinct efficacies for two endogenous ligands on a single cognate gonadoliberin receptor. Eur $\mathrm{J}$ Biochem. 243: 134-140

Thigpen JT, Brady MF, Alarez RD, Adelson MD, Homesley HD, Manetta A, Soper JT, Given FT (1999): Oral medroxyprogesterone acetate in the treatment of advanced or 
recurrend endometrial carcimoma: a dose-response study by the Gynecologic Oncology Group. J Clin Oncol. 17: 1736-1744

Tortolero-Luna G, Mitchell MF (1995): The epidemiology of ovarian cancer. J Cell Biochem Suppl. 23: 200-207

Towbin H, Staehelin T, Gordon J (1979): Electrophoretic transfer of proteins from polyacrylamide gels to nitrocellulose sheets; procedure and some applications. Proc Natl Acad Sci. USA 76: 4350-4354

Urbanski HF, White RB, Fernald RD, Kahoma SG, Garyfallou VT, Densmore VS (1999): Regional expression of mRNA encoding a second form of gonadotropinreleasing hormone in the macaque brain. Endocrinology 140: 1945-1948

Van Biljon W, Wykes S, Scherer S, Krawetz SA, Hapgood J (2002): Type II Gonadotropin-Releasing Hormone Receptor Transkripts in Human Sperm. Biol Reprod. 67: 1741-1749

Van Die IM, Bergmans HE, Hoeckstra WP (1983): Tranformation in Escherischia coli: studies on the role of the heat shock in induction of competence. J Gen Microbiol 129 (Pt 3): 663-670

Verses G, Gibbs RA, Scherer SE, Caskey CT (1987): The molecular basis of the sparse fur mouse mutation. Science 237: 415-417

Völker P, Gründker C, Schmidt O, Schulz KD, Emons G (2002): Expression of receptors for luteinizing hormone-releasing hormone in human ovarian and endometrial cancers: frequency, autoregulation and correlation with direct antiproliferative activity of LHRH analogues. Am J Obstet Gynecol. 186(2): 171-179 
Vogelstein B, Gillespie D (1979): Preparative and analytical purification of DNA from agarose. Proc Natl Acad Sci USA 76: 615-619

Walker GR, Schlesselmann JJ, Ness RB (2002): Family history of cancer, oral contraceptive use, and ovarian cancer risk. Am J Obstet Gynecol. 186(1): 8-14

Weiderpass E, Adami HO, Baron JA, Magnusson C, Lindgren A, Persson I (1999): Use of oral contraceptives and endometrial cancer risk (Sweden). Cancer Causes Control. 10(4): 277-784

Weiderpass E, Persson I, Adami HO, Magnusson C, Lindgren A, Baron JA (2000): Body size in different periods of life, diabetes mellitus, hypertension, and risk of postmenopausal endometrial cancer (Sweden). Cancer Causes Control. 11(2):185-192

Weiss B, Jacquemin-Sablon A, Live TR, Fareed GC, Richardson CC (1968): Enzymatic breakage and joining of deoxyribonucleic acid VI. Further purification and properties of polynucleotide ligase from Escherischia coli infected with bacteriophage T4. J Biol Chem. 243: 4543-4555

Wells A (1999): EGF receptor. Int J Biochem Cell Biol. 31: 637-643

White RB, Eisen JA, Kasten TL, Fernlas RD (1998): Second gene for gonadotropin releasing hormone in humans. Proc Natl Acad Sci. USA 95: 305-309

Woodburn JR (1999): The epidermal growth factor receptor and its inhibition in cancer therapy. Pharmacol Ther. 82: 241-250

Yano T, Pinski J, Halmos G, Szepeshazi K, Schally AV (1994): Inhibition of growth of OV-1063 human epithelial ovarian cancer xenograft in nude mice by treamtment with 
luteinizing hormone-releasing hormone antagonist SB-75. Proctl Natl Acad Sci. USA 91: 7090-7094

You Y, Chen CY, Shyu AB (1992): U-rich sequence-binding proteins (URBPs) interacting with a 20-nukleotide U-rich sequence in the 3 untranslated region of c-fos mRNA may be involved in the first step of c-fos mRNA degradation. Mol Cell Biol. 12(7): 2931-2940

Zwick E, Hackel PO, Prenzel N, Ullrich A (1999): The EGF receptor as central transducer of heterologous signalling systems. Trends Pharmacol Sci. 20: 408-412 


\section{ZUSAMMENFASSUNG}

Über $80 \%$ aller Endometrium- und Ovarialkarzinome exprimieren das GonadotropinReleasing Hormon (GnRH-I) und seinen Rezeptor (GnRH-I Rezeptor) als Teil eines autokrinen Regulationsmechanismus der Zellproliferation. Die klassische Signaltransduktion wie sie in der Hypophyse vorliegt, ist in Tumoren nicht relevant. Vielmehr aktiviert GnRH-I über das G-Protein ai eine Phosphotyrosin-Phosphatase (PTP) und konterkariert somit die EGF-induzierte mitogene Signaltransduktion. Die Proliferation der Tumorzellen wird dadurch gehemmt.

In Säugetieren wurde kürzlich die Expression eines zweiten GnRH`s (GnRH-II, chicken-GnRH) gefunden, welches signifikant stärker antiproliferativ auf humane Endometrium- und Ovarialkarzinomzellen wirkt als GnRH-I Agonisten. Es konnte gezeigt werden, dass diese antiproliferativen Effekte von GnRH-II nicht über den GnRH-I Rezeptor vermittelt werden.

Das GnRH-II Rezeptorsystem in Säugetieren ist weitgehend erforscht. Neill et al. und Miller et al. gelang es 2001 den GnRH-II Rezeptor bei Säugern und Primaten zu klonieren und charakterisieren. Mittels Reverse-Transkriptase (RT) -PCR wurde die Expression dieses Rezeptors ebenfalls in Endometrium- und Ovarialkarzinomen bestätigt. Ein funktioneller GnRH-II Rezeptor konnte beim Menschen allerdings bisher noch nicht nachgewiesen werden, da ein vorzeitiges Stopcodon im zweiten Exon die Schwierigkeit darstellt, die GnRH-II Rezeptor Sequenz komplett zu erfassen.

In dieser Arbeit konnte gezeigt werden, dass der GnRH-II Agonist [D-Lys ${ }^{6}$ GnRH-II durch die Aktivierung einer PTP die EGF-induzierte Autotyrosinphosphorylierung der EGF-Rezeptoren signifikant hemmt. Die Aktivierung der mitogen-aktivierten Proteinkinase (MAPK) wird dadurch ebenfalls reduziert. Dies führt zur Hemmung der EGF-induzierten $c$-fos Expression durch [D-Lys ${ }^{6}$ GnRH-II und damit zur Reduktion der Zellproliferation. Die Signaltransduktion von GnRH-II und seines Agonisten [DLys $\left.{ }^{6}\right] \mathrm{GnRH}-\mathrm{II}$ scheint der des GnRH-I und seiner Analoga zu ähneln.

Zur Identifizierung des GnRH-II Rezeptorproteins wurde ein polyklonales Antiserum generiert, welches gegen eine hochkonservierte Region der dritten extrazellulären 
Domäne des Weißbüschelaffen (Callithrix jacchus) GnRH-II Rezeptors gerichtet ist. Eine Datenbankanalyse zeigte nur eine Sequenzähnlichkeit mit dem putativen humanen GnRH-II Rezeptor. In immunhistologischen Gewebeschnitten sowie in Western Blot Analysen menschlicher Plazenten und humaner gynäkologischer Tumoren konnte die GnRH-II Rezeptor Protein Expression nachgewiesen werden. Ein Nachweis der Daten erfolgte mit der Photoaffinitätsmethode.

Diese Ergebnisse sind die ersten klaren Hinweise für die Existenz eines GnRH-II Rezeptorproteins in der menschlichen Plazenta sowie in Tumoren humaner reproduktiver Gewebe. Zur vollständigen Identifizierung sowie zur Charakterisierung des Rezeptors muss unter anderem die Sequenzierung des Proteins und/oder Gens erfolgen. 


\section{DANKSAGUNG}

Herrn PD Dr. C. Gründker danke ich für das äußerst interessante Thema, die sehr gute Zusammenarbeit, die vielen hilfreichen Diskussionen und Anregungen und die gewissenhafte Durchsicht dieses Manuskripts.

Herrn Prof. G. Emons danke ich für die Möglichkeit diese Arbeit in seinem Forschungslabor in der Abteilung Molekulare Gynäkologie unter der Leitung von Herrn PD Dr. C. Gründker anfertigen zu können.

Herrn Prof. R. Hardeland danke ich für die Bereitschaft, das Erstreferat für diese Arbeit zu übernehem, für sein Interesse und seine hilfreiche Unterstützung.

Herrn Prof. F. Schürmann danke ich für die Bereitschaft das Korreferat zu übernehemen.

Natürlich bedanke ich mich auch bei meinen lieben Kollegen in der Abteilung Molekulare Gynäkologie für die sehr nette Zusammenarbeit in freundschaftlicher Atmosphäre. Ganz besonders möchte ich mich bei Renate Dietrich, Hiltrud Schulz und Mathias Läsche bedanken, die mir immer eine große Hilfe im Laboralltag waren und zum Gelingen dieser Arbeit beigetragen haben.

Ein besonderer Dank geht auch an Christa Hahmann, Stefanie Fister, Wiebke Hüls, Götz Kemper und Fadi Hussein, für die unverzichtbare Unterstützung in vielen Laborund Lebensfragen, sowie die vielen lustigen Stunden während der langen Arbeitstage.

Desweiteren möchte ich mich bei Dr. Tamara Becker (Deutsches Primatenzentrum, Göttingen) für die Ovarien des Weißbüschelaffens bedanken. Ebenso bedanke ich mich bei Dr. M. Béhé (Abteilung Nuklearmedizin, Phillips-Universität Marburg) für die Unterstützung in einigen Versuchsdurchführungen.

Bei der Deutschen Forschunsgesellschaft (DFG) bedanke ich mich recht herzlich für die Förderung dieses Projektes. 


\section{PUBLIKATIONEN}

Gründker C, Schlotawa L, Viereck V, Eicke N, Horst A, Kairies B, Emons G (2004): Antiproliferative effects of the GnRH antagonists cetrorelix and of GnRH-II on human endometrial and ovarian cancer cells are not mediated through the GnRH type I receptor. Eur J Endocrinol. 151: 141-149

Eicke N, Günthert AR, Viereck V, Siebold D, Behé M, Becker T, Emons G, Gründker C (2005): GnRH-II receptor-like antigenicity in human placenta and in cancers of human reproductive organs. Eur J Endocrinol. 153(4): 605-612

Günthert AR, Gründker C, Olata A, Läsche J, Eicke N, Emons G (2005): Analogs of Gonadotropin-Releasing Hormone I (GnRH-I) and GnRH-II inhibit epidermal growth factor-induced signal transduction and resensitize resistant human breast cancer cells to 4OH-Tamoxifen. Eur J Endocrinol. 153(4): 613-625

Eicke N, Günthert AR, Emons G, Gründker C (2006): GnRH-II agonist [DLys $^{6}$ ]GnRH-II inhibits the EGF-induced mitogenic signaltransduction in human endometrial- and ovarian cancer cells. (in Bearbeitung) 


\section{ANHANG}

\section{Sequenzen des Gonadotropin-Releasing Hormone (GnRH) Rezeptors Typ II}

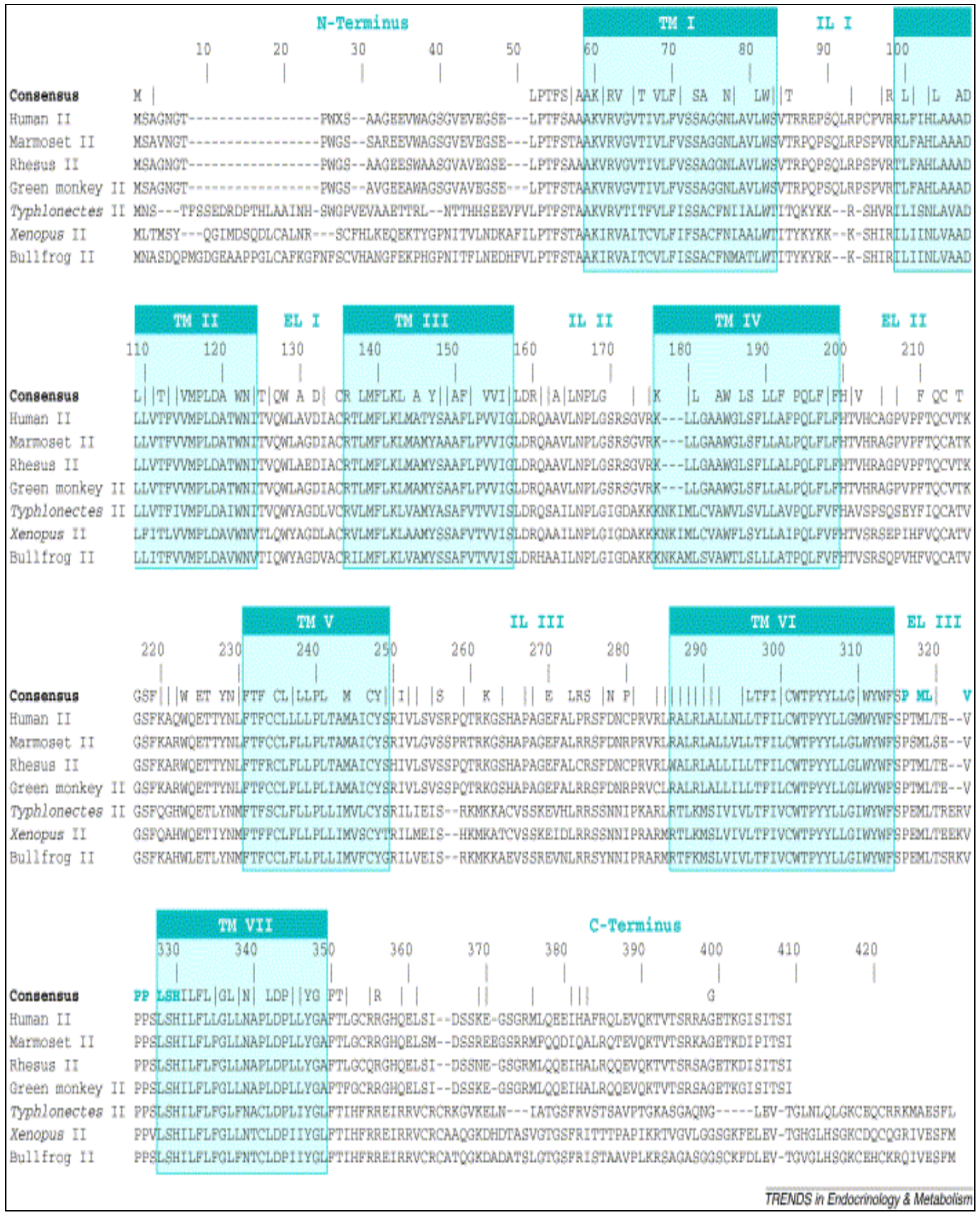


Abb.: Sequenzen des Gonadotropin-Releasing Hormone (GnRH) Rezeptors Typ II. Die Transmembran-Domänen (TM) sind grün gerahmt. Die intrazellulären Loops (IL) sowie die extrazellulären Loops (EL) sind in grüner Schrift. Die Übereinstimmungen in allen Sequenzen sind als, Consensussequenz anngegeben. Substitutionen sind als, ,' gekennzeichnet. In der Reihenfolge sind die GnRH-II Rezeptorsequenzen von folgenden Organismen angegeben: Human: Mensch (Homo sapiens), Marmoset: Weißbüschelaffe (Callithrix jacchus), Rhesus: Rhesusaffe (Macaca mulatta), Green monkey: Grüne Meerkatze (Cercopithecus aethiops), Schwimmwühle (Typhlonectes natans), Krallenfrosch (Xenopus laevis), Bullfrog: Ochsenfrosch (Rana catesbeiana) (nach Millar 2002). 


\section{LEBENSLAUF}

\section{Persönliche Daten}

\begin{tabular}{ll}
\hline \hline $\begin{array}{l}\text { Name } \\
\text { Vorname }\end{array}$ & $\begin{array}{l}\text { Eicke } \\
\text { Nicola }\end{array}$ \\
$\begin{array}{l}\text { Geburtsdatum } \\
\text { Geburtsort } \\
\text { Familienstand }\end{array}$ & $\begin{array}{l}\text { 17. September 1975 } \\
\text { Bremen, Deutschland } \\
\text { Ledig }\end{array}$ \\
Anschrift & $\begin{array}{l}\text { Böttingerstrasse 1 } \\
\text { 37073 Göttingen } \\
\text { Deutschland }\end{array}$ \\
& \\
\hline
\end{tabular}

\section{Ausbildung}

2002-2006

Promotion zum Thema: „Expression und Wirkungsmechanismen von Gonadotropin-Releasing Hormon Typ II (GnRH-II) und seines Rezeptors in Endometrium- und Ovarialkarzinomen" in der Abteilung für Gynäkologie und Geburtshilfe an der GeorgAugust-Universität Göttingen. Arbeitsgruppe von PD Dr. Carsten Gründker

1999-2001

Diplomarbeit zum Thema „Zytogenetische und molekulargenetische Untersuchungen an Uterus Leiomyomen zur Analyse des Fusionsgens RAD51L1/HMGA2" am Zentrum für Humangenetik der Universität Bremen. Arbeitsgruppe von Herrn Prof. Dr. Jörn Bullerdiek

1994-2001

Studium der Biologie an der Universität Bremen Hauptfach: Genetik

1. Nebenfach: Zoologie

2. Nebenfach: Biochemie

Abschluss: Diplom-Biologin

1981-1994

Schulausbildung

Abschluss: Abitur am Schulzentrum Lehmhorsterstrasse in Bremen-Blumenthal 